\title{
Translocation of Intracellular CD24 Towards Cell Membrane Constitutes a Triggering Event for Drug Resistance in Breast Tumor Cell: Correlation With Dynamics of p38MAPK Activation
}

Hugo Werner Huth

Universidade Federal de Minas Gerais

Alfredo Miranda de Goes

Universidade Federal de Minas Gerais

Catherine Ropert ( $\square$ ropertcatherine@gmail.com )

Instituto de Ciências Biológicas, Av. Antônio Carlos 6627 - Pampulha, 31270-901 Belo Horizonte, Minas Gerais, Brazil https://orcid.org/0000-0002-3077-714X

Research article

Keywords: Breast Cancer, Cancer Stem Cell, CD24, Chemoresistance, p38/MAPK, Phenotype Switching, Bcl-2

Posted Date: November 19th, 2020

DOl: https://doi.org/10.21203/rs.3.rs-109614/v1

License: (9) This work is licensed under a Creative Commons Attribution 4.0 International License. Read Full License 


\section{Abstract}

\section{Background}

The adaptation capacity of tumor cells to shift dynamically between different states could be responsible for chemoresistance and has been commonly linked to the acquisition of stem cell properties. Here, we have provided new elements concerning the role of the Cancer Stem Cell marker CD24 in the dynamics of tumor cell plasticity and the acquirement of drug resistance in breast cancer.

\section{Methodology}

Breast cancer cell lines and cell lineage obtained from Brazilian patients were treated with cytotoxic and non-cytotoxic drugs and the phenotype switching associated with drug resistance was evaluated. Different markers were quantified like the expression of CD24 through microscopy and FACS, the regulation of pro- and anti-apoptotic proteins $\mathrm{Bax}$ and $\mathrm{Bcl}-2$, epigenetic changes and MAPK activation using western blotting in wild type and CD24 silencing cells.

\section{Results}

The translocation of CD24 from cytosol to cell membrane was a triggering event for the phenotype change of tumor cells exposed to drug stress. Importantly, this phenomenon was observed in all the cells of the different population that was rendered possible thanks to the presence of an intracellular pool of CD24 in each given breast tumor cell. In these CD24 ${ }^{+}$cells, a strong and continuous phosphorylation of the p38 MAPK leading to drug resistance through the tri-methylation of H3K9 and overexpression of the anti-apoptotic protein Bcl-2 was observed. Importantly, the drug-resistant CD24 ${ }^{+}$cells entered into slowdown of cell cycle and restarted to proliferate after several weeks. The reawakened cells presented constitutive p38 activation, higher drug resistance and higher migration capacity. Notably, the use of a p38 activity inhibitor sensitized cells to drug treatment and avoided the appearance of chemoresistance.

\section{Conclusions/significance}

In this study, we have associated the cellular localization of CD24 with the changes in the dynamics of p38MAPK activation in breast tumor cells under drug stress. The tandem CD24/p38 plays a crucial role in the acquisition of drug resistance and new cell identity. The use of p38 inhibitor was able to disrupt this partnership and consequently to avoid chemotherapy-induced cell state transition. These results suggest that targeting p38 in breast cancer can overcome adaptive resistance to doxorubicin treatment.

\section{Introduction}

Plasticity endows cancer cells with the capacity to shift dynamically between different states which could be responsible for chemoresistance. The adaptation capacity of tumor cells has been commonly associated with stemness when the acquisition of Cancer Stem Cell (CSC) properties by non-CSCs has been reported under different conditions. Indeed, CSCs would be responsible for tumor initiation, 
maintenance, metastasis formation, phenotypic plasticity and drug resistance [1-7]. CD24, a cell surface adhesion glycoprotein, was identified as a CSC marker and is present in various types of cancer including breast, pancreatic and lung [8] and has often been associated with more aggressive diseases in ovarian, breast, lung and prostate cancers $[9,10]$. This explains the considerable interest for this marker in tumor biology and also in treatment outcome. In this line, relevant studies have revealed that the phenotype switching associated with the detection of surface CD24 could be responsible for chemoresistance $[11,12]$. For instance, CD24 expression level has appeared to be a significant molecular phenotype of cisplatin-resistant residual cells in laryngeal carcinoma lines which corresponds to a differential expression of critical apoptotic and drug resistance [13]. Goldman et al. have observed an enrichment of $\mathrm{CD} 24^{+}$cells following treatment with docetaxel in different breast tumor cell lineages, which corresponded to the generation of new CSCs from non-CSCs [12]. Importantly, the mechanism leading to an increased surface CD24 expression in tumor cells under drug stress remains unknown.

Recent findings support the hypothesis that epigenetic mechanisms are key players in the phenotypically transition of tumor cells $[14,15]$. Epigenetic can result in drastic changes not only in cell plasticity but also in drug resistance [16,17]. Besides, MAPK signaling pathways, which are deregulated in tumor $[18,19]$, have been constantly associated with chemoresistance in different type of cancer [20-22]. For instance, it has been reported that $\mathrm{p} 38$ and JNK MAPK pathways play a role in the control of the balance of autophagy and apoptosis in response to genotoxic stress [20]. Others have explored the role of ERK and p38 MAPK in breast cancer chemotherapy [21]. But, little is known concerning the involvement of MAPK in tumor plasticity. Indeed, the molecular mechanisms that control cellular plasticity upon drug treatment remain to be fully established.

Here, using different breast cancer cell lines, we have evaluated the impact of drug stress on the immediate phenotype change. We have shown that the rapid translocation of the CSC marker CD24 from cytosol to cell membrane was the triggering event for the acquisition of chemoresistance. In drugresistant MDA-MB-231 cells, we have identified a tandem constituted by CD24 and MAPK p38, where the continuous p38 activation controlled the tri-methylation of $\mathrm{H} 3 \mathrm{~K} 9$ and the overexpression of the survival marker Bcl-2. This phenotype enabled the cells to enter in slow-down of cell cycle, after which several weeks later, the dormant cells retrieved their capacity to proliferate, and were characterized by an increased resistance to drug and migratory capacity. Importantly, the use of p38 inhibitor was able to block the acquisition of drug resistance by impeding the upregulation of the anti-apoptotic protein Bcl-2. The treatment with the TLR7 agonist Imiquimod, which reduced cell proliferation without affecting phenotype switching neither $\mathrm{Bcl}-2$ expression allowed confirming a direct correlation between translocation of CD24 and increased expression of Bcl-2. Finally, we propose that the association of the p38 inhibitor, SB203580, with doxorubicin, a drug leader in clinic, could open up a new strategy in the fight with cancer.

\section{Materials And Methods}

\section{Reagents}


Thiazolyl Blue Tetrazolium Blue (MTT), Doxorubicin, Staurosporine and RIPA buffer were purchased from Sigma-Aldrich. p38 inhibitor SB203580 and Imiquimod were obtained through InvivoGen. Protease cocktail inhibitor and phosphatase cocktail inhibitor (Roche) were acquired from Sigma Aldrich. Monoclonal antibodies against phospho-p44/42 (ERK1/2), phospho-p38 MAPK, p38 MAPK, cyclin D1, btubulin, $b$-actin and peroxidase-conjugated goat anti-mouse Ig $G$ and goat anti-rabbit $I g G$ were obtained from Cell Signaling Technology and anti-BCl-2 (Novex) and anti-Bax (Invitrogen) from Thermo Fisher Scientific. Polyclonal antibodies anti-Histone H3 (tri-methyl K9) and anti-Histone H3 (Acetyl K9) were purchased from Abcam; Apoptosis, DNA Damage and Cell Proliferation Kit from BD Biosciences and Lipofectamin 300 transfection reagent (Invitrogen) from Thermo Fisher Scientific. SiRNAs for CD24 silencing (Cat\# Hs01 00232148) and for control (Cat\# SIC001) were synthetized by Sigma-Aldrich. PVDF membranes $(0.45 \mathrm{mM})$ and Luminat (Millipore) were acquired from Merck and nitrocellulose membrane (022mM) from Bio-Rad.

\section{Cell Culture Conditions}

We obtained the breast tumor cell lines MDA-MB-231 from ATCC (USA). MACL-1 and MGSO-3 were obtained from Brazilian patients with breast cancer [51]. Cells were grown at $37^{\circ} \mathrm{C}$ in a humidified atmosphere of $5 \% \mathrm{CO}_{2}$ in DMEM supplemented with $10 \%$ heat inactivated fetal bovine serum (FBS). For starvation conditions, cells were incubated with serum-free DMEM for $2 \mathrm{~h}$ before the addition of the respective stimuli.

\section{Obtaining of the resistant cell clones from parental MDA-MB-231}

The procedures to obtain MDA-MDA-231 cells resistant to doxorubicin (named CD24 ${ }^{+} / \mathrm{DxR}$ cells) are schematized in figure $4 a$. Briefly, MDA-MB-231 cells were incubated with doxorubicin at $0.6 \mathrm{mM}$ for $48 \mathrm{~h}$.

The remaining cells, named $C D 24^{+} / D x R$, were trypsinized and used in the respective experiments. These cells were characterized as non-proliferative. DxR/30 achievement is schematized in figure 5a. After obtaining CD24 $4^{+}$DxR cells, these cells were cultured with DMEM $10 \%$ of fetal bovine serum for 15 days, then cells were cultured under stress condition (DMEM $1 \%$ of fetal bovine serum for $48 \mathrm{~h}$ ) following by incubation in normal culture conditions until they recover their proliferative activity. From then, cells were named DxR/30. In order to obtain MDA-MDA-231 cells resistant to Imiquimod, MDA-MB-231 cells were incubated with Imiquimod at $1 \mathrm{mg} / \mathrm{ml}$ for $96 \mathrm{~h}$. The remaining cells were trypsinized and used in the respective experiments.

\section{MTT (viability assay)}

For doxorubicin assay, MDA-MB-231 cells $\left(10^{4} /\right.$ well) were plated in 96-well plates in DMEM with $10 \%$ serum. Cells were incubated for $24 \mathrm{~h}$ with different stimuli according to the figures. For Imiquimod assay, MDA-MB-231 cells ( $10^{4} /$ well) were plated in 24 -well plates in DMEM with $10 \%$ serum. Cells were incubated for $96 \mathrm{~h}$ with different stimuli according to the figures. After the respective treatment time, the medium was removed and cells were incubated with $50 \mathrm{ml} /$ well of DMEM $10 \% \mathrm{FBS}$ plus of $40 \mathrm{ml} /$ well of 
MTT $(5 \mathrm{mg} / \mathrm{ml})$ for doxorubicin assay or $\mathrm{ml} /$ well of DMEM $10 \%$ FBS plus of $40 \mathrm{ml} /$ well of MTT $(5 \mathrm{mg} / \mathrm{ml})$ for Imiquimod assay for $2 \mathrm{~h}$ at $37^{\circ} \mathrm{C}$. After removing the medium, $50 \mathrm{ml}$ (for doxorubicin) or $200 \mathrm{ml}$ (for Imiquimod) of DMSO were added to dissolve the crystals of formazan and the absorbance was measured in a microplate reader at a wavelength of $595 \mathrm{~nm}$. A value of $100 \%$ was assigned to untreated control cultures. Results were derived from at least three independent sets of triplicate experiments.

\section{Histone extraction}

After harvesting and washing with ice-cold PBS (twice), cells were resuspended in Triton Extraction Buffer (TEB: PBS containing $0.5 \%$ Triton X 100 (v/v), $2 \mathrm{mM}$ phenylmethylsulfonyl fluoride (PMSF), $0.02 \%(\mathrm{w} / \mathrm{v}$ ) $\mathrm{NaN3}$ ) at a cell density of $10^{7}$ cells per ml. Cells were lysed on ice for 10 minutes with gentle stirring. Then, cells were centrifuged at 2000rpm for 10 minutes at $4^{\circ} \mathrm{C}$ and the supernatant was discarded. In the next step, cells were washed in half the volume of TEB and centrifuge at before. The pellet was ressupended in $0.2 \mathrm{~N} \mathrm{HCl}$ at a cell density of $4 \times 10^{7}$ cells per $\mathrm{ml}$ over night at $4^{\circ} \mathrm{C}$. Then, samples were centrifugated at $2000 \mathrm{rpm}$ for 10 minutes at $4^{\circ}$ and the aliuots were stored $-20^{\circ} \mathrm{C}$.

\section{RNA silencing}

MDA-MB-231 cells were seeded in 24-well plates at a density of $2 \times 10^{4}$ cells/well. After $24 \mathrm{~h}$ of incubation, the cells were transiently transfected with short interfering RNA (siRNA) specific for CD24 or control siRNA at a final concentration of $100 \mathrm{nM}$ by using Lipofectamin 3000 Transfection Reagent according to manufacturer's instructions. Briefly, siRNA and Lipofectamin were diluted separately in serum-free OPTI MEM. Then, the diluted Lipofectamin and siRNA were mixed (1:1 v/v). After $5 \mathrm{~min}$, the mix was added drop-wise onto the cells under their normal growth conditions and after $48 \mathrm{~h}$ silenced cells were used in the different assays. CD24 silencing was confirmed by western blotting.

\section{Western Blotting}

For protein expression, cells were harvested, counted and lysed in RIPA buffer supplemented with phosphatase and protease inhibitor cocktail according to the manufacturer's instructions. For the evaluation of the phosphorylated form of MAPKs, cells were seeded in 6-well plates ( $10^{6}$ cells/well) and were starved for $2 \mathrm{~h}$ in free-serum medium (SFM). Then, cells were treated for 30 60 min with medium containing $10 \%$ FBS as stimuli. At the end of treatment cells were lysed in RIPA buffer supplemented with phosphatase and protease inhibitor cocktail according to the manufacturer's instructions. Protein lysates were separated by polyacrylamide gel electrophoresis on $10 \%$ or on $15 \%$ gels when concerned histone extract, and electrotransferred to PVDF-0,45mM membranes (Milipore) or nitrocellulose-0,22mM (BioRad) when concerned histone extracts. Membranes were blocked overnight with $5 \%$ dry milk and were incubated with primary antibodies in $5 \%$ BSA also overnight. After incubation with the peroxidaseconjugated secondary antibody for $1 \mathrm{~h}$, protein expression was detected using Luminat HRP reagent (Milipore) and analyzed using LAS-4000 imaging system (Fuji) or C-DiGit Blot Scanner (Li-Cor).

\section{Magnetic sorting}


The different cell subpopulations (CD24 ${ }^{+}$and $\mathrm{CD} 24^{-}$) were sorted from parental MDA-MB-231 cells using CD24 MicroBead Kit (MACS Miltenyi Biotec) following manufacturer's instructions. Briefly, the CD $24^{+}$cells were indirectly magnetically labeled with CD24-Biotin antibodies and Anti-Biotin MicroBeads. Then the cell suspension was loaded onto a MACS Column, which is placed in the magnetic field of a MACS Separator. The magnetically labeled $\mathrm{CD} 24^{+}$cells were retained within the column. The unlabeled cells (CD24 cells) ran through; this cell fraction was thus depleted of $\mathrm{CD} 24^{+}$cells. After removing the column from the magnetic field, the magnetically retained $\mathrm{CD} 24^{+}$cells can be eluted as the positively selected cell fraction. The purity of the sorted populations was verified by Flow Cytometry.

\section{Flow cytometry analysis}

To evaluate the proliferative activity of cells, an assay using the Apoptosis, DNA Damage, and Cell Proliferation Kit from BD Biosciences was realized in accord with the manufacturer's instructions. Cells were cultured as indicated in the figure legends and washed/blocked in staining buffer (PBS $4 \%$ fetal bovine serum - v/v). Cells were fixed and permeabilized using CitoFix/CitoPerm reagent for 20 min on ice, nucleus was permeabilized using CitoFix/CitoPerm Plus for 10 min on ice and finally treated with DNAse (30 mg $/ 10^{6} \mathrm{cells}$ ) for $1 \mathrm{~h}$ at $37^{\circ} \mathrm{C}$ in humidified chamber. Then, cells were simultaneously stained with antiBrdU/PerCP-Cy5.5 and anti-gH2AX/Alexa647 (BD Biosciences) fluorescent antibodies for $20 \mathrm{~min}$ at room temperature. Between every step cells were washed with $1 \times$ PBS/PermWash (BD Biosciences). Concerning CD24 and p38 staining, the following step by step was realized. For extracellular staining, MDA-MB-231 cells were washed/blocked in staining buffer (PBS $4 \%$ fetal bovine serum - v/v) and were labeled using anti-CD24/Pe-Cy7 (eBioscience) or anti-CD24 (BD Pharmigen) for 20 min on ice, and when necessary, followed by FITC-conjugated equivalent secondary antibody (BD Pharmigen) for more 20 min on ice. For intracellular staining, after extracellular labeling, cells were fixed and permeabilized using CitoFix/CitoPerm reagent for $20 \mathrm{~min}$ on ice. Then, cells were incubated with anti-CD24/Pe-Cy7 (eBioscience) and/or with anti-pp38 (Cell Signaling) for $20 \mathrm{~min}$ at room temperature, and when necessary, followed by FITC-conjugated secondary antibody (BD Pharmigen) for $20 \mathrm{~min}$ at room temperature. Between every step cells were washed with 1 x PBS/PermWash (BD Biosciences). After labeling protocols, cells were fixed in PFA $4 \%$ overnight $\left(4^{\circ} \mathrm{C}\right.$ lightless). Cells were re-suspended in isoton buffer and analyzed by flow cytometry. Single-stain controls were used to set gating parameters and any compensations. All flow cytometry results were analyzed by FlowJo software following a rigorous doublet discrimination based on FSC:A versus width as well as FSC:A versus height. Data were collected by the cell analyzing LSRFortessa (BD Biosciences - Immunocytometry Systems) using "BD FACSDivaTM Software" (BD Biosciences) and analyzed with "FlowJo (Tree Star) Software".

\section{Wound Healing Assay}

MDA-MB-231 and DxR/30 cells were seeded $\left(8 \times 10^{5}\right)$ in 6 wells plate and let in growing conditions (DMEM $10 \% \mathrm{FBS}$, at $37^{\circ}, 5 \% \mathrm{CO}_{2}$ ) for 24 hours or until cells get confluent. Then, using a $100 \mathrm{ml}$ tip, a scratch was performed in the cell monolayer and cells were cultured in DMEM supplemented with $2 \%$ of FBS in order 
to avoid cell proliferation. To obtain the same field during the image acquisition, pen markings were performed at the bottom of the culture plates as reference points close to the scratch. Cell migration was registered by light microscopy (Evos Skedda) at 24, 48 and 72 hours post scratch. Using ImageJ software the wound healing was measured and a closing-time percentage was calculated based on the initial scratch size of each cell type.

\section{Statistical analysis}

The data were presented as mean of triplicates ${ }^{+} /$SD or as means of triplicates. Statistical significance was determined using Student's t-test, or Two-way ANOVA followed by Bonferroni post-test. The criterion for statistical significance was $p<0.05$.

\section{Results}

\section{1 - The translocation of CD24 from cytosol to membrane is an early event in breast tumor cells under drug stress}

Phenotype switching, also commonly referred to as cell plasticity, is an important process observed during treatment of cancer which was repeatedly associated with stemness. Here, using breast cancer cell line, we explored the dynamics of the CSC marker CD24 after doxorubicin treatment. At first, we sought to define the localization of CD24 in MDA-MB-231 cells by extra and intracellular staining. As shown by our results obtained by flow cytometry (Fig $1 a, b)$ only about $5 \%$ of cells expressed CD24 in cell membrane corroborating with other studies [23] which explains why MDA-MB-231 is considered as CD24 $4^{\text {low/-. }}$. By contrast, a significant intracellular pool of CD24 was encountered in all cells. Fluorescence microscopy confirmed the presence of both extracellular (yellow arrows) and intracellular CD24 (white arrows) (Fig 1C). After the treatment with doxorubicin at 0,6mM - concentration representing the EC50 after 24h treatment calculated in MDA-MB-231 cell line - a cell phenotype switching occurred which corresponded to an enrichment of the $\mathrm{CD}_{24} 4^{+}$subpopulation (Fig 1d). Notably, MFI analysis showed an increase of surface CD24 density during drug treatment (Fig 1e). This phenomenon occurred rapidly since $\sim 42 \%$ of cells converted into $\mathrm{CD} 24^{+}$after $2 \mathrm{~h}$ to finally reach $\sim 96 \%$ after $48 \mathrm{~h}$ of treatment, as visualized by flow cytometry (Fig 1d). Importantly, the majority of cells remained positive even after a pause in the treatment (incubation in drug-free medium for $48 \mathrm{~h}$ after treatment) as visualized by the last pseudocolor plot in the figure $1 \mathrm{~d}$. The fact that this event was detected in the first hours of treatment excludes the possibility of a Darwinian selection of $\mathrm{CD}_{24}{ }^{+}$cells. These results led us to hypothesize that the intracellular pool of CD24 immediately available might play a role in this process by translocating from the cytosol toward cell surface under doxorubicin treatment. To support these data, MDA-MB-231 cells were sorted into $\mathrm{CD} 24^{+}$and $\mathrm{CD} 24^{-}$subpopulations (Fig $1 \mathrm{~h}$ ) by using magnetic beads and the CD24 localization was evaluated in CD24 cells after doxorubicin treatment. As shown in the figure $1 \mathrm{i}$, the translocation of CD24 occurred even in CD24- population obtained after cell sorting since CD24 cells were able to rapidly convert in $\mathrm{CD} 24^{+}$cells. Such data reinforce the idea that $\mathrm{CD} 24^{+}$cells enrichment 
during drug treatment does not correspond to a pre-selection of clones but to a drug-induced phenotype switching. In order to confirm this theory, we took the opportunity of using brefeldin A, an inhibitor of protein transport from endoplasmic reticulum to Golgi apparatus, to disturb the CD24 traffic after drug treatment. After flow cytometry analysis, we observed that when MDA-MB-231 cells were treated with brefeldin A before doxorubicin, the translocation of CD24 was reduced (Fig 1f). These results were consistent with the fluorescence microscopy images obtained from doxorubicin-treated cells and stained with anti-CD24 without permeabilization to solely detect surface CD24 (Fig 1g). To discard the hypothesis that the increased membrane CD24 expression could be partially due to an increased protein synthesis, we used actinomycin D, a DNA-transcription inhibitor. The incapability of actinomycin $D$ to reduce the $\mathrm{CD} 24^{+}$phenotype enrichment in presence of doxorubicin indicated that the intracellular pool of CD24 was the main source of CD24 traffic in the presence of doxorubicin (data not shown).

Concerning MACL-1 and MGSO-3 breast cell lines, obtained from Brazilian patients, the percentage of CD24 $4^{+}$cells was about $5 \%$ and $46 \%$ respectively, corroborating with their classification in other study [24]. The presence of intracellular CD24 was also detected in the whole population of both cell lines, like observed in MDA-MB-231 population (Fig 2a,b). As observed in MDA-MB-231 cells under treatment, phenotype switching occurred in both cell lines which corresponded to an enrichment of the CD24 ${ }^{+}$ subpopulation (Fig 2c,d) since $\sim 27 \%$ and $~ 45 \%$ of MACL-1 and MGSO3 cells, respectively, converted into $\mathrm{CD} 24^{+}$after $4 \mathrm{~h}$ of treatment with doxorubicin. After $24 \mathrm{~h}$ of treatment, the conversion rate in $\mathrm{CD} 24^{+}$cells reached $\sim 90 \%$ for MDA-MB-231 and MACL-1 and 70\% for MGSO-3 cells.

Therefore, we propose a new dynamic model of cell transition phenotype under drug stress that could allow each cell of breast cancer to convert into $\mathrm{CD} 24^{+}$cells which involves the translocation of intracellular CD24 accompanied with its increased expression at cell surface.

\section{2 - Translocation of CD24 correlates with the upregulation of Bcl-2 expression leading to chemoresistance in MDA-MB-231 cells treated with doxorubicin}

Here, we investigated the molecular identity of the survival cells after $48 \mathrm{~h}$ of doxorubicin treatment named CD $24^{+} / \mathrm{DxR}$ cells. The figure 3 a represents the methodology used to obtain CD $24^{+} / \mathrm{DxR}$ cells and schematize the steps to perform the following MTT and western blot assays. At first, we tested the sensibility of the $\mathrm{CD} 24^{+} / \mathrm{DxR}$ cells to respond to a second doxorubicin treatment using MTT assay. As shown in the figure $3 \mathrm{~b}$, only a slight reduction of CD24 $/ \mathrm{DxR}$ cell number was noted after a second treatment with doxorubicin while the viability of naïve cells, that received the treatment for the first time, declined below $40 \%$. These data indicated that CD $24^{+} / \mathrm{DxR}$ cells became tolerant. So, we sought to identify whether this phenotype change corresponded to a putative cell reprogramming in response to drug stress. By using western blot assay, we compared the protein profile of naïve and CD24 $4^{+} / \mathrm{DxR}$ cells. When we focused on protein expression involved in cell proliferation or death, it was detected a significant increase of $\mathrm{Bcl}-2$ expression which was inversely correlated with Bax expression in CD24 $/ \mathrm{DxR}$ (Fig 3c). In addition, a remarkable decrease of cyclin D1, a regulator of cell cycle progression, was noted, 
suggesting that acquisition of drug tolerance controlled by Bcl-2 expression may also require cells to exit the cell cycle (Fig 3c). In previous studies, we have focused on the role of p38 MAPK and ERK1/2 in the proliferation of MDA-MB-231 cells $[25,26]$, so we analyzed their activation profile in the resistant $\mathrm{CD}^{2} 4^{+} / \mathrm{DxR}$ cell. Interestingly, this phenotype switching was accompanied by a strong and continuous activation of p38 MAPK at the detriment of another MAPK, ERK1/2 (Fig 3d). Then, we verified the relationship between $\mathrm{CD} 24$ and $\mathrm{Bcl}-2$ by silencing CD24 using interference-RNA. In CD24-silenced cells (SiCD24), a decreased Bcl-2 and p38 expression was observed (Fig 3f). This may explain the reduced capacity of SiCD24 cells to resist to drug treatment in all the doxorubicin concentrations tested when compared with control-silenced ( $\mathrm{SiC}$ ) and parental MDA-MB-231 cells (Fig 3e). By contrast, CD24subpopulation, obtained from magnetic sorting, presented a similar drug sensibility when compared with CD24 ${ }^{+}$subpopulation and parental MDA-MB-231 cells, probably due to the phenotype switching after drug treatment thanks to CD24 translocation as shown in the figure $1 \mathrm{j}$ (Fig $3 \mathrm{e}$ ).

Next, we sought to treat MDA-MB-231 cells with a drug capable to reduce cell proliferation without inducing immediate death, like doxorubicin does. We tested the efficacy of the TLR7 agonist Imiquimod, previously used in skin cancer treatment and in the treatment of cutaneous metastatic breast cancer [2729], on MDA-MB-231 cell proliferation. At the concentration of $1 \mathrm{mM}$, a significant decreased in cell proliferation was observed while a total blocking of cell replication was noted at $10 \mathrm{mM}$ during the period of experiment (Fig $3 \mathrm{~g}$ ). No significant cell death was observed in the first 48 hours in the presence of both concentrations of Imiquimod. In such context, we tested the capacity of cells to respond to a second treatment $96 \mathrm{~h}$ after the first dose of Imiquimod. As shown in the figure $3 \mathrm{~h}$, where the results are expressed in \% of cell viability, we observed a similar pattern when an unique dose or two subsequent treatments with the TLR7 agonist were used indicating that no phenotype change occurred after the first treatment and consequently avoid chemoresistance. When we used CD24 as a phenotypic marker, we confirmed that no switching phenotype of MDA-MB-231 population leading to an enrichment of CD24 ${ }^{+}$ cells occurred (Fig 3i). In accord with this, no upregulation of Bcl-2 expression was detected in cells treated with Imiquimod (Fig 3j).

Taken together these data indicated that translocation of CD24 is a triggering event leading to phenotype change and upregulation of $\mathrm{Bcl}-2$ expression.

\section{3 - CD24 and p38 work in tandem in the chemoresistance acquisition phenotype in breast cancer cells.}

According to the figure $3 d$, p38 phosphorylation was stronger, constitutive and independent on serum in CD24 /DxR cells contrasting with the serum-dependent activation of p38 in MDA-MB-231 cells under normal culture conditions. This suggests that $\mathrm{p} 38$ activation in different configurations can cause different outputs and may participate in the phenotype switching.

The next question was whether there was a privileged relationship between CD24 and p38. At first, we explored this point in MDA-MB-231 cells under growing culture conditions. After magnetic sorting, we evaluated by western blot the status of MAPK activation after cell stimulation with serum according to 
the kinetic presented in the figure $4 a$. As clearly shown, $\mathrm{CD}_{24}{ }^{+}$cells phosphorylated p38 in a more pronounced way than CD24 subpopulation. In contrast, a higher phosphorylation of ERK1/2 was observed in the CD24 and parental MDA-MB-231 cells. The results obtained by flow cytometry confirmed the correlation between surface CD24 expression and preferential p38 phosphorylation, as observed by the fact that $\sim 70 \%$ of the $C D 24^{+}$cells phosphorylated $\mathrm{p} 38$, while in only $\sim 15 \%$ of the CD $24{ }^{-}$cells the activation of this MAPK was observed (Fig 4b).

Another evidence demonstrating that CD24 and p38 work together is presenting in the figure 4c. According to the western blotting, siRNA-mediated knockdown of CD24 decreased the phosphorylation of p38 when cells were submitted to doxorubicin treatment indicating that the absence of CD24 jeopardized the cell capacity to induce activation of p38 MAPK.

The sustained p38 activation in CD24 $4^{+}$DxR cells makes it a prime target. In this context, we used SB203580, a p38 activity inhibitor [30] to evaluate its impact on drug resistance. According to the results obtained by cell counting, the combination of SB203580 and doxorubicin was more efficient in reducing cell number than doxorubicin alone (Fig 4d). Concerning the results observed by MTT assay, the inhibition of p38 was benefit from two aspects: firstly, SB203580 sensitized MDA-MB-231 cells to the therefore doxorubicin treatment (blue line vs black line) and at second, SB203580 disrupted the resistantphenotype acquired by the cells that received two consecutives doxorubicin treatments (green line vs red line). The effect of the drug association may be considered as synergistic since the total effect of the combination of SB203580 and doxorubicin was greater than the sum of the individual effects of each drug. Importantly, SB203580 alone was unable to impact on cell viability in the same experimental conditions (Fig 4e).

To visualize these results, we performed the capture of light microscopy images of cells treated with drug pair. These experiments were performed under sub-confluence or confluence conditions to exclude the influence of fluctuating environment. A direct impact of doxorubicin on MDA-MB-231 cells was observed after $24 \mathrm{~h}$ treatment marked by a decreased cell number and changes in morphology. The association of SB203580 and doxorubicin exacerbated the cell phenotype changes under confluent and sub-confluent conditions. The results confirmed that the efficiency of the drug pair constituted by doxorubicin and SB203580 was superior in killing cells in both plating conditions (Fig 4g).

Consistent with the above results, western blots showed that SB203580 prevented the augment of Bcl-2 expression induced by doxorubicin (Fig 4f). Further, in MDA-MB-231, which has high levels of a mutant p53, it has been described that p53 mutants can contribute to the suppression of apoptosis [31]. In line with this, SB203580 was also able to reduce the expression of p53 in doxorubicin treated cells (Fig 4f).

Epigenetic events drive cell reprogramming and tumor cell plasticity $[14,15]$. In this context, we have, evaluated whether the state of histones could be altered in CD $24^{+} / D \times R$ cells. We focused on the lysine 9 at the histone $\mathrm{H} 3$ (H3K9), which can turn genes on or silence them by getting acetylated or methylated [32]. Our western blot analyzes have shown that doxorubicin treatment increased the tri-methylation of 
H3K9 (H3K9me3) which combined with its deacetylation. Importantly, SB203580 was able to prevent the increase of $\mathrm{H} 3 \mathrm{~K} 9 \mathrm{me} 3$ induced by doxorubicin treatment indicating that $\mathrm{p} 38$ can regulate the methylation state of H3K9 observed under drug pressure (Fig 4h).

Taken together, these results suggest that targeting p38 during the chemotherapy-induced phenotypic cell state transition can overcome adaptive resistance to doxorubicin treatment.

\section{4 - CD24/DxR cells become proliferative after a long-lasting period in dormancy.}

The capacity of slow cycling cells to reentry into cell cycle has been a topical debate for quite a time. As reported above, $C D 24^{+} / \mathrm{DxR}$ cells have adopted a slow-down cell cycle after doxorubicin treatment evidenced by a reduction of cyclin D1 (Fig 3c) and were characterized by an enlarged morphology that are hallmarks of dormant cells (Fig $5 b$ ).

So, we sought to monitor $\mathrm{CD} 24^{+} / \mathrm{DxR}$ cells to evaluate the reversibility of their dormant state according to the scenario presented in the figure $5 \mathrm{a}$. CD24 $/$ DxR cells were cultured in drug-free medium for a long period and then were submitted to a serum deprivation for two days followed by the culture in medium contained $10 \%$ of serum. In such conditions, we observed the emergence of revertant cells (named DxR/30) which reacquired the ability to proliferate as confirmed by their capacity to incorporate BrdU (Fig $5 c)$.

The percentage of $\mathrm{CD} 24^{+}$cells in the revertant-population recovered to levels observed in naïve MBA-MB231 cell population (Fig $5 \mathrm{~d}$ ). Importantly, even in the absence of drug, the phosphorylation of p38 in $\mathrm{DxR} / 30$ remained strong and constitutive indicating that $\mathrm{DxR} / 30$ cells have conserved some features of their precedent states while having eliminated others (Fig 5 e).

When we evaluated the drug resistance of $\mathrm{DxR} / 30$ cells, more than one month after the first treatment the cells remained tolerant to doxorubicin. Indeed, as shown in the light microscopy images, the morphology of these cells appeared little affected after treatment when compared to naïve MDA-MB-231 treated cells. More surprisingly, DxR/30 cells retained their capacity to proliferate even in the presence of drug (5 days) without entering in slow cycling stage like CD24 $4^{+}$DxR, confirming that DxR/30 cells have acquired a new identity. After 12 days of treatment, they have re-colonized the plastic dishes (Fig 5f). One of the hypothesis is that $\mathrm{DxR} / 30$ cells might have a competitive advantage over naïve cells under drug stress due to their constitutive phosphorylation of p38. Finally, we evaluated the migratory capacity of these cells by using the in vitro wound healing assay based on the creation of an artificial gap, so called "scratch", on a confluent cell monolayer. Images were captured every 24 hours during cell migration, the scratch was measured and a comparison of time required to close the scratch between naïve cells and $\mathrm{DxR} / 30$ was performed. The incubation time was determined at $48 \mathrm{~h}$ when the faster moving cells $\mathrm{DxR} / 30$ were just about to close the scratch. The confirmation of the migratory capacity of both cells was made by using the software Image $\mathrm{J}$ (Fig $5 \mathrm{~g}$ ). 
According to our data, slow-cycling cells under stress may reentry into cell cycle leading to cells that possess new properties, including higher drug resistance and higher migratory capacity, reaffirming that they have acquired a new identity.

\section{Discussion}

Tumor cells have been shown to hijack signaling pathways involved in reprogramming to become phenotypically plastic and evolve towards drug-refractory cell identities. Our results provide new insight about these mechanisms leading to the emergence of resistant subpopulation during chemotherapy treatment. Robust evidence showed that the CSC subpopulation is enriched after chemotherapy, suggesting that this subset is responsible for the majority of treatment failure [33,34]. Here, by monitoring the CSC marker CD24 during doxorubicin treatment, we have shown the uniform conversion of CD24breast cancer cell population into $\mathrm{CD} 24^{+}$cells characterized as drug resistant cells. In the same line, Goldman et al have reported that the treatment of breast or ovarian cancer cells with high concentration of taxanes results in the generation of 'persistent' cells, which are defined by a transition towards a $\mathrm{CD} 44^{\mathrm{Hi}} \mathrm{CD} 24^{\mathrm{Hi}}$ expression status [12]. Others studies have demonstrated an enrichment for CSC-like phenotype after chemotherapy in glioblastoma [35] indicating how the phenomenon is ubiquitous.

Importantly, our data revealed that each given breast tumor cell may convert into CD $24^{+}$phenotype thanks to the translocation of CD24 from cytosol to cell membrane made possible by the presence of an intracellular pool of CD24, never described until now. Such findings suggest that CSC may not be considered as a clonal identity but rather a state as also claimed by Dirske etal [35]. The conversion observed between non-CSC and CSC after chemotherapy demonstrates that cell plasticity emerges as an important contributor to therapy escape. This was verified when we used the TLR7 agonist Imiquimod, capable to reduce MDA-MB-231 cell proliferation without inducing translocation of $\mathrm{CD} 24^{+}$, neither resistance to a second treatment, nor changes in the expression of the anti-apoptotic protein Bcl-2 that contrasted with the overexpression of $\mathrm{Bcl}-2$ observed in cells under doxorubicin treatment. In this regard, great efforts have been directed towards finding small molecules to inhibit these anti-apoptotic Bcl-2 family proteins to tackle anti-apoptotic adaptation of tumor cells [36].

Hence, targeting cell plasticity should provide a unique opportunity to improve the efficiency of existing therapies. The identification of signaling pathways involved in the cell phenotype changes during treatment may be a key to impede chemoresistance. The tandem constituted by CD24 and the MAPK p38 appears crucial in cell fate of MDA-MB-231 population. A preferential use of p38 in CD24 ${ }^{+}$cells have been noted under normal conditions which has been amplified under drug treatment in accord with the dynamics of CD24. The relationship between CD24 and p38 is supported by the incapability of SiCD24 cells to activate p38 under drug stress. Indeed, we hypothesize that the change in the dynamics of p38 activation that turned sustained early after CD24 translocation is linked to the increased surface CD24 expression observed in doxorubicin treated cells. In this regard, a very recent paper reported that MAPK cascade signaling dynamics (transient to sustained activation) may be controlled by the activation 
kinetics of a given membrane receptor and not necessarily by the intracellular topology of the kinase networks. In the same study, it was proposed that redirecting signal dynamics may be a more fruitful and effective approach than controlling receptor activation in pathologic situation [37]. This is why we considered the profile of p38 activation as an important marker of the resistant cell identity (CD24 $\left.4^{+} / \mathrm{DxR}\right)$ and a choice target to impede phenotype switching during doxorubicin treatment.

The relevance of this strategy was verified when we compared the protein expression pattern of $\mathrm{CD} 24^{+} / \mathrm{DxR}$ cells characterized by an overexpression of Bcl-2 and decline of cyclin D1 which are indicators of adaptative cellular reprogramming and also considered as markers of premature senescence [38-40] and naïve MDA-MB-231 cells treated with doxorubicin in the presence of the p38 inhibitor SB203580. In such conditions, SB203580 was capable not only to reduce Bcl-2 expression but to decrease the tri-methylation of $\mathrm{H} 3 \mathrm{~K} 9$ which constitutes a hallmark for stress response leading to cell reprogramming including drug resistance [41-43]. The benefit of this association was translated into a synergism of the cytotoxic effect of the combination of SB203580 and doxorubicin. The impact of SB203580 on cell fate may also correlate with the capacity of p38 to control expression of p53. Recently, p53 was also considered as a marker of cell reprogramming and acquisition of stemness [44]. Finally, an interesting point to note is that SB203580 had no effect on cell viability at $24 \mathrm{~h}$ at the concentration used. This sustains the idea that p38 is an early active player in drug resistance by inducing cell identity changes, notably increasing cell survival marker expression.

To better assess the long term consequences of the rapid phenotype switching after drug treatment we have evaluated whether the slow-cycling state of $\mathrm{CD} 24^{+} / \mathrm{DxR}$ cells was reversible after several weeks in drug-free medium since several studies have demonstrated the reversibility of senescence [45-48]. In fact, the revertant cells (named DxR/30), recovered their capacity to proliferate and importantly, have gained higher drug resistance and stronger migratory properties. This may be put in parallel with the constitutive activation of p38 in these cells. Interestingly, in the absence of the drug pressure and in proliferative conditions, the DxR/30 population retrieved a basal level of $\mathrm{CD} 24^{+}$cells. This follows mathematical models that tend to establish that tumor cell populations always maintain its heterogeneity at fixed ratio in dynamic conditions like proliferation [49].

So, here we have established a model to accompany the journey of MDA-MD-231 cells after drug treatment starting from their switching to $\mathrm{CD} 24^{+}$phenotype to their entry in slow-cycling state and reversion into proliferative cells. Notably, the sustained p38 phosphorylation observed in all the posttreatment stages may also indicate the participation of this MAPK in the network that successfully promotes the formation of metastasis at distant organs. Previous studies have shown that the program EMT (Epithelial-Mensenchymal Transition) has been involved in the distant metastases frequently detected following chemotherapy [50] that could also include p38. The monitoring of cell evolution throughout this journey has shown that they have conserved some features of previous state while having eliminated others, in other words, that they have acquired hybrid properties corresponding to a new identity. 
The pertinence of using a drug pair, associating a leading drug with an inhibitor of cell reprogramming, was illustrated by the high efficiency of the combination of p38 inhibitor and doxorubicin on the killing of aggressive MDA-MB-231 breast cancer cell line as schematized in the figure 6.

\section{Conclusions}

This study reaffirms how a better understanding of the biology and molecular drivers of the CSCs plasticity will enable identification of new anticancer targets. More specifically, we have shown here that the cellular localization of CD24 associated with the changes in the dynamics of p38MAPK activation in breast tumor cells under drug stress plays a crucial role in the acquisition of drug resistance and new cell identity. The use of p38 inhibitor was able to disrupt this partnership and consequently to avoid chemotherapy-induced cell state transition. These results suggest that targeting p38 in aggressive breast cancer might be an interesting approach in order to overcome adaptive resistance to doxorubicin treatment.

\section{Declarations}

\section{Ethical Approval and Consent to participate}

Not applicable

\section{Consent for publication}

The authors read and approved the final manuscript

\section{Availability of supporting data}

Not applicable

\section{Competing interests}

Not applicable

\section{Funding}

Not applicable

\section{Conflict of Interest}

The authors declare no conflicts of interest to disclose.

\section{Contributions}

HWH was involved in the laboratory experimental work, data analysis and interpretation and writing the manuscript. AMG participated in the study formulation. CR was involved in the supervision of the 
experimental work, in the study formulation and writing the manuscript. The authors read and approved the final manuscript.

\section{Acknowledgment}

H.W.H. is a Ph.D. student fellow from CAPES. A.M.G. is a professor from Biochemistry and Immunology department from UFMG. C.R. is a research fellow from CNPQ (Conselho Nacional de Pesquisa e Desenvolvimento). The authors thank the Program for Technological Development in Tools for HealthPDTIS - Instituto René Rachou/FIOCRUZ (Belo Horizonte, Minas Gerais, Brazil) for use of its facilities. We are grateful to Professor Ricardo Tostes Gazzinelli (Depto. de Bioquímica e Imunologia/UFMG and FIOCRUZ - Belo Horizonte, Minas Gerais, Brazil) for use of his laboratory facilities and for reagent supplies.

\section{References}

1. Beck B, Blanpain C. Unravelling cancer stem cell potential. Nat Rev Cancer. 2013;13(10):727-38. https://doi.org/10.1038/nrc3597

2. Bjerkvig R, Tysnes B, Aboody KS, Najbauer J, Terzis AJA. The origin of the cancer stem cell: current controversies and new insights. Nat Rev Cancer. 2005;5(12):995. https://doi.org/10.1038/nrc1740

3. Clarke MF, Dick JE, Dirks PB, Eaves CJ, Jamieson CHM, Jones DL, et al. Cancer stem cells Perspectives on current status and future directions: AACR workshop on cancer stem cells. Cancer Res. 2006;66(19):9339-44. https://doi.org/10.1158/0008-5472.CAN-06-3126

4. Nguyen $L$ V, Vanner R, Dirks P, Eaves CJ. Cancer stem cells: an evolving concept. Nat Rev Cancer. 2012;12(2):133-43. https://doi.org/10.1038/nrc3184

5. O'Brien-Ball C, Biddle A. Reprogramming to developmental plasticity in cancer stem cells. Dev Biol. 2017;430(2):266-74. https://doi.org/ 10.1016/j.ydbio.2017.07.025

6. Reya T, Morrison SJ, Clarke MF, Weissman IL. Stem cells, cancer, and cancer stem cells. Nature. 2001;414:105-11. https://doi.org/10.1016/j.ydbio.2017.07.025

7. Shibue T, Weinberg RA. EMT, CSCs, and drug resistance: The mechanistic link and clinical implications. Nat Rev Clin Oncol. 2017;14(10):611-29. https://doi.org/10.1038/nrclinonc.2017.44

8. Fang X, Zheng P, Tang J, Liu Y. CD24: from A to Z. Cell Mol Immunol [Internet]. 2010;7(November 2009):100-3. https://doi.org/10.1038/cmi.2009.119

9. Kristiansen G, Winzer K-J, Mayordomo E, Bellach J, Schlüns K, Denkert C, et al. CD24 expression is a new prognostic marker in breast cancer. Clin Cancer Res. 2003;9:4906-13. pmid: 14581365

10. Kristiansen G, Sammar M, Altevogt P. Tumour biological aspects of CD24, a mucin-like adhesion molecule. J Mol Histol. 2004;35(3):255-62. https://doi.org/10.1023/b:hijo.0000032357.16261.c5

11. Sharma S V., Lee DY, Li B, Quinlan MP, Takahashi F, Maheswaran S, et al. A Chromatin-Mediated Reversible Drug-Tolerant State in Cancer Cell Subpopulations. Cell. 2010;141:69-80. https://doi.org/10.1016/j.cell.2010.02.027 
12. Goldman A, Majumder B, Dhawan A, Ravi S, Goldman D, Kohandel M, et al. Temporally sequenced anticancer drugs overcome adaptive resistance by targeting a vulnerable chemotherapy-induced phenotypic transition. Nat Commun. 2015;6:6139. https://doi.org/10.1038/ncomms7139

13. Modur V, Joshi P, Nie D, Robbins KT, Khan AU, Rao K. CD24 Expression May Play a Role as a Predictive Indicator and a Modulator of Cisplatin Treatment Response in Head and Neck Squamous Cellular Carcinoma. PLoS One. 2016;11(6):e0156651. https://doi.org/10.1371/journal.pone.0156651

14. Easwaran H, Tsai H-C, Baylin SB. Cancer epigenetics: tumor heterogeneity, plasticity of stem-like states, and drug resistance. Mol Cell. 2014;54(5):716-27. https://doi.org/10.1016/j.molcel.2014.05.015

15. Nickel A, Stadler SC. Role of epigenetic mechanisms in epithelial-to-mesenchymal transition of breast cancer cells. Transl Res J Lab Clin Med. 2015;165(1):126-42. https://doi.org/10.1016/j.trsl.2014.04.001

16. Brown R, Curry E, Magnani L, Wilhelm-Benartzi CS, Borley J. Poised epigenetic states and acquired drug resistance in cancer. Nat Rev Cancer. 2014;14(11):747-53. https://doi.org/10.1038/nrc3819

17. Flavahan WA, Gaskell E, Bernstein BE. Epigenetic plasticity and the hallmarks of cancer. Science. 2017;357(6348):eaal2380. https://doi.org/10.1126/science.aal2380

18. Wagner EF, Nebreda AR. Signal integration by JNK and p38 MAPK pathways in cancer development. Nat Rev Cancer. 2009;9:537-49. https://dx.doi.org/10.1038/nrc2694

19. Ropert C, Huth HW. New Challenges in Cancer Therapy: MAPK Inhibitors from Bench to Bedside. Molecular Oncology: Underlying Mechanisms and Translational Advancements. 2017. p. 67-91. https://doi.org/10.1007/978-3-319-53082-6_3

20. Sui X, Kong N, Ye L, Han W, Zhou J, Zhang Q, et al. P38 and JNK MAPK pathways control the balance of apoptosis and autophagy in response to chemotherapeutic agents. Cancer Lett. 2014;344:174-9. https://doi.org/10.1016/j.canlet.2013.11.019

21. Jia Y, Zhou J, Luo X, Chen M, Chen Y, Wang J, et al. KLF4 overcomes tamoxifen resistance by suppressing MAPK signaling pathway and predicts good prognosis in breast cancer. Cell Signal. 2018;42:165-75. https://doi.org/10.1016/j.cellsig.2017.09.025

22. Li S, Fong K-W, Gritsina G, Zhang A, Zhao JC, Kim J, et al. Activation of MAPK signaling by CXCR7 leads to enzalutamide resistance in prostate cancer. Cancer Res. 2019;79(10):2580-92. https://doi.org/10.1158/0008-5472.CAN-18-2812

23. Meyer M, Fleming JM, Ali MA, Pesesky MW, Ginsburg E, Vonderhaar BK. Dynamic regulation of CD24 and the invasive, CD44posCD24neg phenotype in breast cancer cell lines. Breast Cancer Res. 2009;11(6). https://doi.org/10.1186/bcr2449

24. Correa NCR, Kuasne H, Faria J a Q a, Seixas CCS, Santos IGD, Abreu FB, et al. Genomic and phenotypic profiles of two Brazilian breast cancer cell lines derived from primary human tumors. Oncol Rep. 2013;29:1299-307. https://doi.org/10.3892/or.2013.2284

25. Huth HW, Albarnaz JD, Torres AA, Bonjardim CA, Ropert C. MEK2 controls the activation of MKK3/MKK6-p38 axis involved in the MDA-MB-231 breast cancer cell survival: Correlation with 
cyclin D1 expression. Cell Signal. 2016;28(9):1283-91. https://doi.org/10.1016/j.cellsig.2016.05.009

26. Huth HW, Santos DM, Gravina HD, Resende JM, Goes AM, De Lima ME, et al. Upregulation of p38 pathway accelerates proliferation and migration of MDA-MB-231 breast cancer cells. Oncol Rep. 2017;37(4):2497-505. https://doi.org/10.3892/or.2017.5452

27. Schön MP, Schön M. TLR7 and TLR8 as targets in cancer therapy. Oncogene. 2008;27:190-9. https://doi.org/10.1038/sj.onc.1210913

28. Adams S, Kozhaya L, Martiniuk F, Meng T-C, Chiriboga L, Liebes L, et al. Topical TLR7 agonist imiquimod can induce immune-mediated rejection of skin metastases in patients with breast cancer. Clin Cancer Res. 2012;18(24):6748-57. https://doi.org/10.1158/1078-0432.CCR-12-1149

29. Krishnasamy SR, Almazan TH, Suero-Abreu GA, Jung JY. Successful treatment of cutaneous metastatic breast cancer with topical treatments that potentially synergize with systemic therapy: A case series. JAAD case reports. 2018;4(7):711-5. https://doi.org/10.1016/j.jdcr.2018.04.013

30. Tong L, Pav S, White DM, Rogers S, Crane KM, Cywin CL, et al. A highly specific inhibitor of human p38 MAP kinase binds in the ATP pocket. Nat Struct Biol. 1997;4(4):311-6. https://doi.org/10.1038/nsb0497-311

31. Hui L, Zheng Y, Yan Y, Bargonetti J, Foster DA. Mutant p53 in MDA-MB-231 breast cancer cells is stabilized by elevated phospholipase $D$ activity and contributes to survival signals generated by phospholipase D. Oncogene. 2006;25(55):7305-10. https://doi.org/10.1038/sj.onc.1209735

32. Park JA, Kim AJ, Kang Y, Jung YJ, Kim HK, Kim KC. Deacetylation and methylation at histone H3 lysine 9 (H3K9) coordinate chromosome condensation during cell cycle progression. Mol Cells. 2011;31(4):343-9. https://doi.org/10.1007/s10059-011-0044-4

33. Visvader JE, Lindeman GJ. Cancer stem cells in solid tumours: Accumulating evidence and unresolved questions. Nature Reviews Cancer. 2008;8(10):755-68. https://doi.org/10.1038/nrc2499

34. Alison MR, Lim SML, Nicholson LJ. Cancer stem cells: Problems for therapy? Journal of Pathology. 2011. p. 147-61. https://doi.org/10.1002/path.2793

35. Dirkse A, Golebiewska A, Buder T, Nazarov P V., Muller A, Poovathingal S, et al. Stem cell-associated heterogeneity in Glioblastoma results from intrinsic tumor plasticity shaped by the microenvironment. Nat Commun. 2019;10(1):1787. https://doi.org/10.1038/s41467-019-09853-z

36. Montero J, Letai A. Why do BCL-2 inhibitors work and where should we use them in the clinic? Cell Death Differ. 2018;25(1):56-64. https://doi.org/10.1038/cdd.2017.183

37. Kiyatkin A, van Alderwerelt van Rosenburgh I k, Klein DE, Lemmon MA. Kinetics of receptor tyrosine kinase activation define ERK signalling dynamics. Sci Signal. 2020;13(645):eaaz5267. https://doi.org/10.1126/scisignal.aaz5265

38. Crescenzi E, Palumbo G, Brady HJM. Bcl-2 activates a programme of premature senescence in human carcinoma cells. Biochem J. 2003 Oct;375(2):263-74. https://doi.org/10.1038/s41467-01909853-z

39. Yosef R, Pilpel N, Tokarsky-Amiel R, Biran A, Ovadya Y, Cohen S, et al. Directed elimination of senescent cells by inhibition of BCL-W and BCL-XL. Nat Commun. 2016;7:11190. 
https://doi.org/10.1038/ncomms11190

40. Freund A, Patil CK, Campisi J. P38MAPK is a novel DNA damage response-independent regulator of the senescence-associated secretory phenotype. EMBO J. 2011;30(8):1536-48. https://doi.org/10.1038/emboj.2011.69

41. Wilting RH, Dannenberg JH. Epigenetic mechanisms in tumorigenesis, tumor cell heterogeneity and drug resistance. Drug Resist Updat. 2012;15(1-2):21-38. https://doi.org/10.1016/j.drup.2012.01.008

42. Kase J, Dorr J, Yu Y, Milanovic M, Ji S, Spiesicke-Wegner S, et al. H3K9me3-Governed Senescence In Tumor Development and Lymphoma Treatment. Blood. 2013;122(21):345. https://doi.org/10.1182/blood.V122.21.345.345

43. Torrano J, Emran A Al, Hammerlindl H, Schaider H. Emerging roles of H3K9me3, SETDB1 and SETDB2 in therapy-induced cellular reprogramming. Clin Epigenetics. 2019;11(1):43. https://doi.org/10.1186/s13148-019-0644-y

44. Beausejour CM, Krtolica A, Galimi F, Narina M, Lowe, S W, Yaswen P, et al. Reversal of human cellular senescence: roles of the $p 53$ and p16 pathways. EMBO J. 2003;22(16):4212-22. https://doi.org/10.1093/emboj/cdg417

45. Yang L, Fang J, Chen J. Tumor cell senescence response produces aggressive variants. Cell Death Discov. 2017;3(1):17049. https://doi.org/10.1038/cddiscovery.2017.49

46. Zhang Z, Aung KM, Uhlin BE, Wai SN. Reversible senescence of human colon cancer cells after blockage of mitosis/cytokinesis caused by the CNF1 cyclomodulin from Escherichia coli. Sci Rep. 2018 Dec;8(1):17780. https://doi.org/10.1038/s41598-018-36036-5

47. Milanovic M, Fan DNY, Belenki D, Däbritz JHM, Zhao Z, Yu Y, et al. Senescence-associated reprogramming promotes cancer stemness. Nature. 2018;553(7686):96-100. https://doi.org/10.1038/nature25167

48. Lee S, Schmitt CA. The dynamic nature of senescence in cancer. Nature Cell Biology. 2019. 21(1):94101. https://doi.org/10.1038/s41556-018-0249-2

49. Zhou JX, Pisco AO, Qian H, Huang S. Nonequilibrium population dynamics of phenotype conversion of cancer cells. PLoS One. 2014;9(12).e110714. https://doi.org/10.1371/journal.pone.0110714

50. Frose J, Chen MB, Hebron KE, Reinhardt F, Hajal C, Zijlstra A, et al. Epithelial-Mesenchimal Transition induces podocalyxinto promote extravasation via Ezrin Signaling. Cell Rep. 2018;24(4):962-72. https://doi.org/10.1016/j.celrep.2018.06.092

51. Correa CR, Bertollo CM, Goes AM. Establishment and Characterization of MACL-1 and MGSO-3 Cell Lines Derived From Human Primary Breast Cancer. Oncol Res Featur Preclin Clin Cancer Ther. 2009;17(10):473-82 https://doi.org/10.3727/096504009789735404

\section{Figures}


a

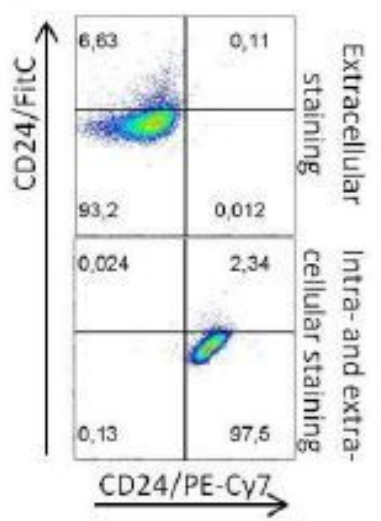

C

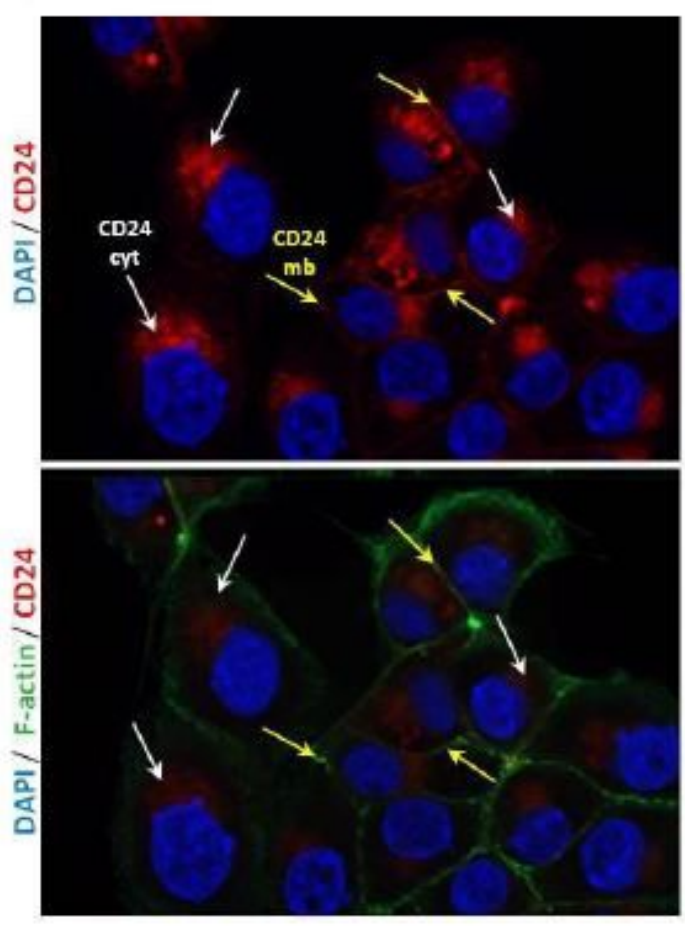

h
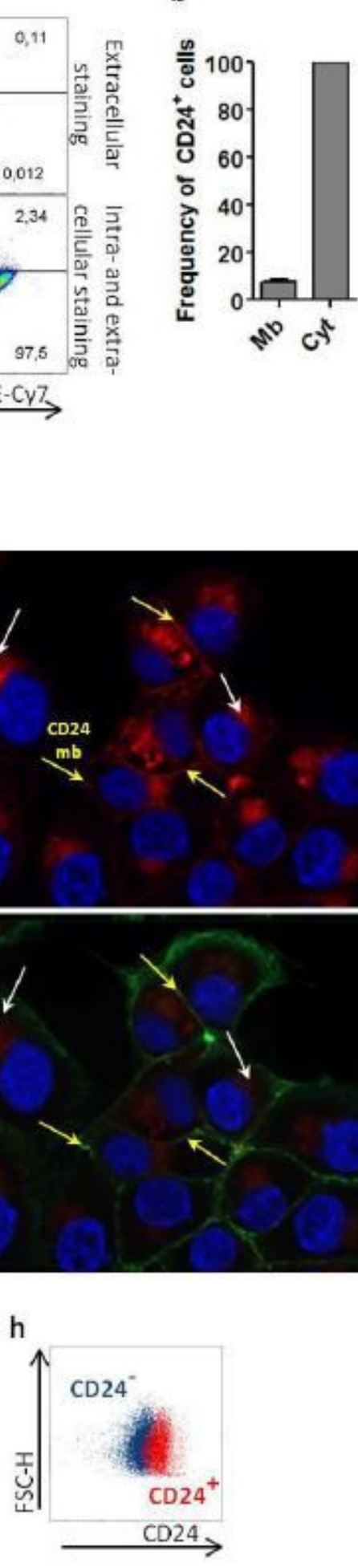

d

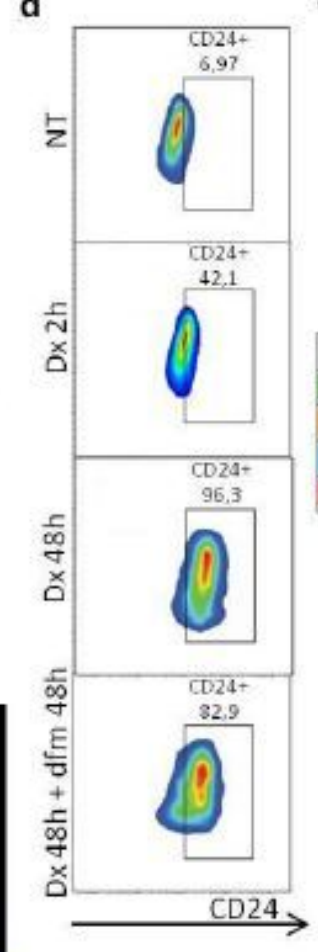

g

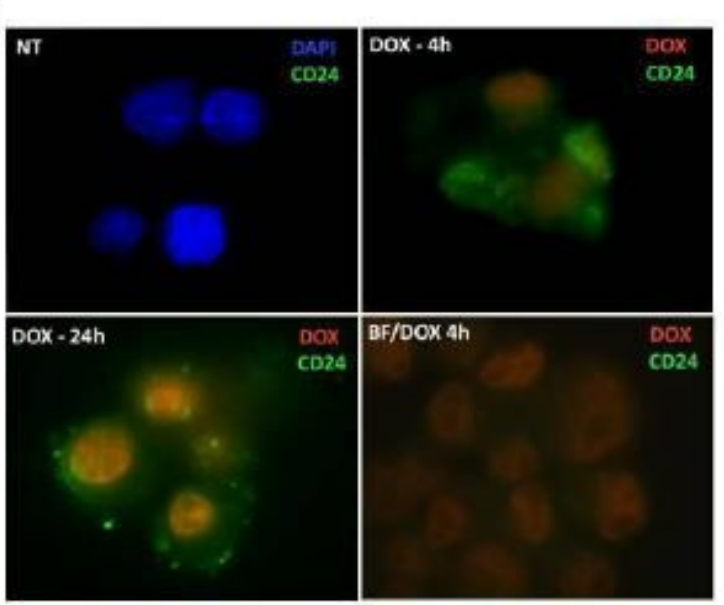

i

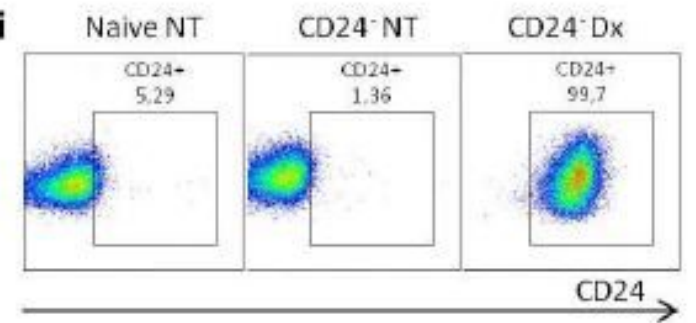

\section{Figure 1}

Translocation of CD24 from cytosol to cell membrane is an early event in MDA-MB-231 cells under drug stress. (a) Evaluation of the localization of CD24 in MDA-MB-231 cell line. MDA-MB-231 cells were stained with anti-CD24/FITC (extracellular staining). Then cells were fixed, permeabilized and stained with anti-CD24/PE-Cy7 (intracellular staining). Pseudocolor plots are representative of triplicates. (b) Frequency of CD24+ cells according to the detection of CD24 in membrane (mb) or in cytosol (cyt). The 
results are representative of four independent experiments (means +/- SD of triplicates). (c) Visualization of CD24 localization by fluorescence microscopy. MDA-MB-231 cells were fixed, permeabilized and then stained using anti-CD24/PE-Cy7, anti-F-actin/Alexa488 and the nuclear dye DAPI. The yellow arrows indicate the membrane CD24 and the white arrows point to the cytosolic CD24. (d) CD24+ cell enrichment in MDA-MB-231 population during doxorubicin (Dx) treatment. MDA-MB-231 cells were treated with Dx $(0.6 \rrbracket \mathrm{M})$ according to the indicated times followed or not by a drug-free medium (dfm) incubation. Then, an extracellular staining was performed using anti-CD24/FITC. The pseudocolor plots are representative of four independent experiments. (e) Histograms represent the shift of CD24 on x axis under different treatments. Table shows the MFI (median fluorescence intensity) values of surface CD24 expression calculated from figure $b$ pseudocolor plots. Graph represents the means of triplicates obtained from the MFI calculation. (f) Reduction of CD24 translocation by brefeldin A in Dx-treated cells. MDA-MB-231 cells were treated with $D x(0.6 \square \mathrm{M})$ and/or with brefeldin $A(1 \mathrm{~g} / \mathrm{ml})$ for $4 \mathrm{~h}$. When associated, brefeldin A was added 30 min before Dx. Then, an extracellular staining was performed using anti-CD24/PE-Cy7. The pseudocolor plots are representative of two independent experiments. (g) Effect of brefeldin A on CD24 localization in doxorubicin-treated cells visualized by fluorescence microscopy. MDA-MB-231 cells were treated with doxorubicin $(0.6 \square \mathrm{M})$ and/or with brefeldin $A(1 \square \mathrm{g} / \mathrm{ml})$ by different times. Then, cells were stained using anti-CD24/Alexa488 and DAPI without fixation and permeabilization. DAPI was not used in the doxorubicin-treated groups. (h) Representative merged pseudoclor plots of CD24+ (red) and CD24(blue) subpopulations obtained from parental MDA-MB-231 cells after magnetic sorting. (i) Translocation of CD24 in CD24- cells during doxorubicin treatment. CD24- cells were treated with $\mathrm{Dx}(0.6 \square \mathrm{M})$ for $4 \mathrm{~h}$. Then cells were stained (extracellular staining) with anti-CD24/Pe-Cy7 antibody to evaluate the expression of surface CD24. The pseudocolor plots are representative of triplicates. 
a

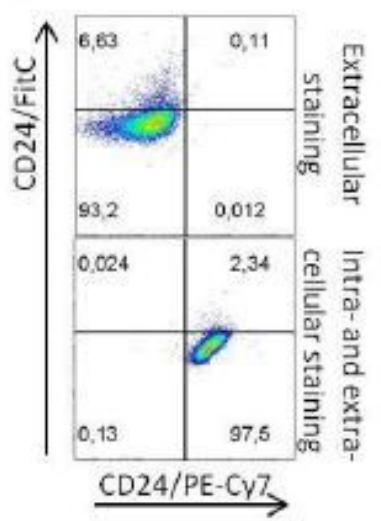

C

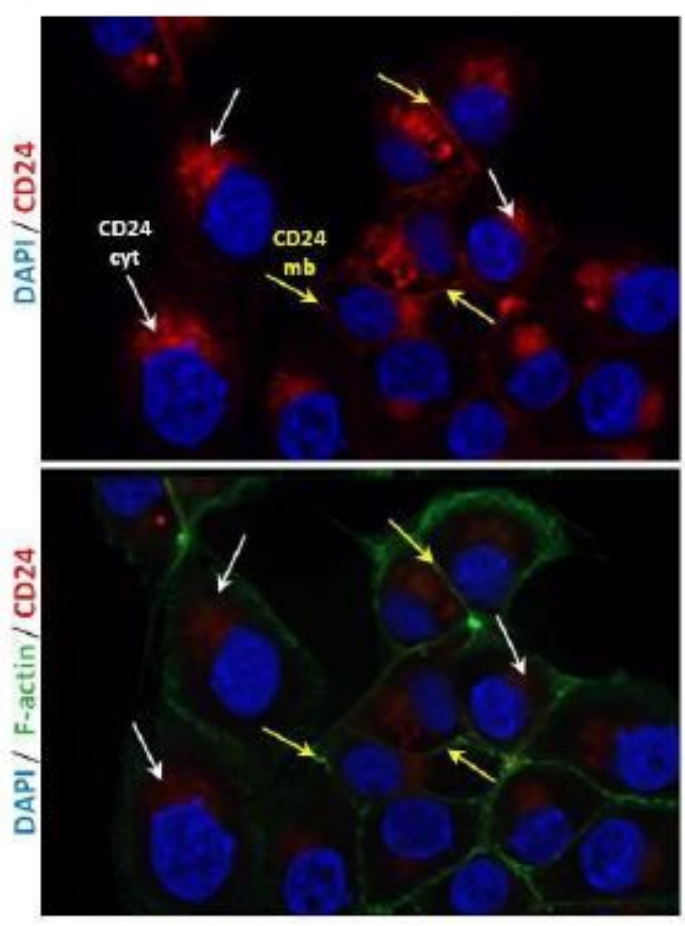

h
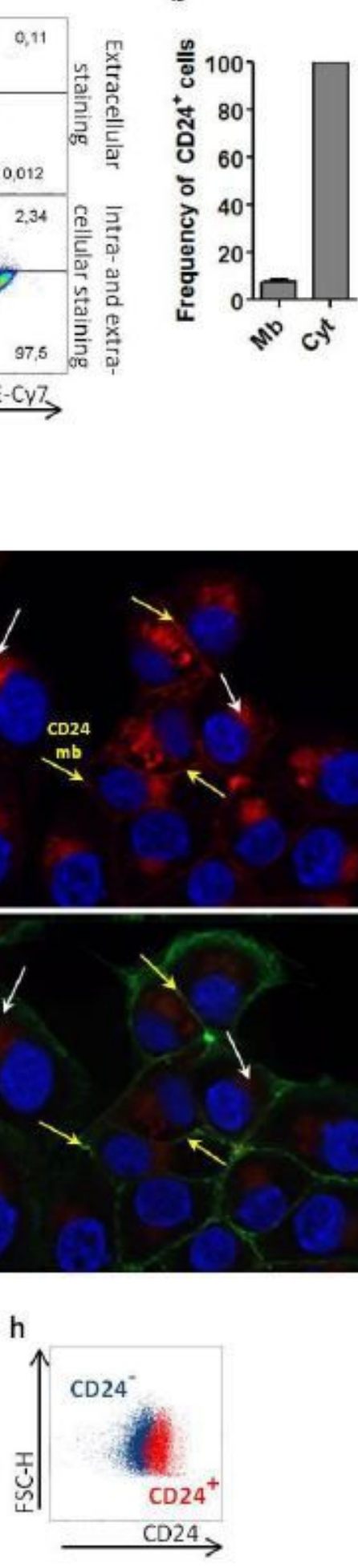

d

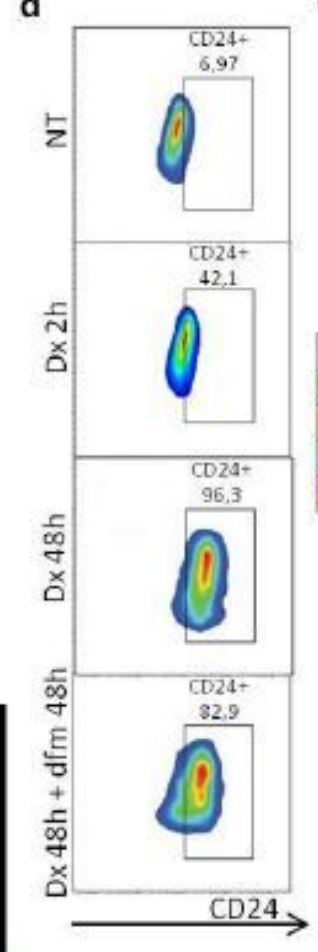

g

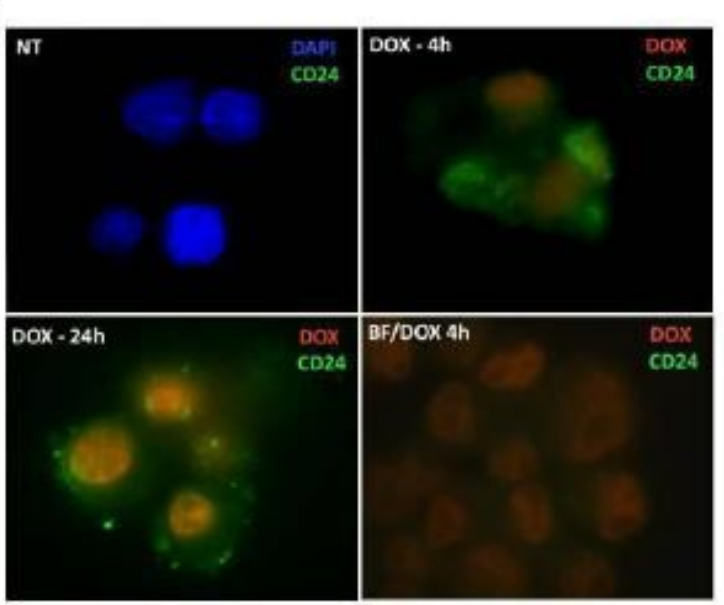

i

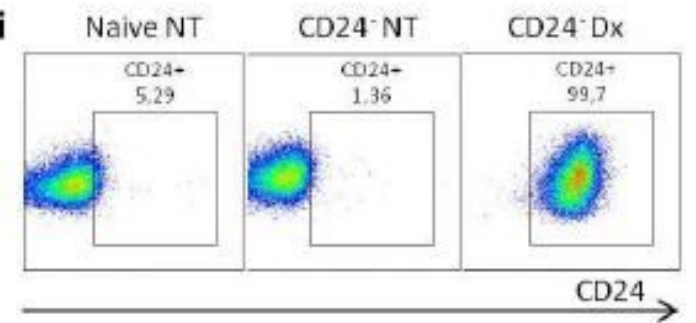

\section{Figure 1}

Translocation of CD24 from cytosol to cell membrane is an early event in MDA-MB-231 cells under drug stress. (a) Evaluation of the localization of CD24 in MDA-MB-231 cell line. MDA-MB-231 cells were stained with anti-CD24/FITC (extracellular staining). Then cells were fixed, permeabilized and stained with anti-CD24/PE-Cy7 (intracellular staining). Pseudocolor plots are representative of triplicates. (b) Frequency of CD24+ cells according to the detection of CD24 in membrane (mb) or in cytosol (cyt). The 
results are representative of four independent experiments (means +/- SD of triplicates). (c) Visualization of CD24 localization by fluorescence microscopy. MDA-MB-231 cells were fixed, permeabilized and then stained using anti-CD24/PE-Cy7, anti-F-actin/Alexa488 and the nuclear dye DAPI. The yellow arrows indicate the membrane CD24 and the white arrows point to the cytosolic CD24. (d) CD24+ cell enrichment in MDA-MB-231 population during doxorubicin (Dx) treatment. MDA-MB-231 cells were treated with Dx $(0.6 \rrbracket \mathrm{M})$ according to the indicated times followed or not by a drug-free medium (dfm) incubation. Then, an extracellular staining was performed using anti-CD24/FITC. The pseudocolor plots are representative of four independent experiments. (e) Histograms represent the shift of CD24 on x axis under different treatments. Table shows the MFI (median fluorescence intensity) values of surface CD24 expression calculated from figure $b$ pseudocolor plots. Graph represents the means of triplicates obtained from the MFI calculation. (f) Reduction of CD24 translocation by brefeldin A in Dx-treated cells. MDA-MB-231 cells were treated with $D x(0.6 \square \mathrm{M})$ and/or with brefeldin $A(1 \mathrm{~g} / \mathrm{ml})$ for $4 \mathrm{~h}$. When associated, brefeldin A was added 30 min before Dx. Then, an extracellular staining was performed using anti-CD24/PE-Cy7. The pseudocolor plots are representative of two independent experiments. (g) Effect of brefeldin A on CD24 localization in doxorubicin-treated cells visualized by fluorescence microscopy. MDA-MB-231 cells were treated with doxorubicin $(0.6 \square \mathrm{M})$ and/or with brefeldin $A(1 \square \mathrm{g} / \mathrm{ml})$ by different times. Then, cells were stained using anti-CD24/Alexa488 and DAPI without fixation and permeabilization. DAPI was not used in the doxorubicin-treated groups. (h) Representative merged pseudoclor plots of CD24+ (red) and CD24(blue) subpopulations obtained from parental MDA-MB-231 cells after magnetic sorting. (i) Translocation of CD24 in CD24- cells during doxorubicin treatment. CD24- cells were treated with $\mathrm{Dx}(0.6 \square \mathrm{M})$ for $4 \mathrm{~h}$. Then cells were stained (extracellular staining) with anti-CD24/Pe-Cy7 antibody to evaluate the expression of surface CD24. The pseudocolor plots are representative of triplicates. 
a

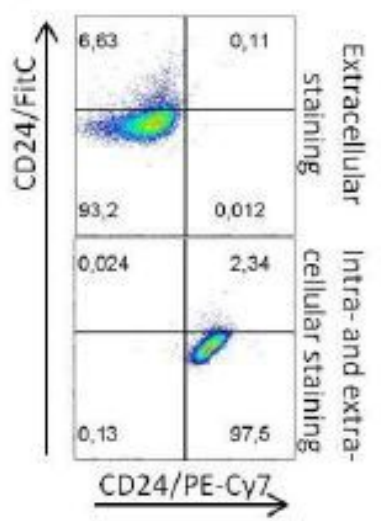

C

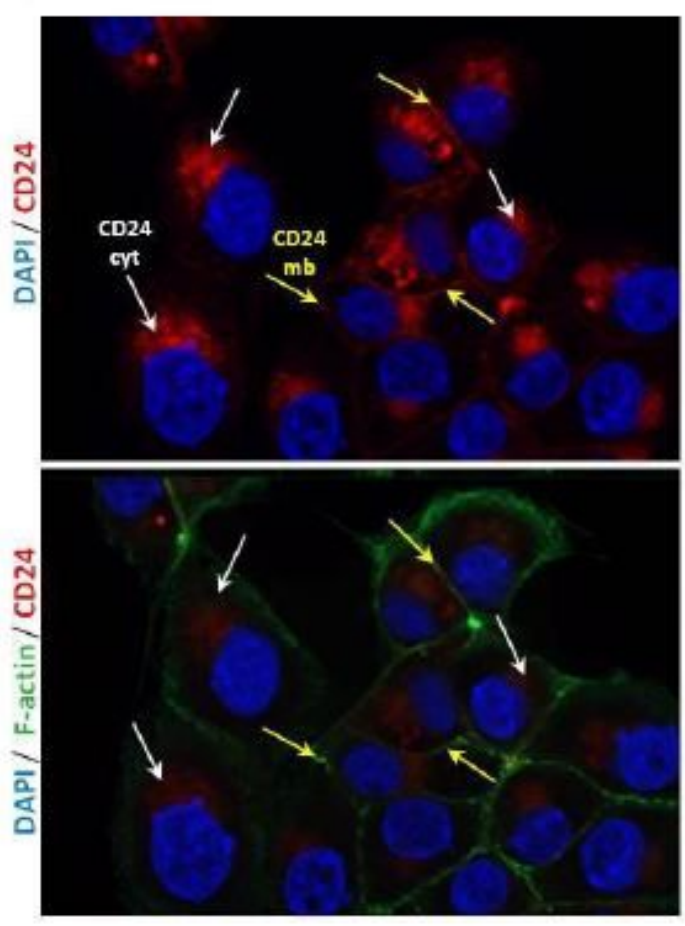

h
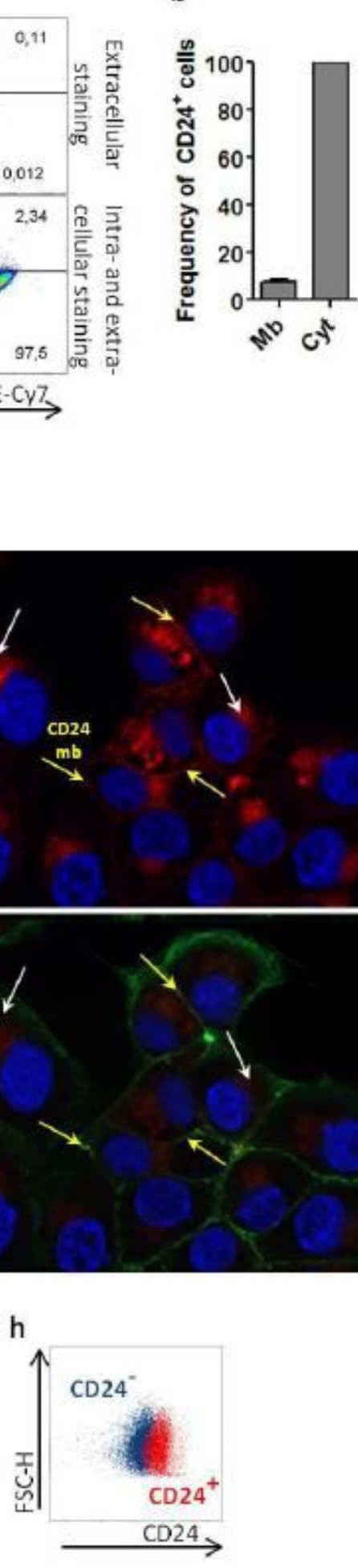

d

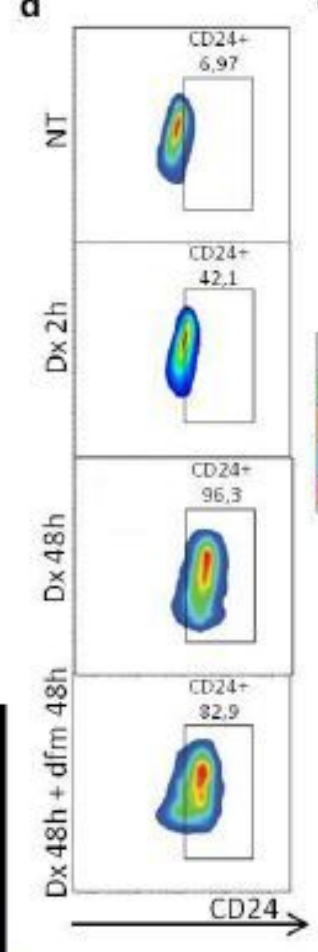

g

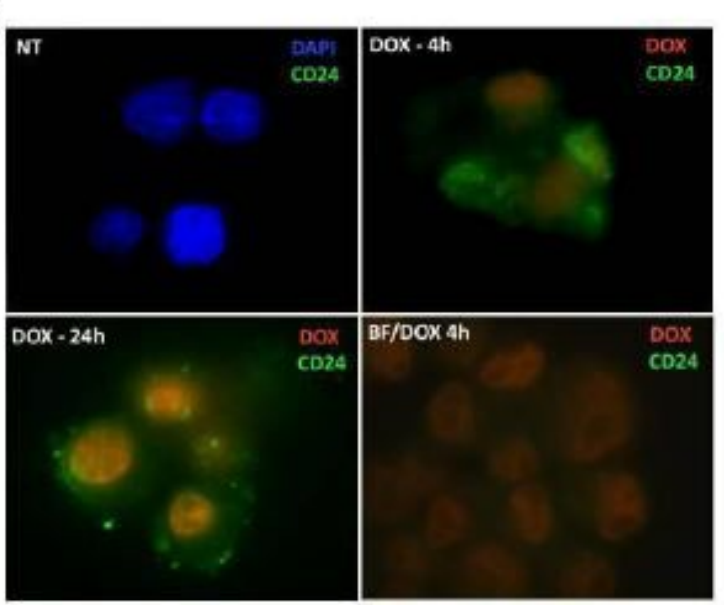

i

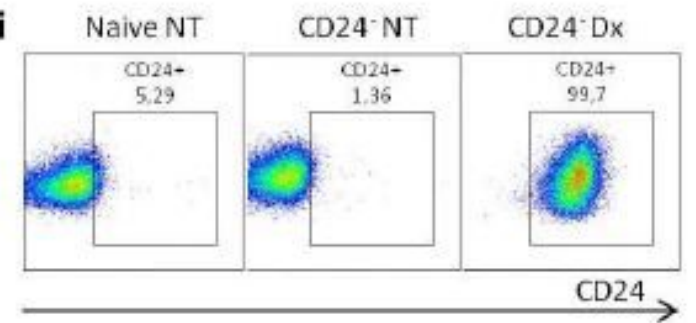

\section{Figure 1}

Translocation of CD24 from cytosol to cell membrane is an early event in MDA-MB-231 cells under drug stress. (a) Evaluation of the localization of CD24 in MDA-MB-231 cell line. MDA-MB-231 cells were stained with anti-CD24/FITC (extracellular staining). Then cells were fixed, permeabilized and stained with anti-CD24/PE-Cy7 (intracellular staining). Pseudocolor plots are representative of triplicates. (b) Frequency of CD24+ cells according to the detection of CD24 in membrane (mb) or in cytosol (cyt). The 
results are representative of four independent experiments (means +/- SD of triplicates). (c) Visualization of CD24 localization by fluorescence microscopy. MDA-MB-231 cells were fixed, permeabilized and then stained using anti-CD24/PE-Cy7, anti-F-actin/Alexa488 and the nuclear dye DAPI. The yellow arrows indicate the membrane CD24 and the white arrows point to the cytosolic CD24. (d) CD24+ cell enrichment in MDA-MB-231 population during doxorubicin (Dx) treatment. MDA-MB-231 cells were treated with Dx $(0.6 \rrbracket \mathrm{M})$ according to the indicated times followed or not by a drug-free medium (dfm) incubation. Then, an extracellular staining was performed using anti-CD24/FITC. The pseudocolor plots are representative of four independent experiments. (e) Histograms represent the shift of CD24 on x axis under different treatments. Table shows the MFI (median fluorescence intensity) values of surface CD24 expression calculated from figure $b$ pseudocolor plots. Graph represents the means of triplicates obtained from the MFI calculation. (f) Reduction of CD24 translocation by brefeldin A in Dx-treated cells. MDA-MB-231 cells were treated with $D x(0.6 \square \mathrm{M})$ and/or with brefeldin $A(1 \mathrm{~g} / \mathrm{ml})$ for $4 \mathrm{~h}$. When associated, brefeldin A was added 30 min before Dx. Then, an extracellular staining was performed using anti-CD24/PE-Cy7. The pseudocolor plots are representative of two independent experiments. (g) Effect of brefeldin A on CD24 localization in doxorubicin-treated cells visualized by fluorescence microscopy. MDA-MB-231 cells were treated with doxorubicin $(0.6 \square \mathrm{M})$ and/or with brefeldin $A(1 \square \mathrm{g} / \mathrm{ml})$ by different times. Then, cells were stained using anti-CD24/Alexa488 and DAPI without fixation and permeabilization. DAPI was not used in the doxorubicin-treated groups. (h) Representative merged pseudoclor plots of CD24+ (red) and CD24(blue) subpopulations obtained from parental MDA-MB-231 cells after magnetic sorting. (i) Translocation of CD24 in CD24- cells during doxorubicin treatment. CD24- cells were treated with $\mathrm{Dx}(0.6 \square \mathrm{M})$ for $4 \mathrm{~h}$. Then cells were stained (extracellular staining) with anti-CD24/Pe-Cy7 antibody to evaluate the expression of surface CD24. The pseudocolor plots are representative of triplicates. 
a

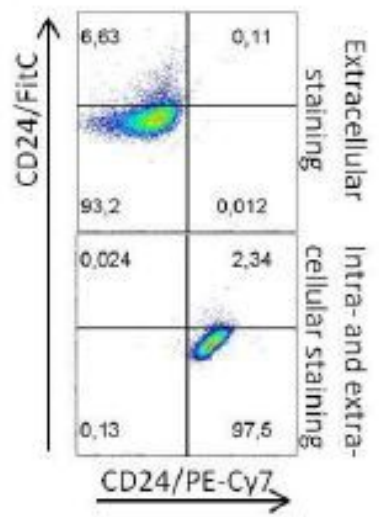

c

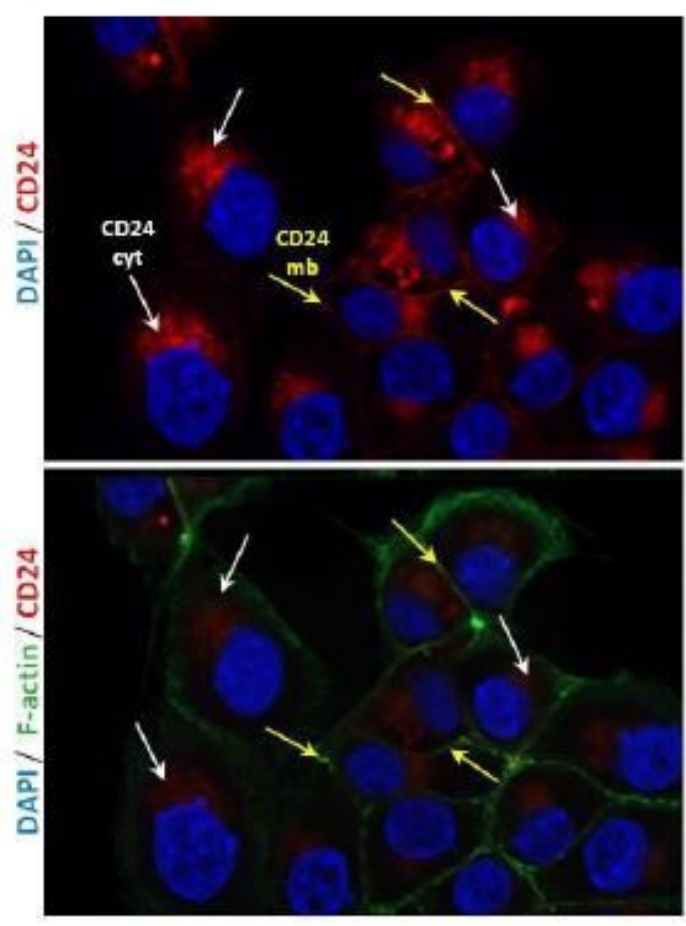

h

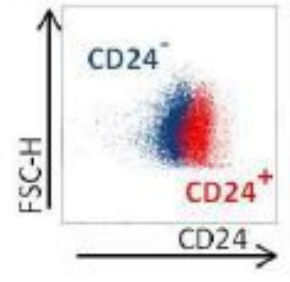

d
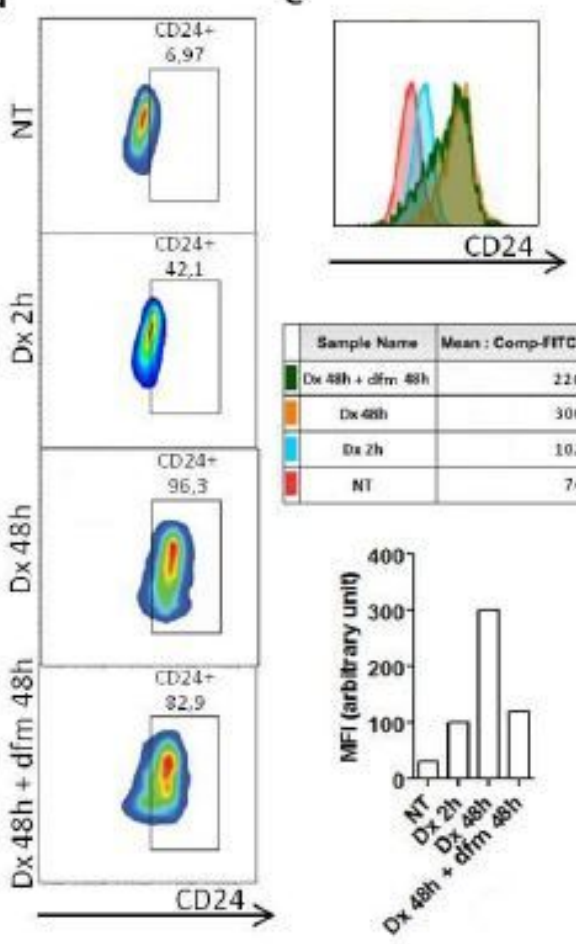

Sample Narre Nean : Comp-rite-A

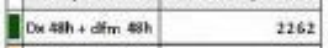

\begin{tabular}{|c|c|}
\hline Dxenth & 3000 \\
\hline Don $2 \mathrm{~h}$ & 1027 \\
\hline NT & 742 \\
\hline
\end{tabular}

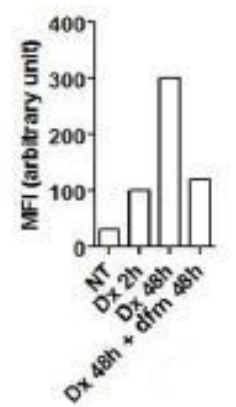

f

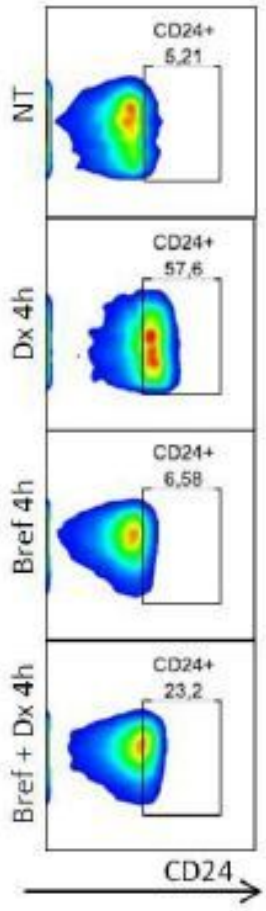

g

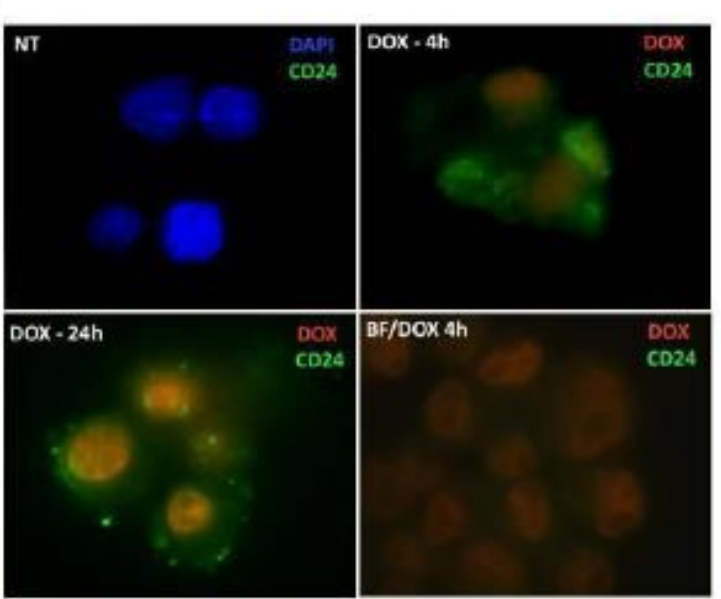

i

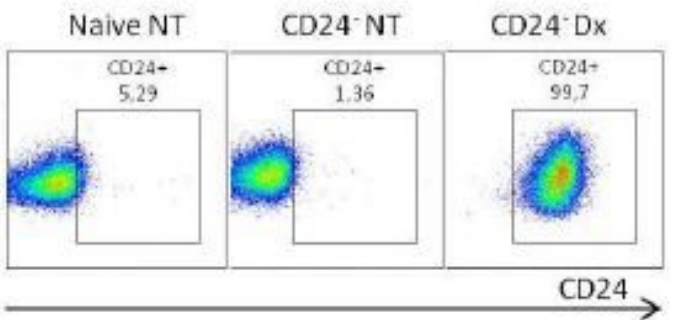

\section{Figure 1}

Translocation of CD24 from cytosol to cell membrane is an early event in MDA-MB-231 cells under drug stress. (a) Evaluation of the localization of CD24 in MDA-MB-231 cell line. MDA-MB-231 cells were stained with anti-CD24/FITC (extracellular staining). Then cells were fixed, permeabilized and stained with anti-CD24/PE-Cy7 (intracellular staining). Pseudocolor plots are representative of triplicates. (b) Frequency of CD24+ cells according to the detection of CD24 in membrane (mb) or in cytosol (cyt). The 
results are representative of four independent experiments (means +/- SD of triplicates). (c) Visualization of CD24 localization by fluorescence microscopy. MDA-MB-231 cells were fixed, permeabilized and then stained using anti-CD24/PE-Cy7, anti-F-actin/Alexa488 and the nuclear dye DAPI. The yellow arrows indicate the membrane CD24 and the white arrows point to the cytosolic CD24. (d) CD24+ cell enrichment in MDA-MB-231 population during doxorubicin (Dx) treatment. MDA-MB-231 cells were treated with Dx $(0.6 \rrbracket \mathrm{M})$ according to the indicated times followed or not by a drug-free medium (dfm) incubation. Then, an extracellular staining was performed using anti-CD24/FITC. The pseudocolor plots are representative of four independent experiments. (e) Histograms represent the shift of CD24 on x axis under different treatments. Table shows the MFI (median fluorescence intensity) values of surface CD24 expression calculated from figure $b$ pseudocolor plots. Graph represents the means of triplicates obtained from the MFI calculation. (f) Reduction of CD24 translocation by brefeldin A in Dx-treated cells. MDA-MB-231 cells were treated with $D x(0.6 \square \mathrm{M})$ and/or with brefeldin $A(1 \mathrm{~g} / \mathrm{ml})$ for $4 \mathrm{~h}$. When associated, brefeldin A was added 30 min before Dx. Then, an extracellular staining was performed using anti-CD24/PE-Cy7. The pseudocolor plots are representative of two independent experiments. (g) Effect of brefeldin A on CD24 localization in doxorubicin-treated cells visualized by fluorescence microscopy. MDA-MB-231 cells were treated with doxorubicin $(0.6 \square \mathrm{M})$ and/or with brefeldin $A(1 \square \mathrm{g} / \mathrm{ml})$ by different times. Then, cells were stained using anti-CD24/Alexa488 and DAPI without fixation and permeabilization. DAPI was not used in the doxorubicin-treated groups. (h) Representative merged pseudoclor plots of CD24+ (red) and CD24(blue) subpopulations obtained from parental MDA-MB-231 cells after magnetic sorting. (i) Translocation of CD24 in CD24- cells during doxorubicin treatment. CD24- cells were treated with $\mathrm{Dx}(0.6 \square \mathrm{M})$ for $4 \mathrm{~h}$. Then cells were stained (extracellular staining) with anti-CD24/Pe-Cy7 antibody to evaluate the expression of surface CD24. The pseudocolor plots are representative of triplicates. 


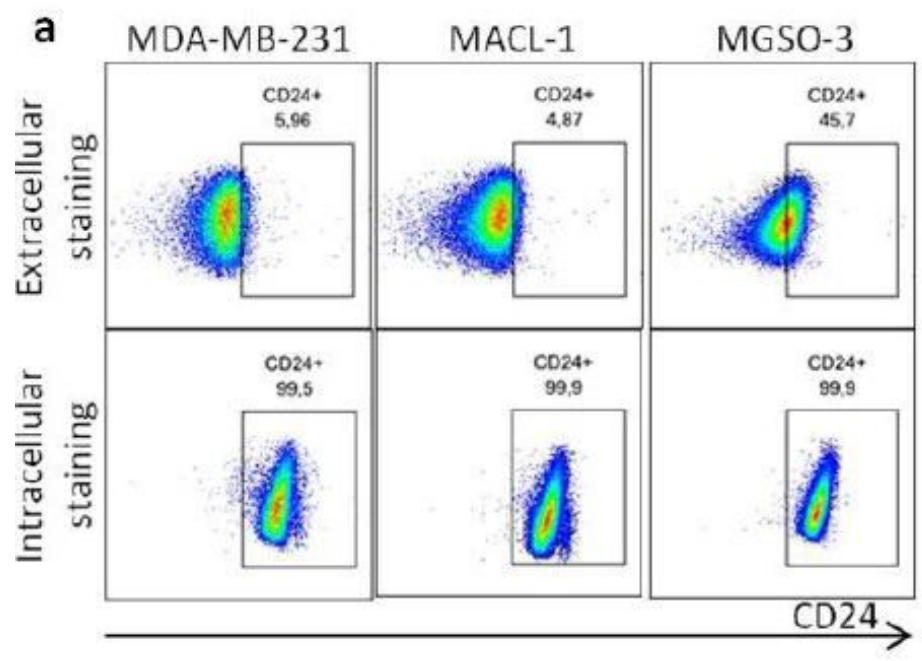

b

c

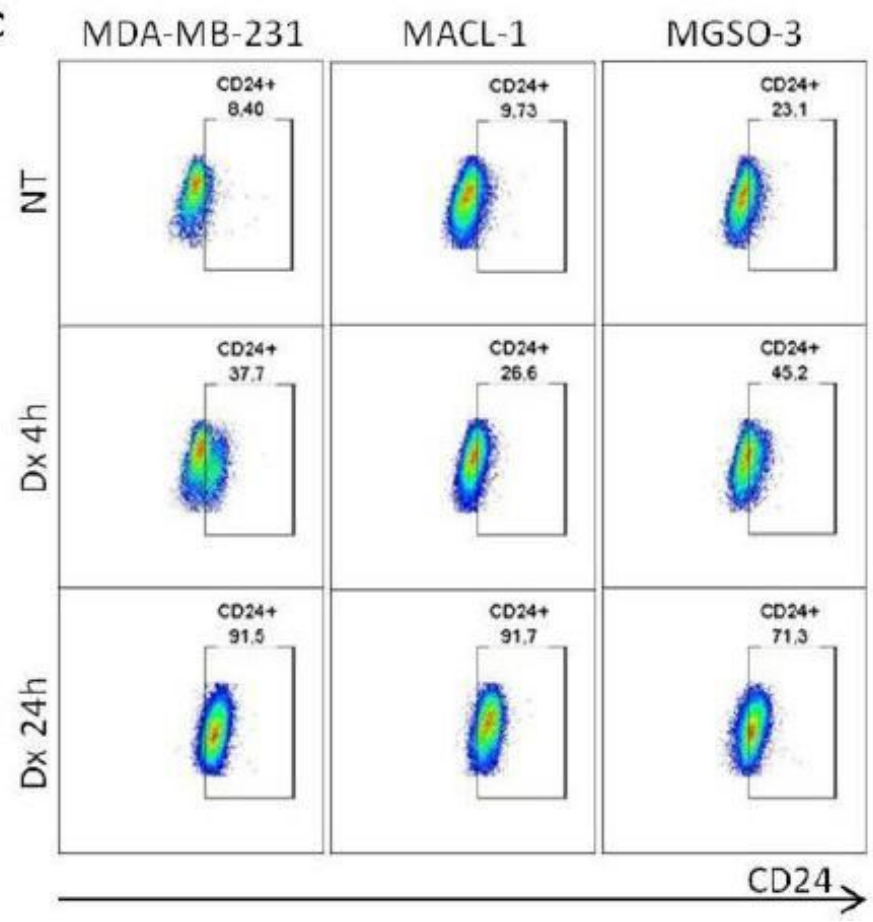

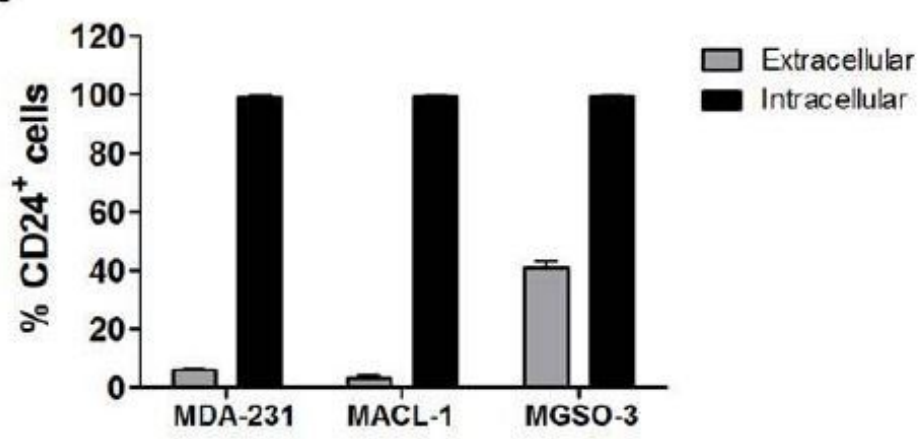

d

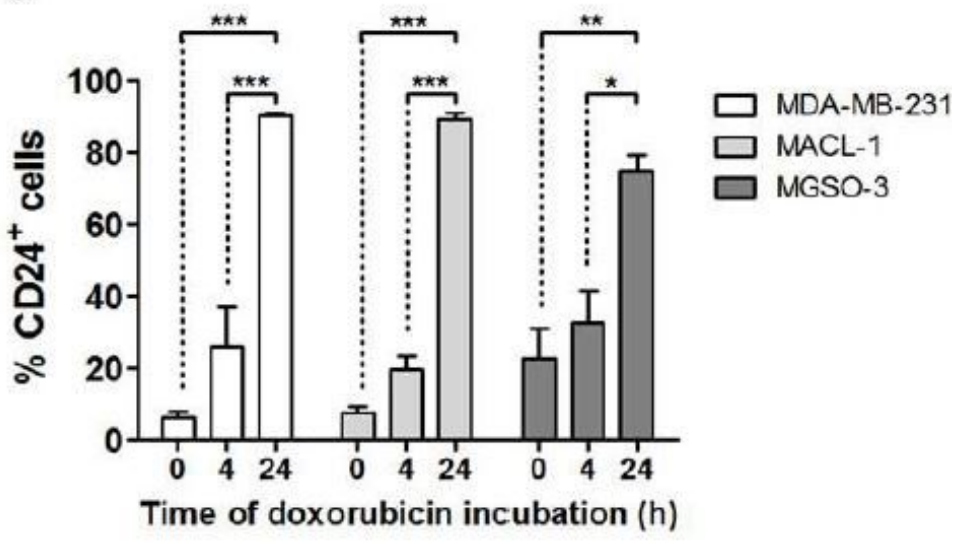

Figure 2

Translocation of CD24 from cytosol to membrane is observed in patient-derived breast cancer cells under drug stress. (a) Detection of CD24 in membrane and cytosol of breast cancer cell lines. MDA-MB-231, MACL-1 and MGSO-3 cells were stained with anti-CD24/Pe-Cy7 (extracellular staining). For intracellular staining, cells were permeabilized and stained with anti-CD24/PE-Cy7 (intracellular staining). Dot-plots are representative of triplicates. (b) Frequency of CD24+ cells according to the detection of CD24 in membrane (extracellular) or in cytosol (intracellular). (c) CD24+ cell enrichment in breast cancer cell lines during Dx treatment. MDA-MB-231, MACL-1 and MGSO-3 cells were treated with Dx (0.6ロM) according to the indicated times. Then, an extracellular staining was performed using anti-CD24/FITC. The dot-plots are representative of triplicates. (d) Frequency of CD24+ cells under Dx treatment according to the detection of CD24 in membrane. Data were plotted as means of triplicates $+/-\mathrm{SD}$. ${ }^{\star \star \star} p<0,001, * \star p<0,01$, * $p<0,05$ (One-way ANOVA with bonferroni post-test). 


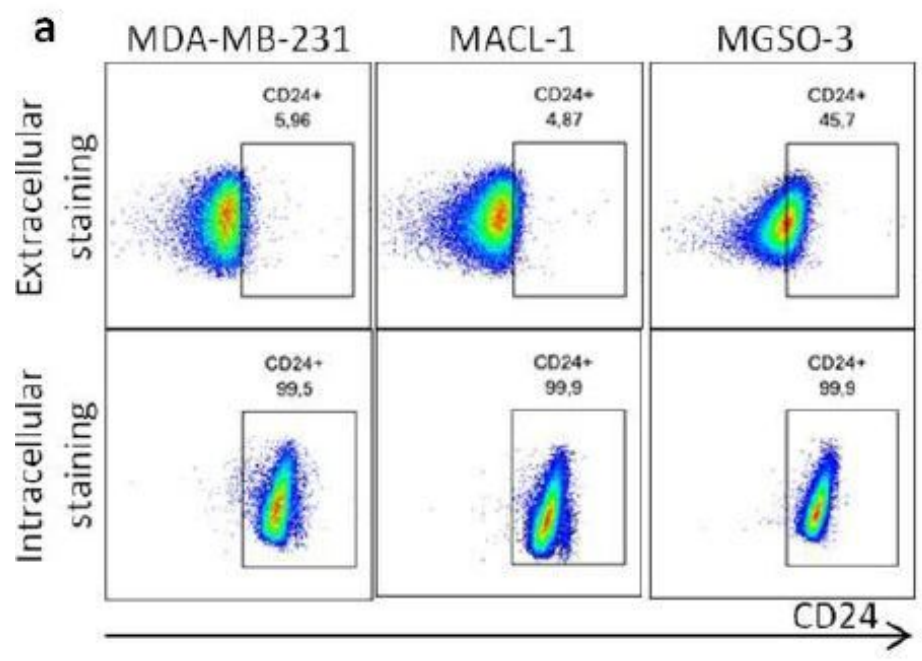

b

c

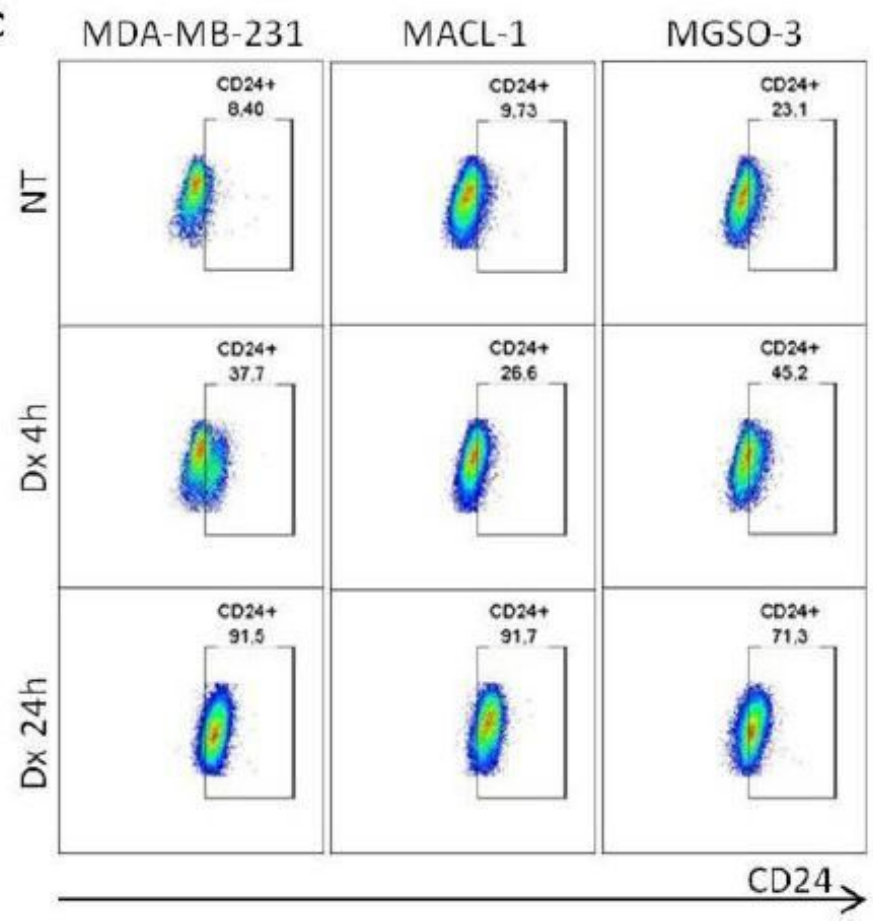

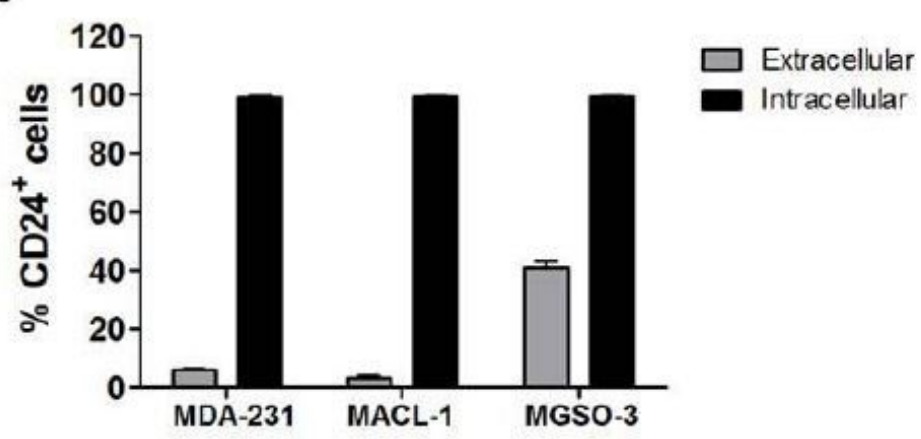

d

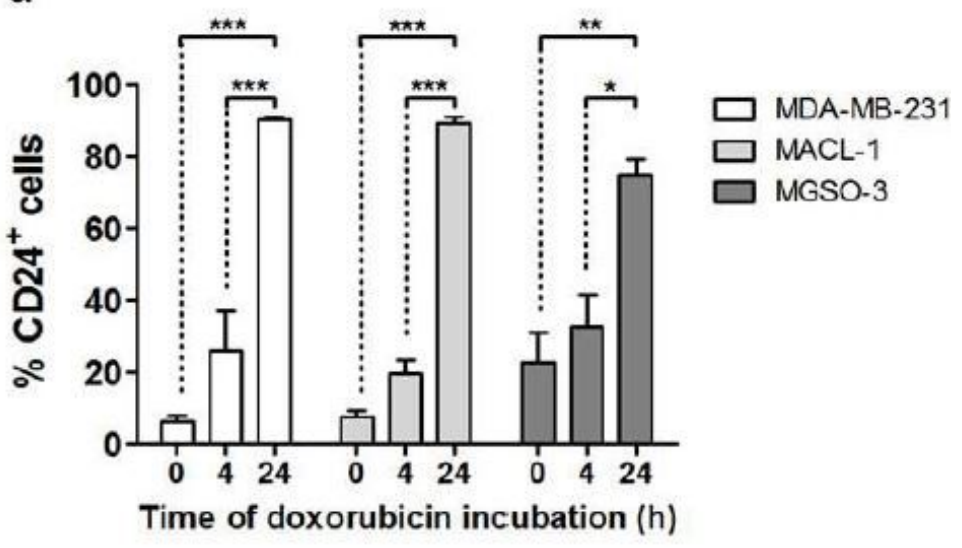

Figure 2

Translocation of CD24 from cytosol to membrane is observed in patient-derived breast cancer cells under drug stress. (a) Detection of CD24 in membrane and cytosol of breast cancer cell lines. MDA-MB-231, MACL-1 and MGSO-3 cells were stained with anti-CD24/Pe-Cy7 (extracellular staining). For intracellular staining, cells were permeabilized and stained with anti-CD24/PE-Cy7 (intracellular staining). Dot-plots are representative of triplicates. (b) Frequency of CD24+ cells according to the detection of CD24 in membrane (extracellular) or in cytosol (intracellular). (c) CD24+ cell enrichment in breast cancer cell lines during Dx treatment. MDA-MB-231, MACL-1 and MGSO-3 cells were treated with Dx (0.6ロM) according to the indicated times. Then, an extracellular staining was performed using anti-CD24/FITC. The dot-plots are representative of triplicates. (d) Frequency of CD24+ cells under Dx treatment according to the detection of CD24 in membrane. Data were plotted as means of triplicates $+/-\mathrm{SD}$. ${ }^{\star \star \star} p<0,001, * \star p<0,01$, * $p<0,05$ (One-way ANOVA with bonferroni post-test). 


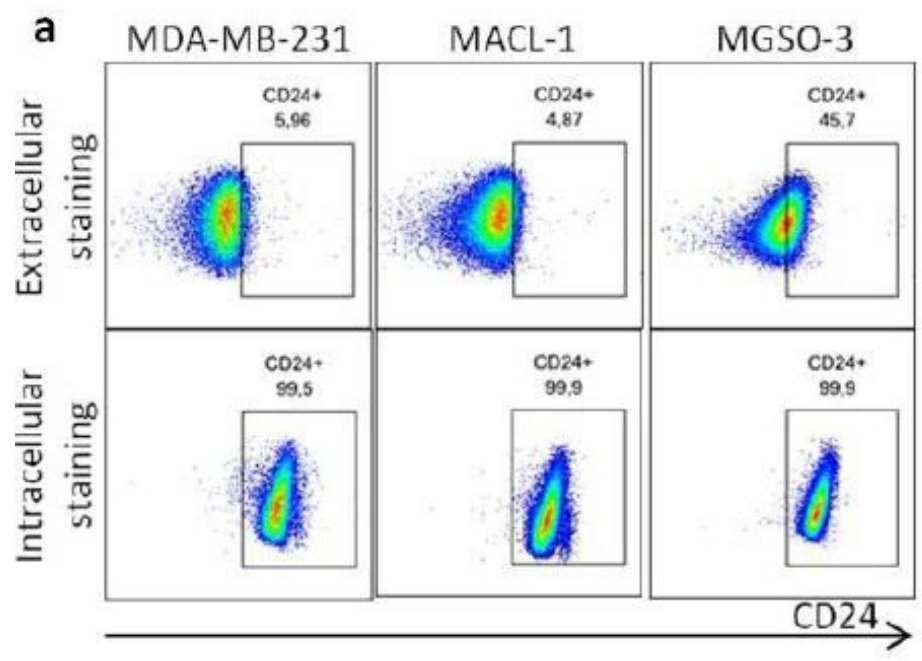

b

c

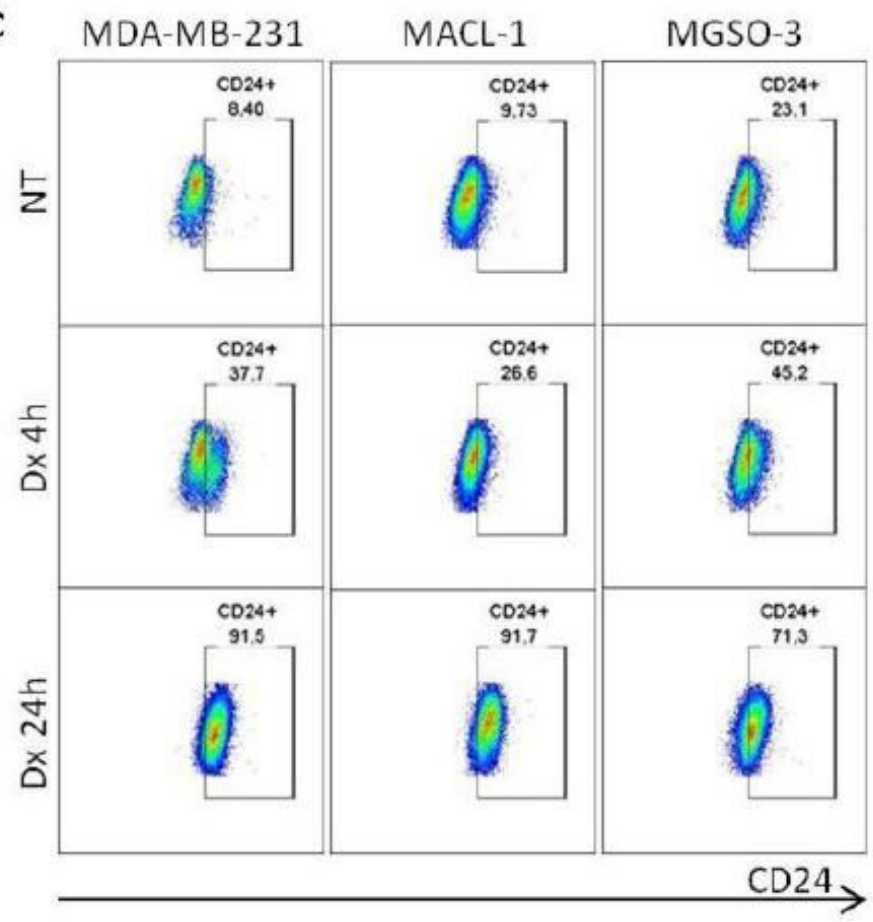

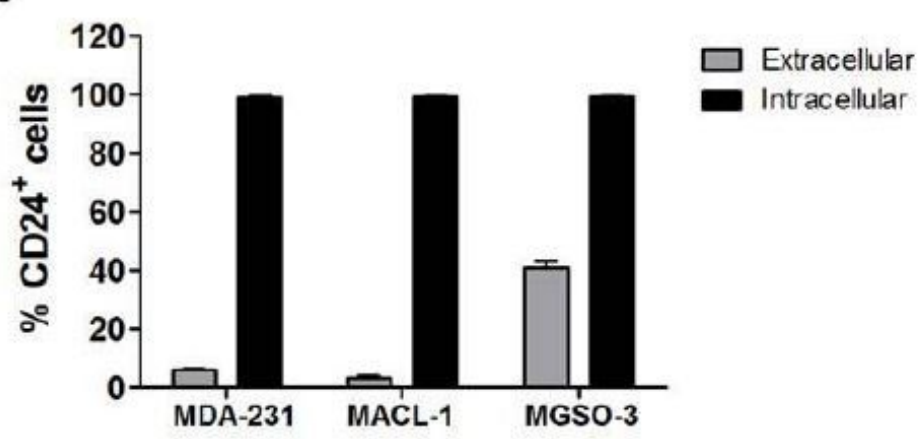

d

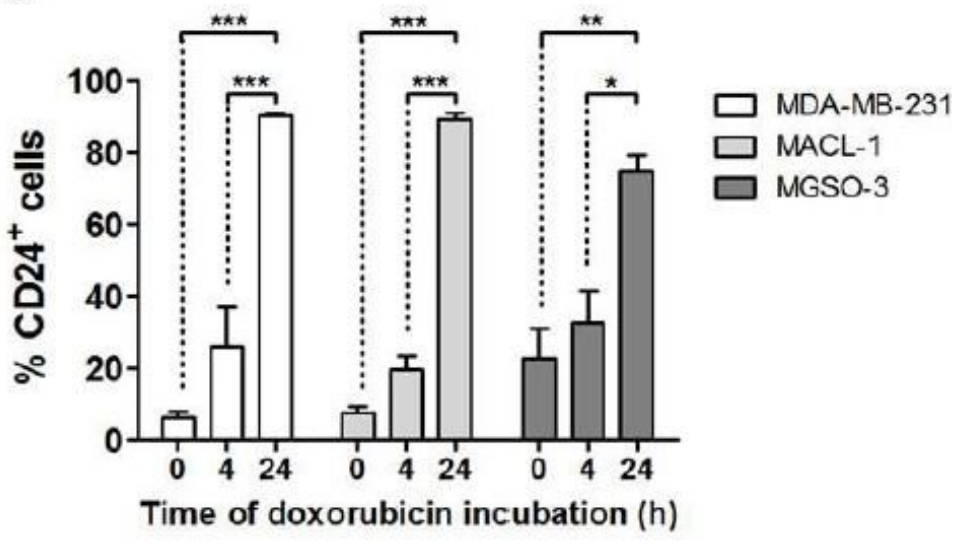

Figure 2

Translocation of CD24 from cytosol to membrane is observed in patient-derived breast cancer cells under drug stress. (a) Detection of CD24 in membrane and cytosol of breast cancer cell lines. MDA-MB-231, MACL-1 and MGSO-3 cells were stained with anti-CD24/Pe-Cy7 (extracellular staining). For intracellular staining, cells were permeabilized and stained with anti-CD24/PE-Cy7 (intracellular staining). Dot-plots are representative of triplicates. (b) Frequency of CD24+ cells according to the detection of CD24 in membrane (extracellular) or in cytosol (intracellular). (c) CD24+ cell enrichment in breast cancer cell lines during Dx treatment. MDA-MB-231, MACL-1 and MGSO-3 cells were treated with Dx (0.6ロM) according to the indicated times. Then, an extracellular staining was performed using anti-CD24/FITC. The dot-plots are representative of triplicates. (d) Frequency of CD24+ cells under Dx treatment according to the detection of CD24 in membrane. Data were plotted as means of triplicates $+/-\mathrm{SD}$. ${ }^{\star \star \star} p<0,001, * \star p<0,01$, * $p<0,05$ (One-way ANOVA with bonferroni post-test). 


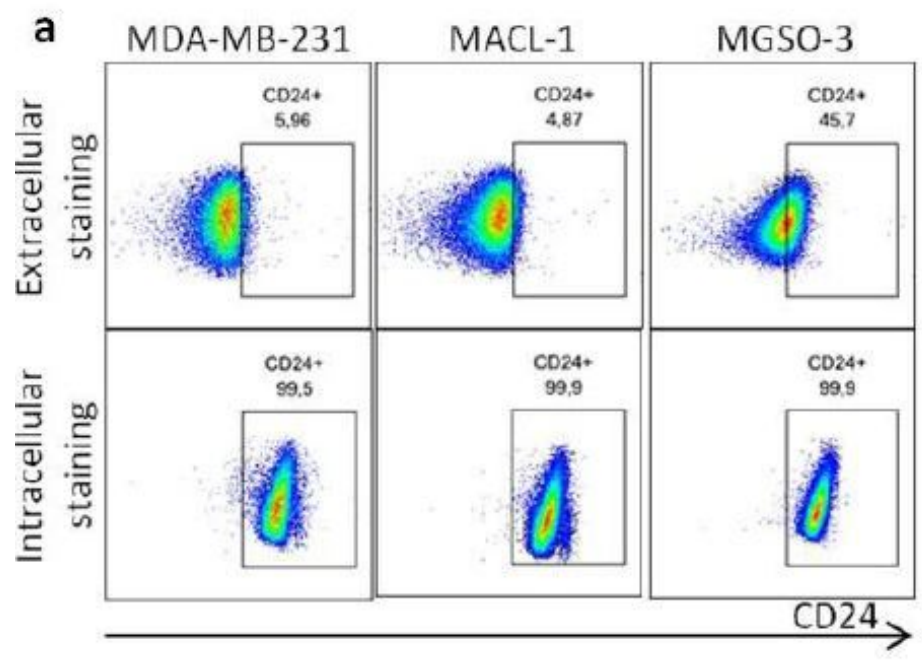

b

c

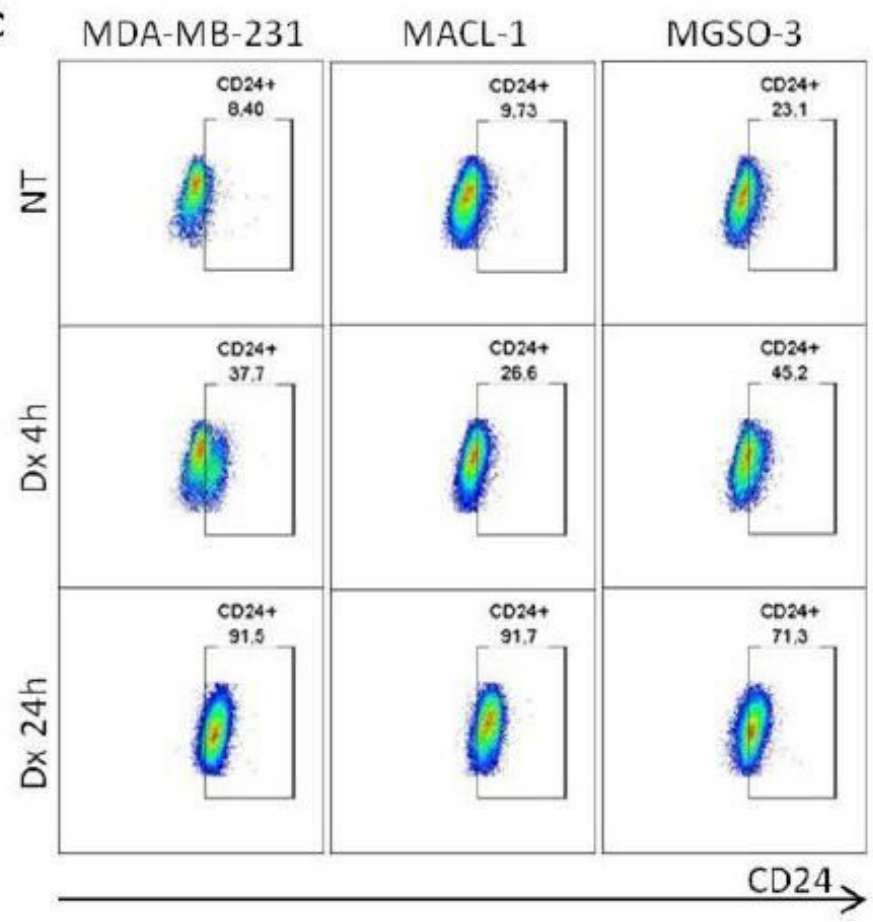

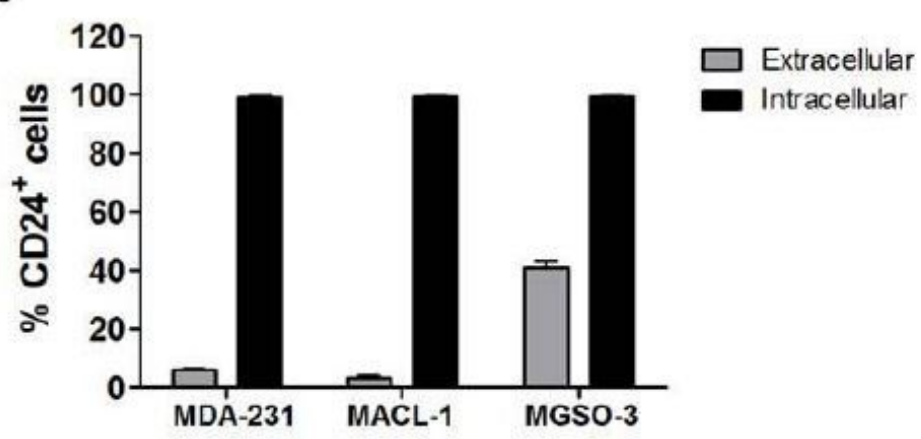

d

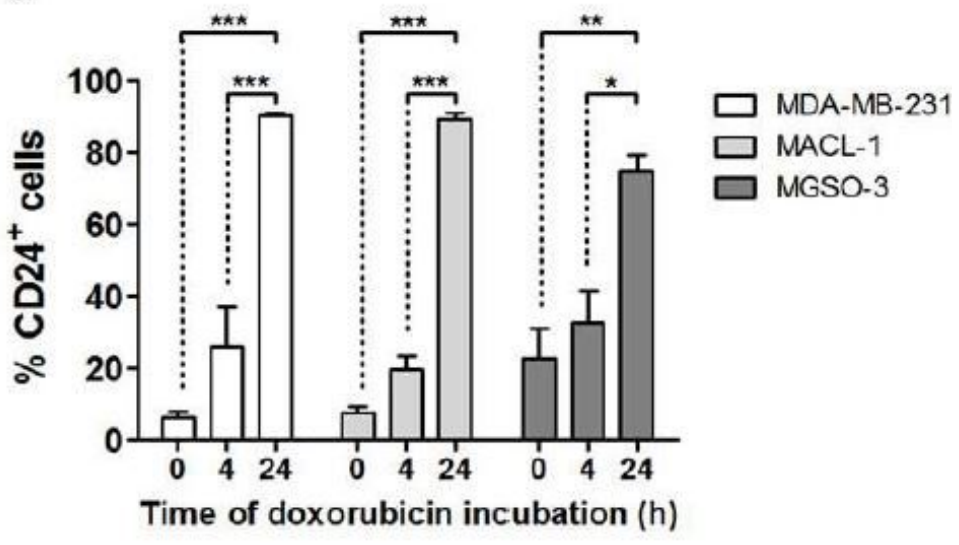

Figure 2

Translocation of CD24 from cytosol to membrane is observed in patient-derived breast cancer cells under drug stress. (a) Detection of CD24 in membrane and cytosol of breast cancer cell lines. MDA-MB-231, MACL-1 and MGSO-3 cells were stained with anti-CD24/Pe-Cy7 (extracellular staining). For intracellular staining, cells were permeabilized and stained with anti-CD24/PE-Cy7 (intracellular staining). Dot-plots are representative of triplicates. (b) Frequency of CD24+ cells according to the detection of CD24 in membrane (extracellular) or in cytosol (intracellular). (c) CD24+ cell enrichment in breast cancer cell lines during Dx treatment. MDA-MB-231, MACL-1 and MGSO-3 cells were treated with Dx (0.6ロM) according to the indicated times. Then, an extracellular staining was performed using anti-CD24/FITC. The dot-plots are representative of triplicates. (d) Frequency of CD24+ cells under Dx treatment according to the detection of CD24 in membrane. Data were plotted as means of triplicates $+/-\mathrm{SD}$. ${ }^{\star \star \star} p<0,001, * \star p<0,01$, * $p<0,05$ (One-way ANOVA with bonferroni post-test). 

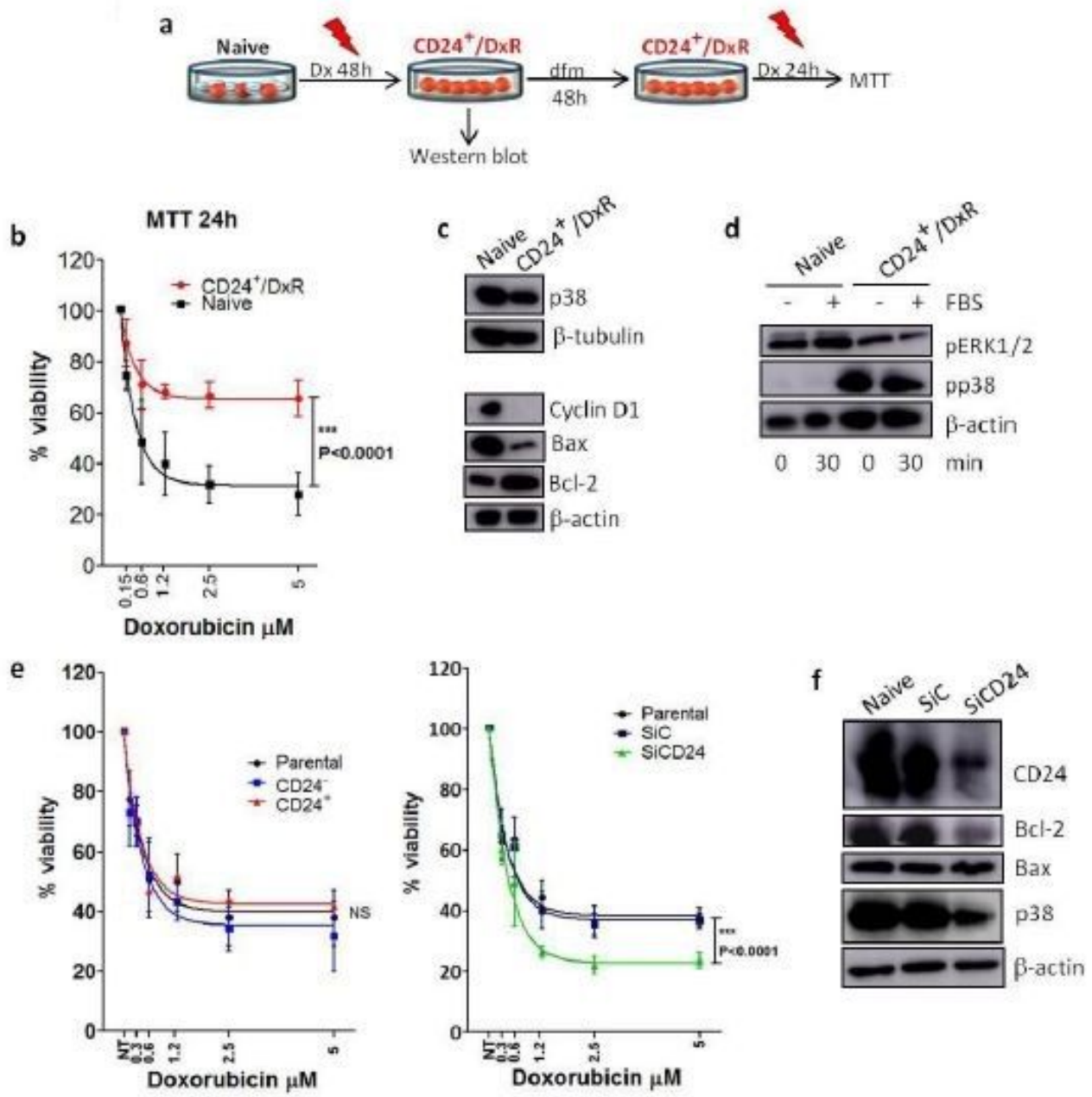

g

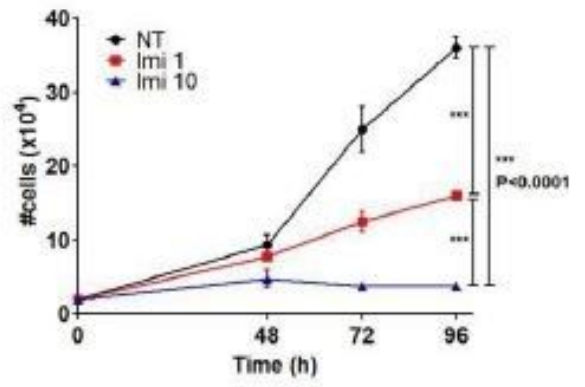

h
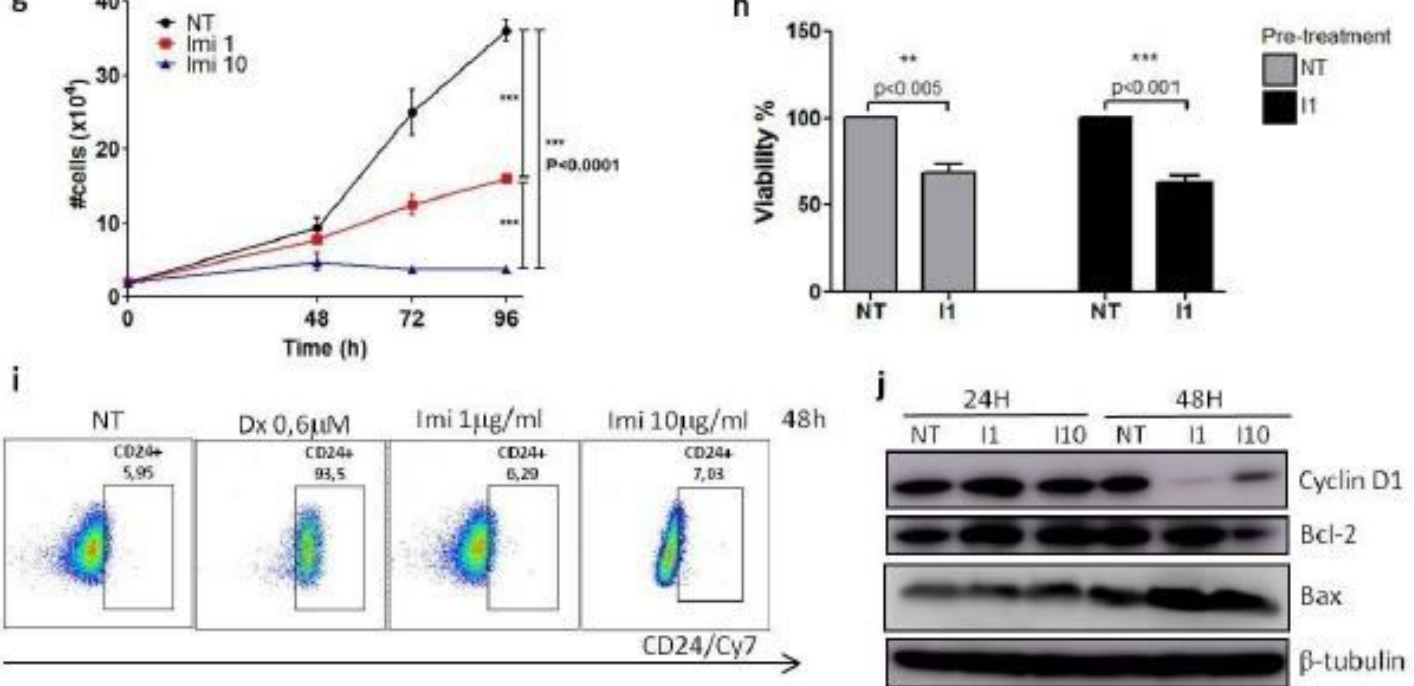

\section{Figure 3}

Translocation of CD24 is associated with chemoresistance and overexpression of Bcl-2 (a) Schematic shows experimental design used to obtain cell populations for MTT (fig $3 b$ ) and western blot assays (fig $3 c$ and $3 \mathrm{~d}$ ). $\mathrm{dfm}=$ drug-free medium; $\mathrm{Dx}=$ doxorubicin; $C D 24+/ D x R=C D 24+$ doxorrubicin-resistant cells. (b) CD24+/DxR cells become tolerant to a second Dx treatment. Parental MDA-MB-231 cells were cultured in the presence of Dx at $0.6 \square \mathrm{M}$ for 48h. After obtention of CD24+/DxR cells, the medium was changed for 
a drug-free medium ( $\mathrm{dfm}$ ) for $48 \mathrm{~h}$. Then, CD24+/DxR cells were submitted to Dx treatment (varying between $0.15 \square \mathrm{M}$ and $5 \square \mathrm{M}$ ) for $24 \mathrm{~h}$ and cell viability was measured by MTT. Naïve cells were used as control. The curves were fitted with non-linear regression as means of triplicates +/- SD. $* \star \star p<0,001$ (Twoway ANOVA with Bonferroni post-test). (c) CD24+/DxR cells are characterized by a reduction of cyclin D1 and Bax expression and increase of Bcl-2 level. Representative image of western blotting are shown and the data have been reproduced two times. (d) CD24+/DxR cells are characterized by a constitutive activation of p38 MAPK. Cells were starved for $2 \mathrm{~h}$ and then stimulated with serum (FBS) for $30 \mathrm{~min}$. Cell lysates were immunobloted with antibodies against the phosphorylated form of p38 (pp38) or ERK (pERK). (e) Correlation between surface CD24 expression and sensitivity to Dx. Cell subpopulations were submitted to Dx treatment (varying between $0.3 \square \mathrm{M}$ and $5 \square \mathrm{M}$ ) for $24 \mathrm{~h}$ and then cell viability was measured by MTT assay. Curves were fitted with non-linear regression as means of triplicates $+/-\mathrm{SD}$. $* \star \star p<0,001$ (Two-way ANOVA with Bonferroni post-test). (f) Downregulation of Bcl-2 and p38 expression in CD24 silenced (SiCD24) cells. After incubation of MDA-MB-231 cells with siRNA complex for $48 \mathrm{~h}$, SiC (control silenced) and SiCD24 (CD24 silenced) cells were lysed. Cell lysate were immunoblotted with the depicted antibodies. Representative images of western blotting are shown and the data have been reproduced three times. (g) Imiquimod reduces MDA-MB-231 cell proliferation. MDA-MB-231 cells were treated with Imiquimod $(1 \mathrm{~g} / \mathrm{ml}$ or $10 \square \mathrm{g} / \mathrm{ml})$ for different time periods. Then, cells were trypsinized, counted and the curves were fitted as means of triplicates +/-SD. $* \star \star p<0,001$ (Two-way ANOVA with Bonferroni post-test). (h) Imiquimod does not induce chemoresistance to subsequent treatments on MDA-MB-231 cells. MDAMB-231 cells were pre-treated with Imiquimod $(1 \mathrm{gg} / \mathrm{ml})$ for $96 \mathrm{~h}$. Then, the medium was changed for a drug-free medium ( $\mathrm{dfm}$ ). After $48 \mathrm{~h}$, cells were trypsinized, counted and treated with a second dose of Imiquimod $(1 \mathrm{gg} / \mathrm{ml})$ for $96 \mathrm{~h}$. Then cell viability was evaluated by MTT. Data were plotted as means of triplicates +/-SD. $* \star p<0,01$ and ${ }^{* \star *} p<0,001$ (T test) (i) Imiquimod does not induce CD24 translocation. MDA-MB-231 cells were treated with doxorubicin $(0.6 \square \mathrm{M})$ or Imiquimod $(1 \mathrm{gg} / \mathrm{ml}$ and $10 \square \mathrm{g} / \mathrm{ml})$ for $48 \mathrm{~h}$. Then, an extracellular staining was performed using anti-CD24/Cy7. The pseudocolor plots are representative of two independent experiments. (j) Imiquimod reduces Bcl-2 expression. MDA-MB-231 cells were treated with Imiquimod $(1 \mathrm{gg} / \mathrm{ml}$ or $10 \square \mathrm{g} / \mathrm{ml})$ in DMEM supplemented with fetal bovine serum (FBS) $10 \%$ for $24 \mathrm{~h}$ and $48 \mathrm{~h}$. Cell lysates were immunobloted with the depicted antibodies. The results are representative of two independent experiments. 

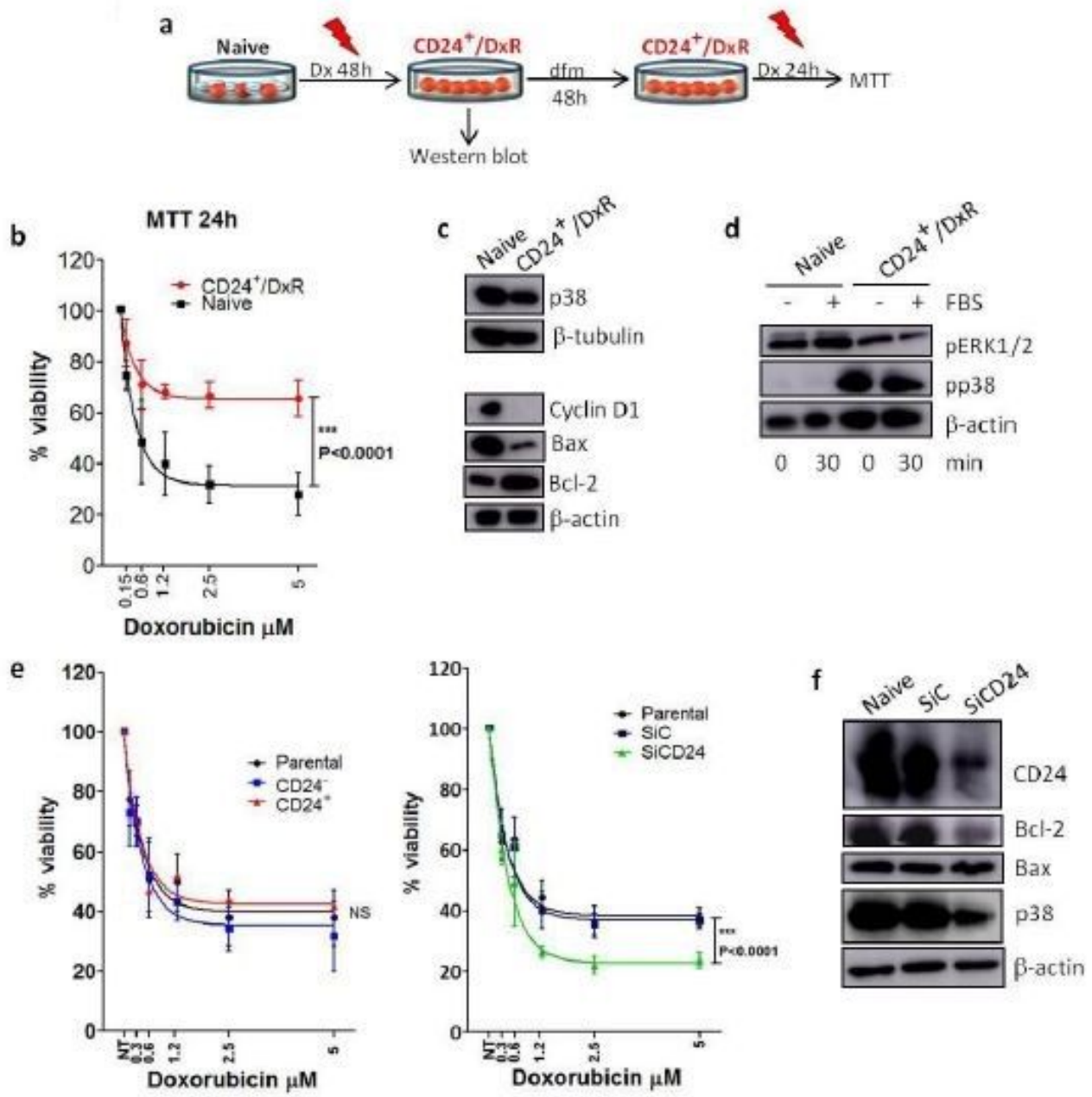

g

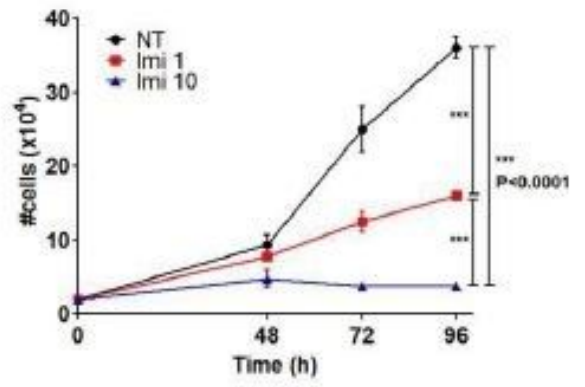

h
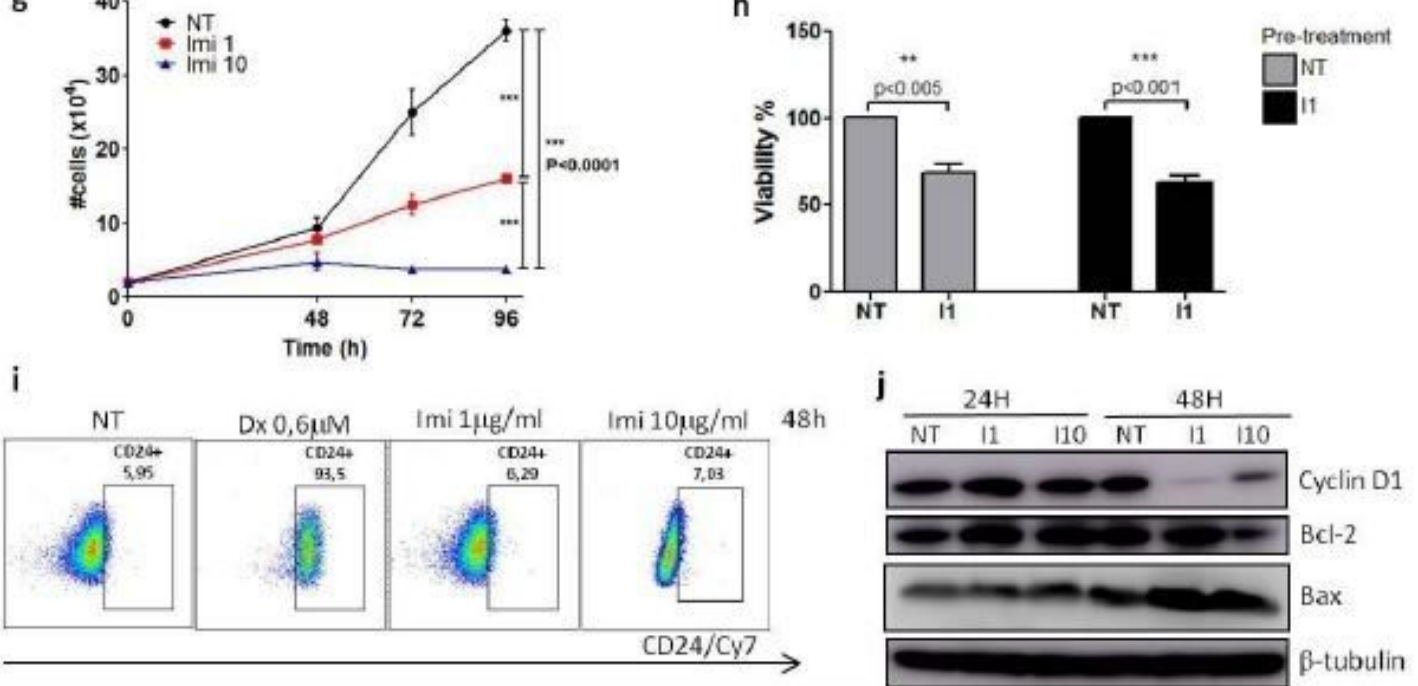

\section{Figure 3}

Translocation of CD24 is associated with chemoresistance and overexpression of Bcl-2 (a) Schematic shows experimental design used to obtain cell populations for MTT (fig $3 b$ ) and western blot assays (fig $3 c$ and $3 \mathrm{~d}$ ). $\mathrm{dfm}=$ drug-free medium; $\mathrm{Dx}=$ doxorubicin; $C D 24+/ D x R=C D 24+$ doxorrubicin-resistant cells. (b) CD24+/DxR cells become tolerant to a second Dx treatment. Parental MDA-MB-231 cells were cultured in the presence of Dx at $0.6 \square \mathrm{M}$ for 48h. After obtention of CD24+/DxR cells, the medium was changed for 
a drug-free medium ( $\mathrm{dfm}$ ) for $48 \mathrm{~h}$. Then, CD24+/DxR cells were submitted to Dx treatment (varying between $0.15 \square \mathrm{M}$ and $5 \square \mathrm{M}$ ) for $24 \mathrm{~h}$ and cell viability was measured by MTT. Naïve cells were used as control. The curves were fitted with non-linear regression as means of triplicates +/- SD. $* \star \star p<0,001$ (Twoway ANOVA with Bonferroni post-test). (c) CD24+/DxR cells are characterized by a reduction of cyclin D1 and Bax expression and increase of Bcl-2 level. Representative image of western blotting are shown and the data have been reproduced two times. (d) CD24+/DxR cells are characterized by a constitutive activation of p38 MAPK. Cells were starved for $2 \mathrm{~h}$ and then stimulated with serum (FBS) for $30 \mathrm{~min}$. Cell lysates were immunobloted with antibodies against the phosphorylated form of p38 (pp38) or ERK (pERK). (e) Correlation between surface CD24 expression and sensitivity to Dx. Cell subpopulations were submitted to Dx treatment (varying between $0.3 \square \mathrm{M}$ and $5 \square \mathrm{M}$ ) for $24 \mathrm{~h}$ and then cell viability was measured by MTT assay. Curves were fitted with non-linear regression as means of triplicates $+/-\mathrm{SD}$. $* \star \star p<0,001$ (Two-way ANOVA with Bonferroni post-test). (f) Downregulation of Bcl-2 and p38 expression in CD24 silenced (SiCD24) cells. After incubation of MDA-MB-231 cells with siRNA complex for $48 \mathrm{~h}$, SiC (control silenced) and SiCD24 (CD24 silenced) cells were lysed. Cell lysate were immunoblotted with the depicted antibodies. Representative images of western blotting are shown and the data have been reproduced three times. (g) Imiquimod reduces MDA-MB-231 cell proliferation. MDA-MB-231 cells were treated with Imiquimod $(1 \mathrm{~g} / \mathrm{ml}$ or $10 \square \mathrm{g} / \mathrm{ml})$ for different time periods. Then, cells were trypsinized, counted and the curves were fitted as means of triplicates +/-SD. $* \star \star p<0,001$ (Two-way ANOVA with Bonferroni post-test). (h) Imiquimod does not induce chemoresistance to subsequent treatments on MDA-MB-231 cells. MDAMB-231 cells were pre-treated with Imiquimod $(1 \mathrm{gg} / \mathrm{ml})$ for $96 \mathrm{~h}$. Then, the medium was changed for a drug-free medium ( $\mathrm{dfm}$ ). After $48 \mathrm{~h}$, cells were trypsinized, counted and treated with a second dose of Imiquimod $(1 \mathrm{gg} / \mathrm{ml})$ for $96 \mathrm{~h}$. Then cell viability was evaluated by MTT. Data were plotted as means of triplicates +/-SD. $* \star p<0,01$ and ${ }^{* \star *} p<0,001$ (T test) (i) Imiquimod does not induce CD24 translocation. MDA-MB-231 cells were treated with doxorubicin $(0.6 \square \mathrm{M})$ or Imiquimod $(1 \mathrm{gg} / \mathrm{ml}$ and $10 \square \mathrm{g} / \mathrm{ml})$ for $48 \mathrm{~h}$. Then, an extracellular staining was performed using anti-CD24/Cy7. The pseudocolor plots are representative of two independent experiments. (j) Imiquimod reduces Bcl-2 expression. MDA-MB-231 cells were treated with Imiquimod $(1 \mathrm{gg} / \mathrm{ml}$ or $10 \square \mathrm{g} / \mathrm{ml})$ in DMEM supplemented with fetal bovine serum (FBS) $10 \%$ for $24 \mathrm{~h}$ and $48 \mathrm{~h}$. Cell lysates were immunobloted with the depicted antibodies. The results are representative of two independent experiments. 

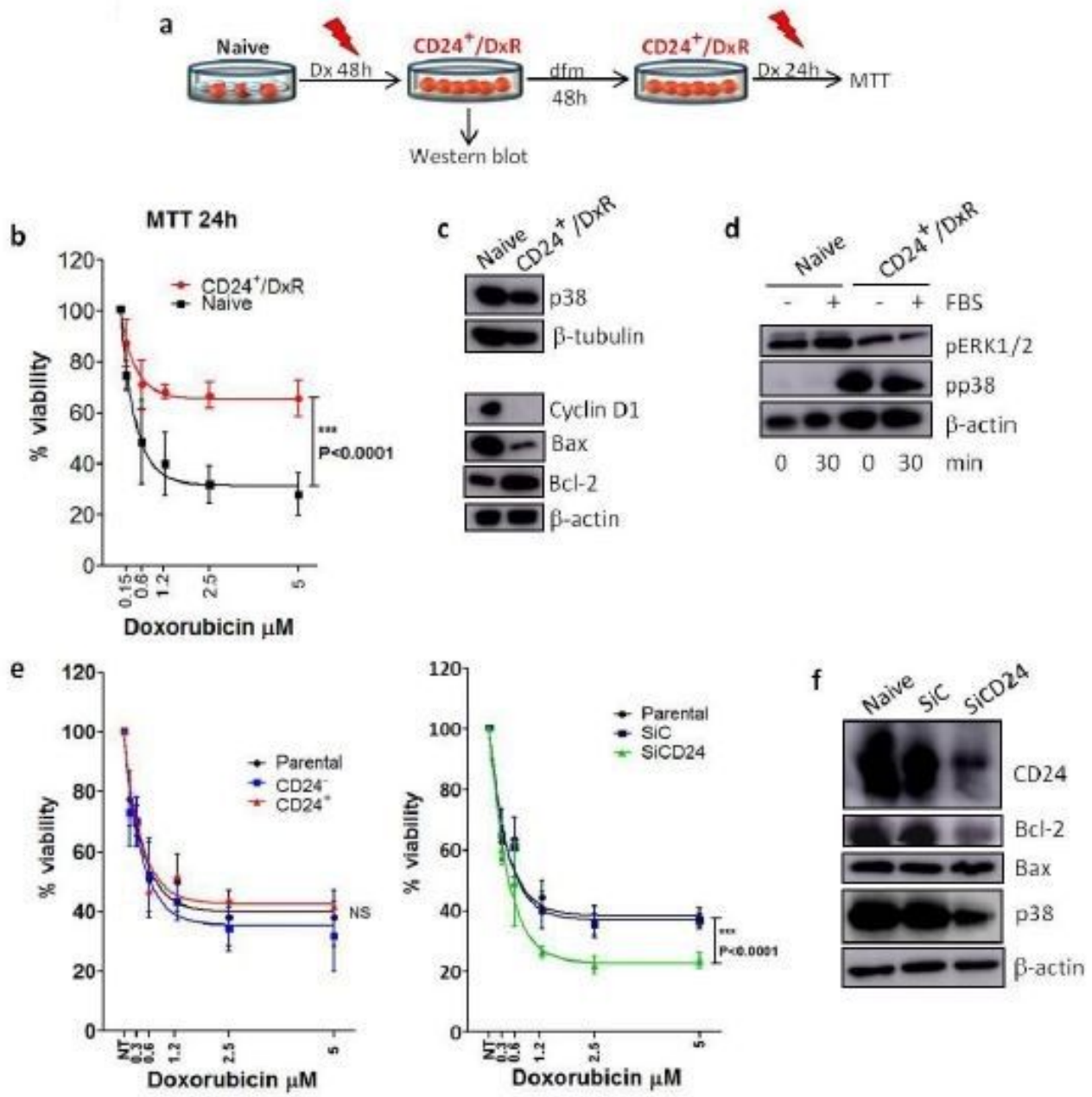

g

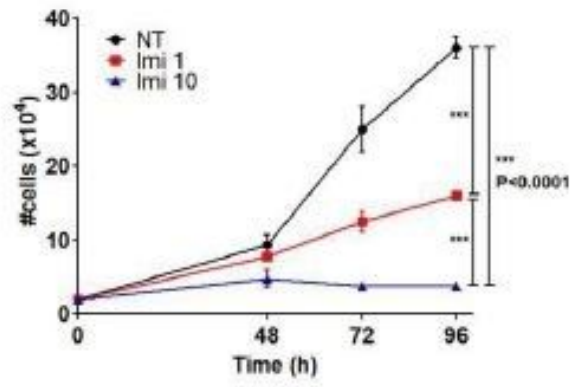

h
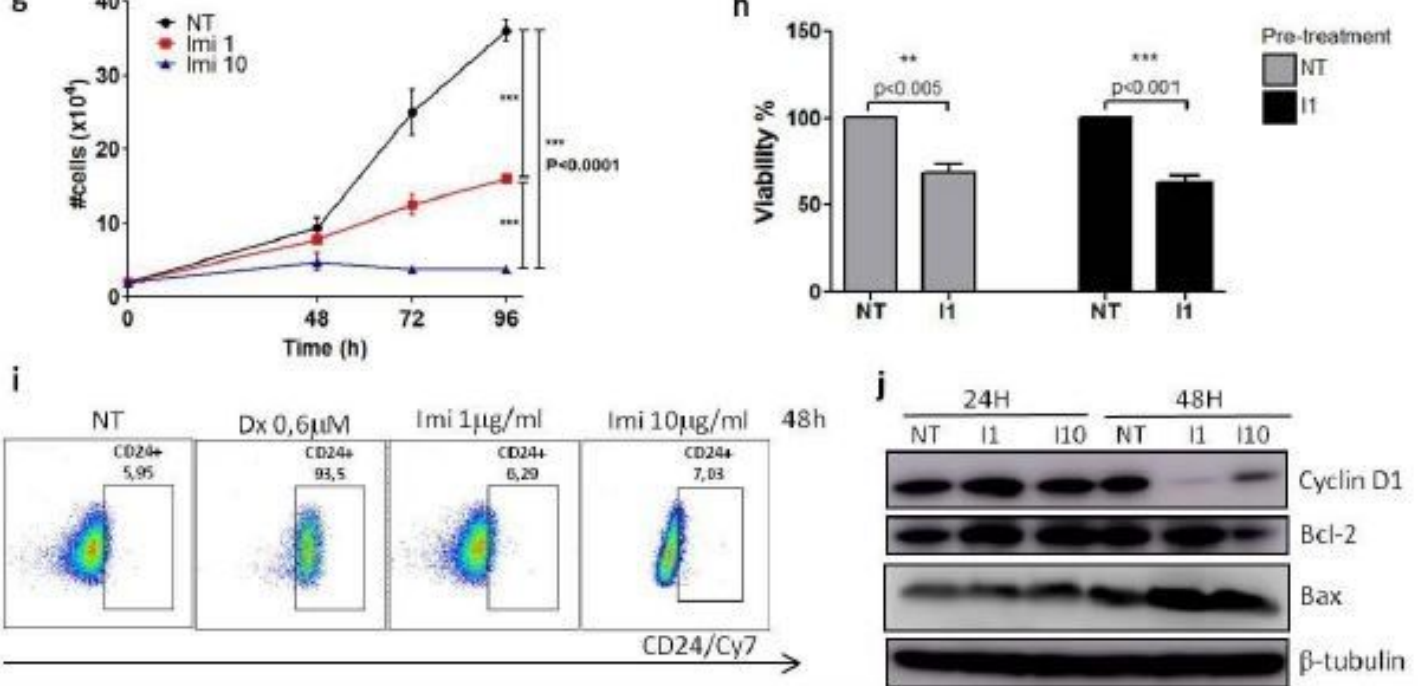

\section{Figure 3}

Translocation of CD24 is associated with chemoresistance and overexpression of Bcl-2 (a) Schematic shows experimental design used to obtain cell populations for MTT (fig $3 b$ ) and western blot assays (fig $3 c$ and $3 \mathrm{~d}$ ). $\mathrm{dfm}=$ drug-free medium; $\mathrm{Dx}=$ doxorubicin; $C D 24+/ D x R=C D 24+$ doxorrubicin-resistant cells. (b) CD24+/DxR cells become tolerant to a second Dx treatment. Parental MDA-MB-231 cells were cultured in the presence of Dx at $0.6 \square \mathrm{M}$ for 48h. After obtention of CD24+/DxR cells, the medium was changed for 
a drug-free medium ( $\mathrm{dfm}$ ) for $48 \mathrm{~h}$. Then, CD24+/DxR cells were submitted to Dx treatment (varying between $0.15 \square \mathrm{M}$ and $5 \square \mathrm{M}$ ) for $24 \mathrm{~h}$ and cell viability was measured by MTT. Naïve cells were used as control. The curves were fitted with non-linear regression as means of triplicates +/- SD. $* \star \star p<0,001$ (Twoway ANOVA with Bonferroni post-test). (c) CD24+/DxR cells are characterized by a reduction of cyclin D1 and Bax expression and increase of Bcl-2 level. Representative image of western blotting are shown and the data have been reproduced two times. (d) CD24+/DxR cells are characterized by a constitutive activation of p38 MAPK. Cells were starved for $2 \mathrm{~h}$ and then stimulated with serum (FBS) for $30 \mathrm{~min}$. Cell lysates were immunobloted with antibodies against the phosphorylated form of p38 (pp38) or ERK (pERK). (e) Correlation between surface CD24 expression and sensitivity to Dx. Cell subpopulations were submitted to Dx treatment (varying between $0.3 \square \mathrm{M}$ and $5 \square \mathrm{M}$ ) for $24 \mathrm{~h}$ and then cell viability was measured by MTT assay. Curves were fitted with non-linear regression as means of triplicates $+/-\mathrm{SD}$. $* \star \star p<0,001$ (Two-way ANOVA with Bonferroni post-test). (f) Downregulation of Bcl-2 and p38 expression in CD24 silenced (SiCD24) cells. After incubation of MDA-MB-231 cells with siRNA complex for $48 \mathrm{~h}$, SiC (control silenced) and SiCD24 (CD24 silenced) cells were lysed. Cell lysate were immunoblotted with the depicted antibodies. Representative images of western blotting are shown and the data have been reproduced three times. (g) Imiquimod reduces MDA-MB-231 cell proliferation. MDA-MB-231 cells were treated with Imiquimod $(1 \mathrm{~g} / \mathrm{ml}$ or $10 \square \mathrm{g} / \mathrm{ml})$ for different time periods. Then, cells were trypsinized, counted and the curves were fitted as means of triplicates +/-SD. $* \star \star p<0,001$ (Two-way ANOVA with Bonferroni post-test). (h) Imiquimod does not induce chemoresistance to subsequent treatments on MDA-MB-231 cells. MDAMB-231 cells were pre-treated with Imiquimod $(1 \mathrm{gg} / \mathrm{ml})$ for $96 \mathrm{~h}$. Then, the medium was changed for a drug-free medium ( $\mathrm{dfm}$ ). After $48 \mathrm{~h}$, cells were trypsinized, counted and treated with a second dose of Imiquimod $(1 \mathrm{gg} / \mathrm{ml})$ for $96 \mathrm{~h}$. Then cell viability was evaluated by MTT. Data were plotted as means of triplicates +/-SD. $* \star p<0,01$ and ${ }^{* \star *} p<0,001$ (T test) (i) Imiquimod does not induce CD24 translocation. MDA-MB-231 cells were treated with doxorubicin $(0.6 \square \mathrm{M})$ or Imiquimod $(1 \mathrm{gg} / \mathrm{ml}$ and $10 \square \mathrm{g} / \mathrm{ml})$ for $48 \mathrm{~h}$. Then, an extracellular staining was performed using anti-CD24/Cy7. The pseudocolor plots are representative of two independent experiments. (j) Imiquimod reduces Bcl-2 expression. MDA-MB-231 cells were treated with Imiquimod $(1 \mathrm{gg} / \mathrm{ml}$ or $10 \square \mathrm{g} / \mathrm{ml})$ in DMEM supplemented with fetal bovine serum (FBS) $10 \%$ for $24 \mathrm{~h}$ and $48 \mathrm{~h}$. Cell lysates were immunobloted with the depicted antibodies. The results are representative of two independent experiments. 

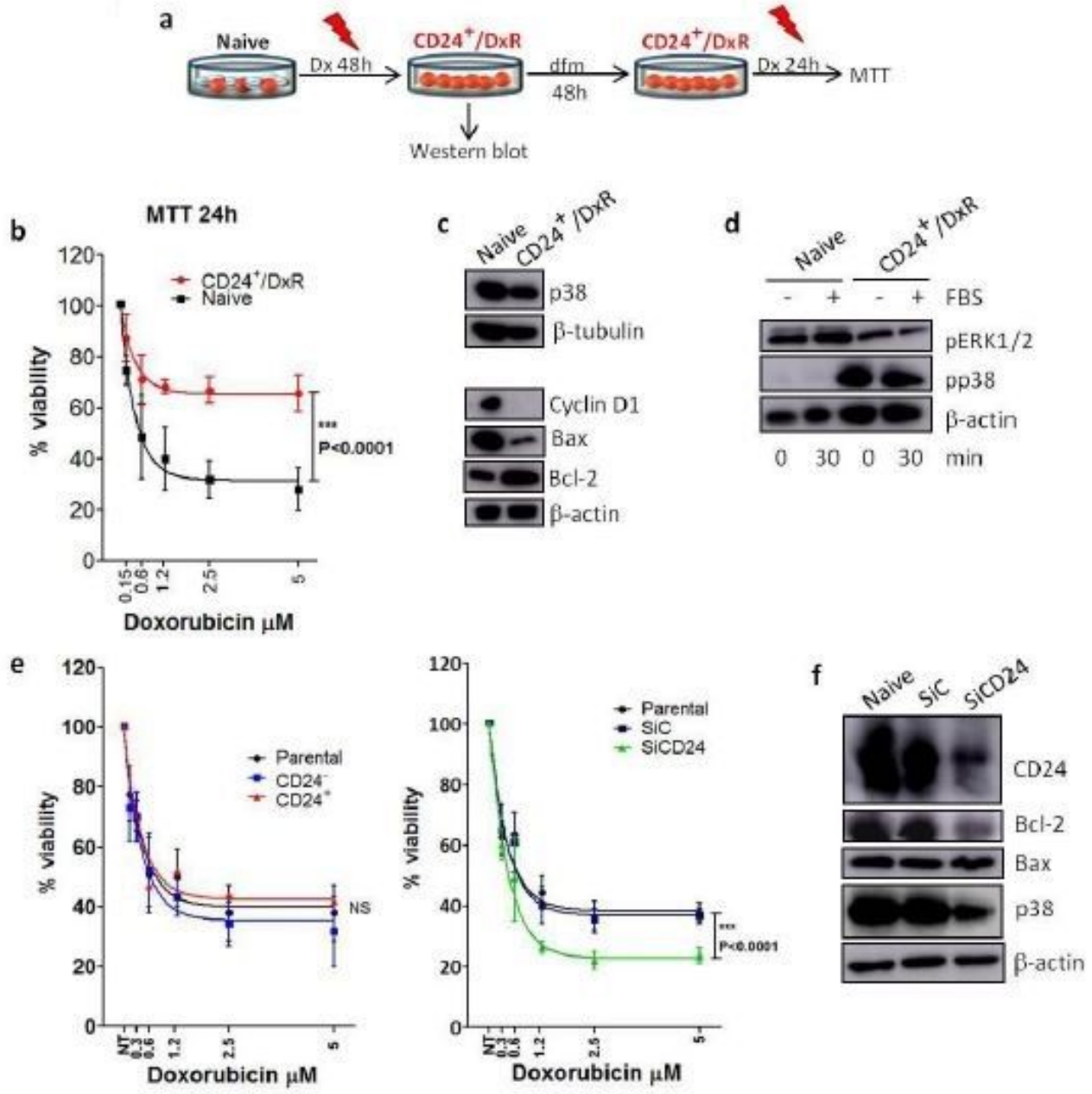

g

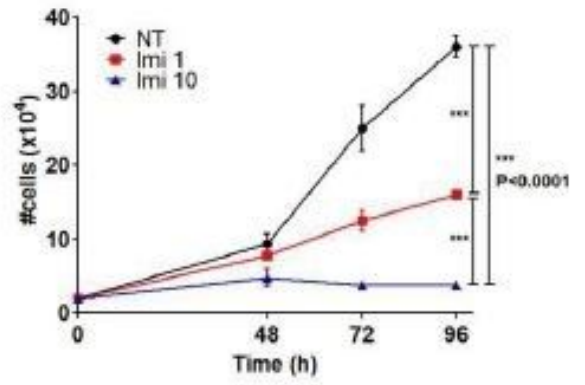

h
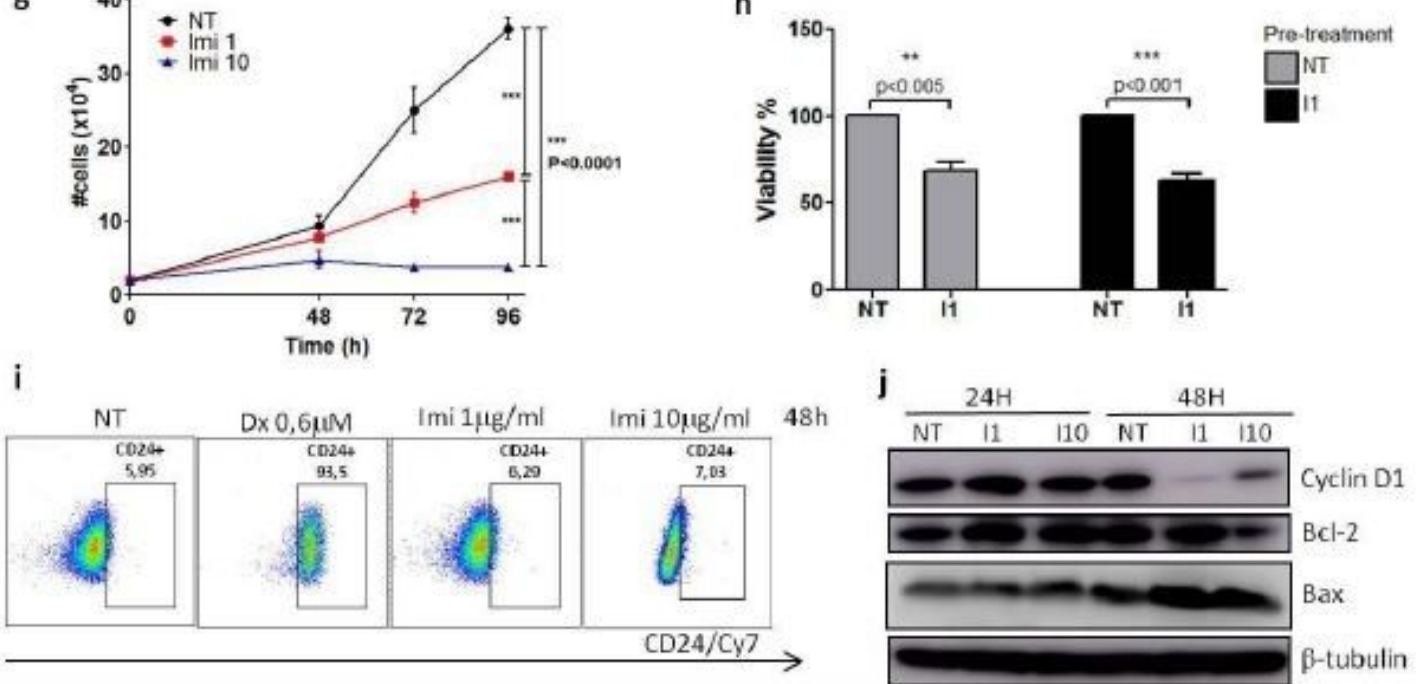

\section{Figure 3}

Translocation of CD24 is associated with chemoresistance and overexpression of Bcl-2 (a) Schematic shows experimental design used to obtain cell populations for MTT (fig $3 b$ ) and western blot assays (fig $3 c$ and $3 \mathrm{~d}$ ). $\mathrm{dfm}=$ drug-free medium; $\mathrm{Dx}=$ doxorubicin; $C D 24+/ D x R=C D 24+$ doxorrubicin-resistant cells. (b) CD24+/DxR cells become tolerant to a second Dx treatment. Parental MDA-MB-231 cells were cultured in the presence of Dx at $0.6 \square \mathrm{M}$ for 48h. After obtention of CD24+/DxR cells, the medium was changed for 
a drug-free medium ( $\mathrm{dfm}$ ) for $48 \mathrm{~h}$. Then, CD24+/DxR cells were submitted to Dx treatment (varying between $0.15 \square \mathrm{M}$ and $5 \square \mathrm{M}$ ) for $24 \mathrm{~h}$ and cell viability was measured by MTT. Naïve cells were used as control. The curves were fitted with non-linear regression as means of triplicates +/- SD. $* \star \star p<0,001$ (Twoway ANOVA with Bonferroni post-test). (c) CD24+/DxR cells are characterized by a reduction of cyclin D1 and Bax expression and increase of Bcl-2 level. Representative image of western blotting are shown and the data have been reproduced two times. (d) CD24+/DxR cells are characterized by a constitutive activation of p38 MAPK. Cells were starved for $2 \mathrm{~h}$ and then stimulated with serum (FBS) for $30 \mathrm{~min}$. Cell lysates were immunobloted with antibodies against the phosphorylated form of p38 (pp38) or ERK (pERK). (e) Correlation between surface CD24 expression and sensitivity to Dx. Cell subpopulations were submitted to Dx treatment (varying between $0.3 \square \mathrm{M}$ and $5 \square \mathrm{M}$ ) for $24 \mathrm{~h}$ and then cell viability was measured by MTT assay. Curves were fitted with non-linear regression as means of triplicates $+/-\mathrm{SD}$. $* \star \star p<0,001$ (Two-way ANOVA with Bonferroni post-test). (f) Downregulation of Bcl-2 and p38 expression in CD24 silenced (SiCD24) cells. After incubation of MDA-MB-231 cells with siRNA complex for $48 \mathrm{~h}$, SiC (control silenced) and SiCD24 (CD24 silenced) cells were lysed. Cell lysate were immunoblotted with the depicted antibodies. Representative images of western blotting are shown and the data have been reproduced three times. (g) Imiquimod reduces MDA-MB-231 cell proliferation. MDA-MB-231 cells were treated with Imiquimod $(1 \mathrm{~g} / \mathrm{ml}$ or $10 \square \mathrm{g} / \mathrm{ml})$ for different time periods. Then, cells were trypsinized, counted and the curves were fitted as means of triplicates +/-SD. $* \star \star p<0,001$ (Two-way ANOVA with Bonferroni post-test). (h) Imiquimod does not induce chemoresistance to subsequent treatments on MDA-MB-231 cells. MDAMB-231 cells were pre-treated with Imiquimod $(1 \mathrm{gg} / \mathrm{ml})$ for $96 \mathrm{~h}$. Then, the medium was changed for a drug-free medium ( $\mathrm{dfm}$ ). After $48 \mathrm{~h}$, cells were trypsinized, counted and treated with a second dose of Imiquimod $(1 \mathrm{gg} / \mathrm{ml})$ for $96 \mathrm{~h}$. Then cell viability was evaluated by MTT. Data were plotted as means of triplicates +/-SD. $* \star p<0,01$ and ${ }^{* \star *} p<0,001$ (T test) (i) Imiquimod does not induce CD24 translocation. MDA-MB-231 cells were treated with doxorubicin $(0.6 \square \mathrm{M})$ or Imiquimod $(1 \mathrm{gg} / \mathrm{ml}$ and $10 \square \mathrm{g} / \mathrm{ml})$ for $48 \mathrm{~h}$. Then, an extracellular staining was performed using anti-CD24/Cy7. The pseudocolor plots are representative of two independent experiments. (j) Imiquimod reduces Bcl-2 expression. MDA-MB-231 cells were treated with Imiquimod $(1 \mathrm{gg} / \mathrm{ml}$ or $10 \square \mathrm{g} / \mathrm{ml})$ in DMEM supplemented with fetal bovine serum (FBS) $10 \%$ for $24 \mathrm{~h}$ and $48 \mathrm{~h}$. Cell lysates were immunobloted with the depicted antibodies. The results are representative of two independent experiments. 
a

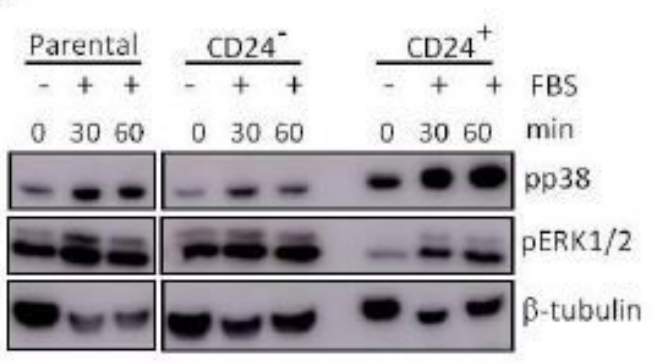

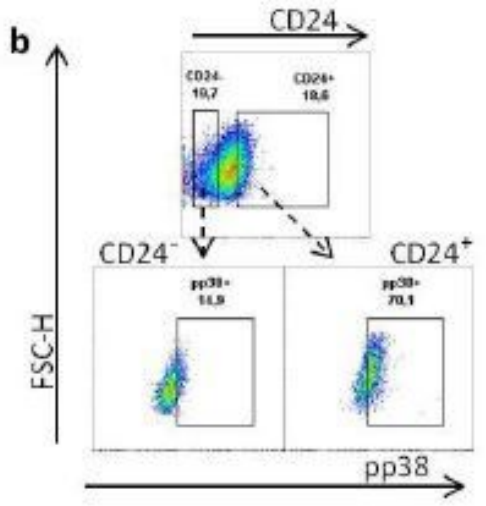

C

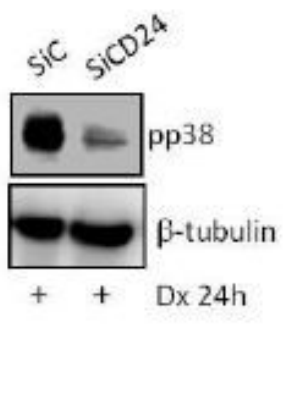

d

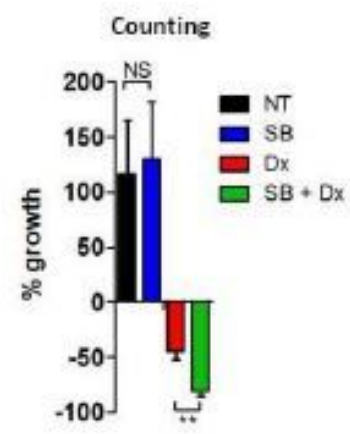

e

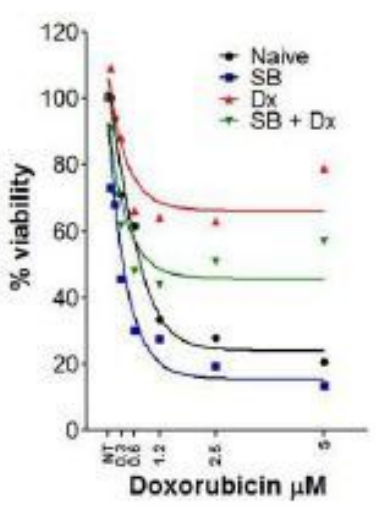

f

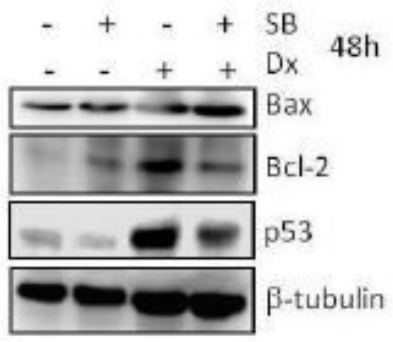

g
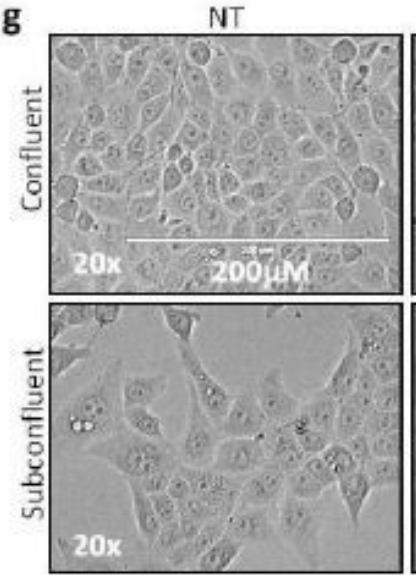

h

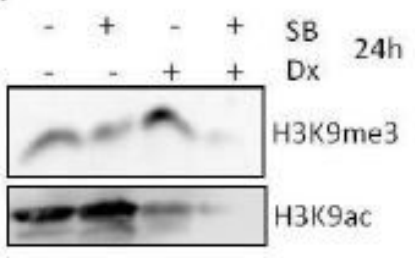

SB
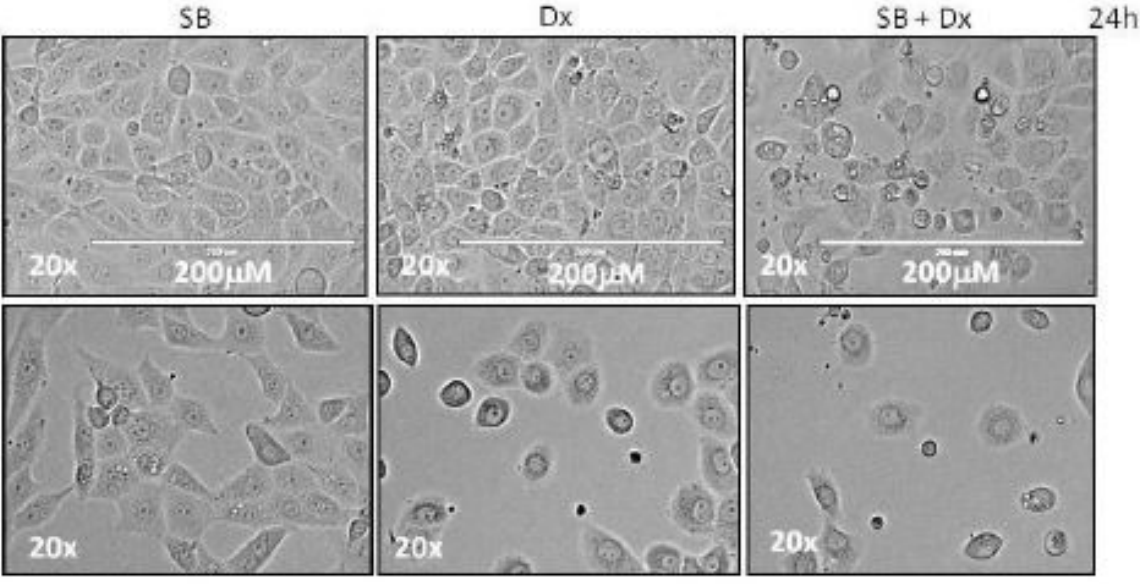

i

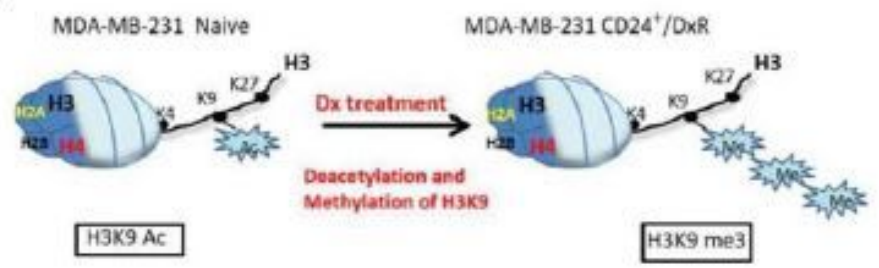

Figure 4

Inhibition of p38 activity impedes phenotype switching of MDA-MB-231 cells under doxorubicin treatment. (a) Differential activation of MAPKs in CD24+ and CD24- subpopulation. Parental and the magnetic sorted CD24+ and CD24- cells were starved for $2 \mathrm{~h}$. Then, cells were submitted to time kinetic using fetal bovine serum (FBS) as stimulus. Cell lysates were immunobloted with the depicted antibodies. The results are representative of two independent experiments. (b) Higher p38 phosphorylation (pp38) 
MAPK in CD24+ cells. Parental MDA-MB-231 cells were stained with anti-CD24/Pe-Cy7 (extracellular staining) and anti-pp38/FITC (intracellular staining). The pseudocolor plots are representative of triplicates. (c) Decreased phosphorylation of p38 (pp38) in SiCD24 cells treated with Dx. SiC and SiCD24 cells were treated with $D x(0.6 \square \mathrm{M})$ for 24 hours. Cell lysates were immunobloted with the depicted antibodies. All blots were performed at least twice. (d) Increased efficiency of Dx when associated with the p38 inhibitor SB203580. Cells were treated with SB203580 (SB) at 10ロM or/and Dx at $0.6 \square \mathrm{M}$ for $48 \mathrm{~h}$. Then, cells were counted and the growth percentage was calculated based on the initial number of cells before each treatment $(\%$ growth $=[\mathrm{fn} / \mathrm{in}-1] \times 100) \#$. Countings were performed in three independent experiments. (e) Reduction in the acquisition of Dx resistance in the presence of the p38 inhibitor SB203580. MDA-MB-231 cells were pre-treated with SB203580 (10ロM) and/or doxorubicin (0.6ロM) during $48 \mathrm{~h}$ before the addition of $\mathrm{Dx}$ at different concentrations (varying between $0.07 \square \mathrm{M}$ and $5 \square \mathrm{M}$ ) for $24 \mathrm{~h}$ and then cell viability was measured by MTT assay. Curves were fitted with non-linear regression as means of triplicates. (f) Increased expression of Bax but decreased expression of $\mathrm{Bcl} 2$ and $\mathrm{p} 53$ after cell treatment with the association of the p38 inhibitor SB203580 and Dx. MDA-MB-231 cells were treated with

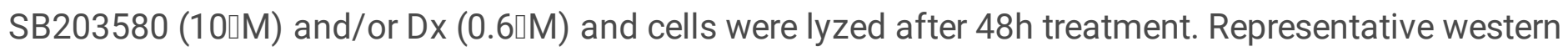
blotting is shown and the data have been reproduced twice. (g) Representative light microscopy images of cell population at confluence (106 cells) or subconfluence $(5 \times 105$ cells) density treated with SB203580 $(10 \varangle \mathrm{M})$ and/or Dx (0.6ロM) for 24h. Cell density and morphology were evaluated by microscopy (Evos Skedda). The microscopy images are representative of triplicates. (h) The p38 inhibitor SB203580 inhibits the tri-methylation state of H3K9 in Dx treated cells. After 24h of treatment with SB203580 (SB) at $10 \square \mathrm{M}$ and/or Dx at $0.6 \square \mathrm{M}, \mathrm{MDA}-\mathrm{MB}-231$ cells were lysed and the status of histone 3 was analyzed by western blotting using antibodies against tri-methylated (H3K9me3) or acetylated (H3K9ac) form of H3K9. (i) Schematic shows the histone modifications and its consequences on MDA-MB-231 cell phenotype after doxorubicin treatment. The reprogramming of doxorubicin-treated cells induced a cell cycle arrest and morphological modifications of MDA-MB-231 cells associated with the H3K9 histone state changes, acetylated vs metylated form under p38 control. 
a

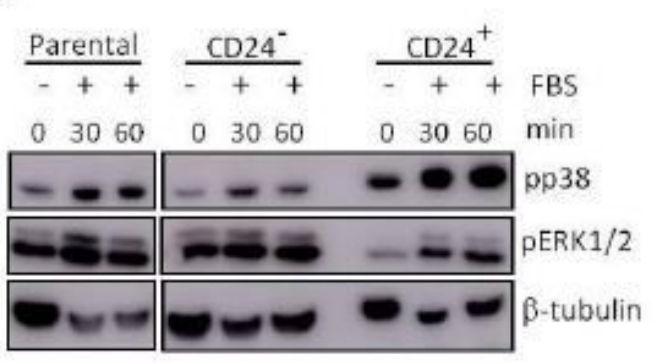

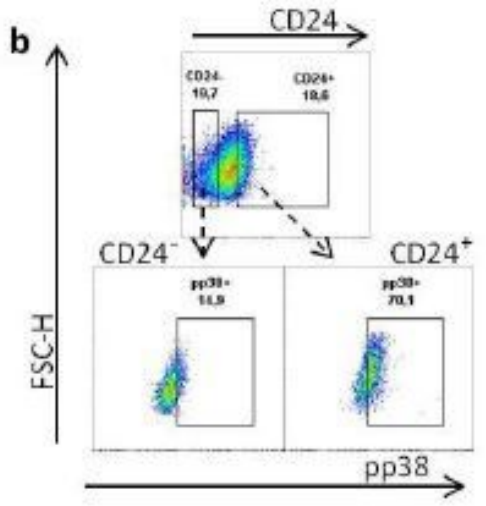

C

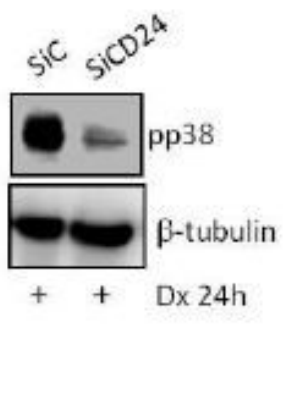

d

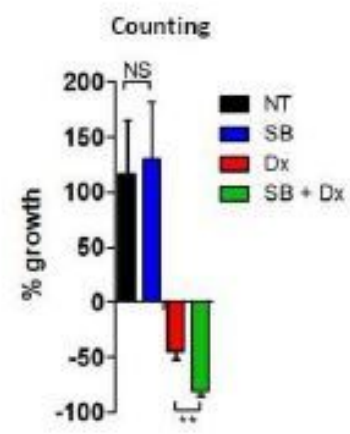

e

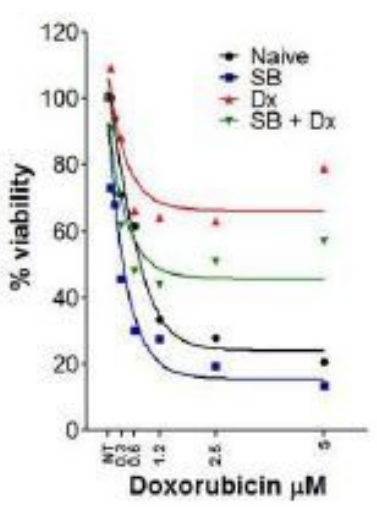

f

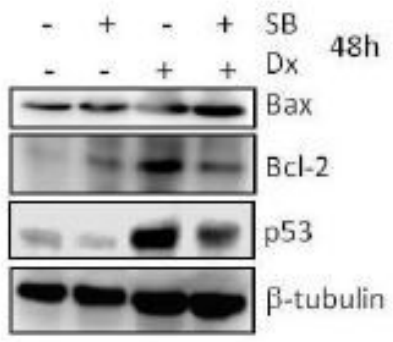

g
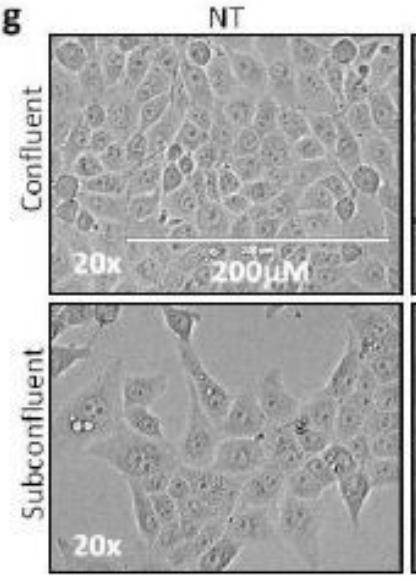

h

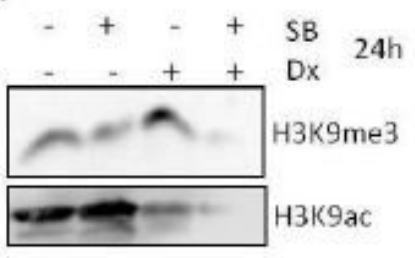

SB
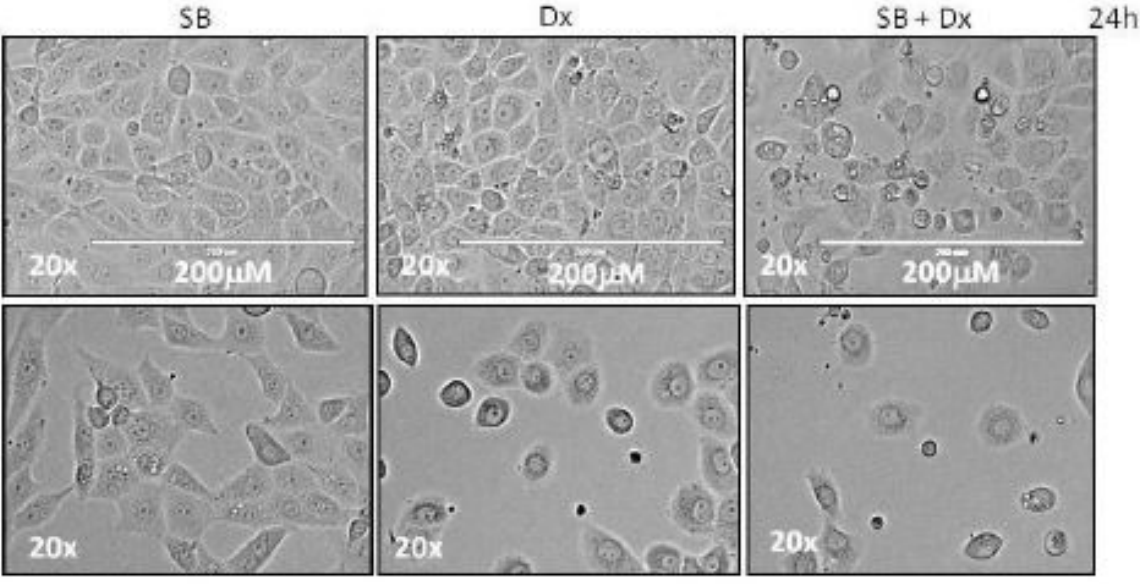

i

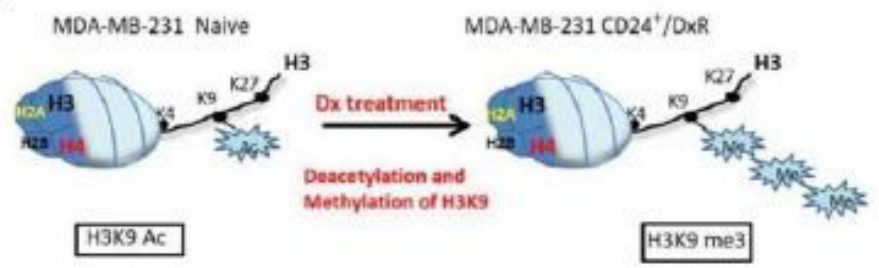

Figure 4

Inhibition of p38 activity impedes phenotype switching of MDA-MB-231 cells under doxorubicin treatment. (a) Differential activation of MAPKs in CD24+ and CD24- subpopulation. Parental and the magnetic sorted CD24+ and CD24- cells were starved for $2 \mathrm{~h}$. Then, cells were submitted to time kinetic using fetal bovine serum (FBS) as stimulus. Cell lysates were immunobloted with the depicted antibodies. The results are representative of two independent experiments. (b) Higher p38 phosphorylation (pp38) 
MAPK in CD24+ cells. Parental MDA-MB-231 cells were stained with anti-CD24/Pe-Cy7 (extracellular staining) and anti-pp38/FITC (intracellular staining). The pseudocolor plots are representative of triplicates. (c) Decreased phosphorylation of p38 (pp38) in SiCD24 cells treated with Dx. SiC and SiCD24 cells were treated with $D x(0.6 \square \mathrm{M})$ for 24 hours. Cell lysates were immunobloted with the depicted antibodies. All blots were performed at least twice. (d) Increased efficiency of Dx when associated with the p38 inhibitor SB203580. Cells were treated with SB203580 (SB) at 10ロM or/and Dx at $0.6 \square \mathrm{M}$ for $48 \mathrm{~h}$. Then, cells were counted and the growth percentage was calculated based on the initial number of cells before each treatment $(\%$ growth $=[\mathrm{fn} / \mathrm{in}-1] \times 100) \#$. Countings were performed in three independent experiments. (e) Reduction in the acquisition of Dx resistance in the presence of the p38 inhibitor SB203580. MDA-MB-231 cells were pre-treated with SB203580 (10ロM) and/or doxorubicin (0.6ロM) during $48 \mathrm{~h}$ before the addition of $\mathrm{Dx}$ at different concentrations (varying between $0.07 \square \mathrm{M}$ and $5 \square \mathrm{M}$ ) for $24 \mathrm{~h}$ and then cell viability was measured by MTT assay. Curves were fitted with non-linear regression as means of triplicates. (f) Increased expression of Bax but decreased expression of $\mathrm{Bcl} 2$ and $\mathrm{p} 53$ after cell treatment with the association of the p38 inhibitor SB203580 and Dx. MDA-MB-231 cells were treated with

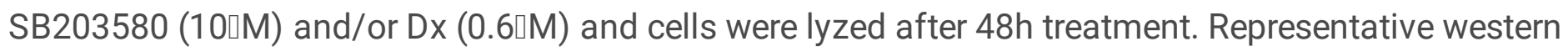
blotting is shown and the data have been reproduced twice. (g) Representative light microscopy images of cell population at confluence (106 cells) or subconfluence $(5 \times 105$ cells) density treated with SB203580 $(10 \varangle \mathrm{M})$ and/or Dx (0.6ロM) for 24h. Cell density and morphology were evaluated by microscopy (Evos Skedda). The microscopy images are representative of triplicates. (h) The p38 inhibitor SB203580 inhibits the tri-methylation state of H3K9 in Dx treated cells. After 24h of treatment with SB203580 (SB) at $10 \square \mathrm{M}$ and/or Dx at $0.6 \square \mathrm{M}, \mathrm{MDA}-\mathrm{MB}-231$ cells were lysed and the status of histone 3 was analyzed by western blotting using antibodies against tri-methylated (H3K9me3) or acetylated (H3K9ac) form of H3K9. (i) Schematic shows the histone modifications and its consequences on MDA-MB-231 cell phenotype after doxorubicin treatment. The reprogramming of doxorubicin-treated cells induced a cell cycle arrest and morphological modifications of MDA-MB-231 cells associated with the H3K9 histone state changes, acetylated vs metylated form under p38 control. 
a

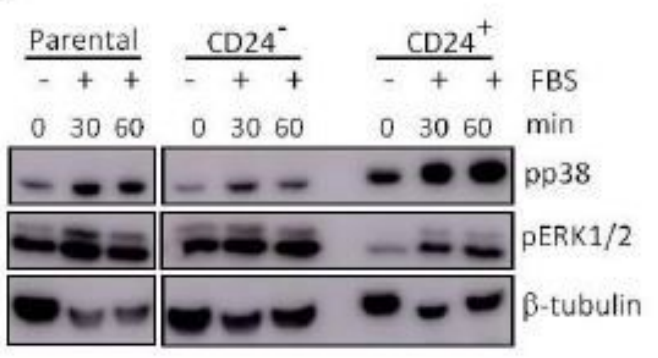

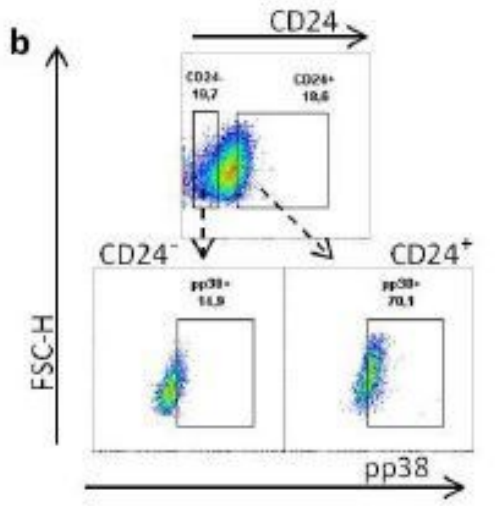

C

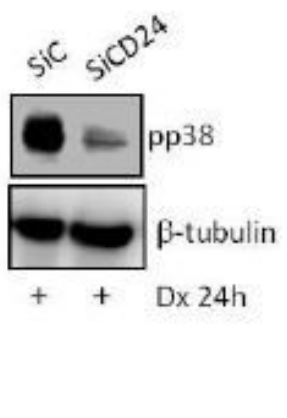

d

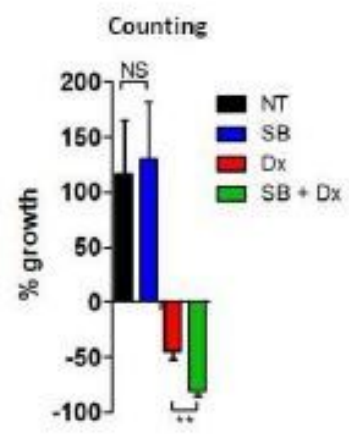

e

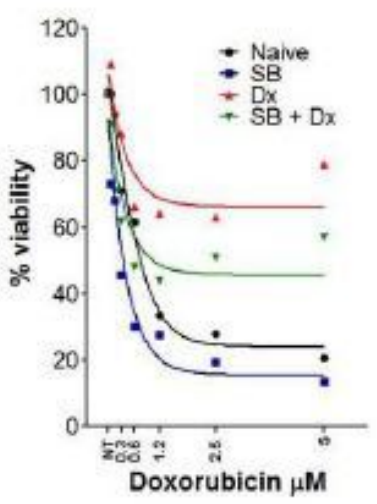

f

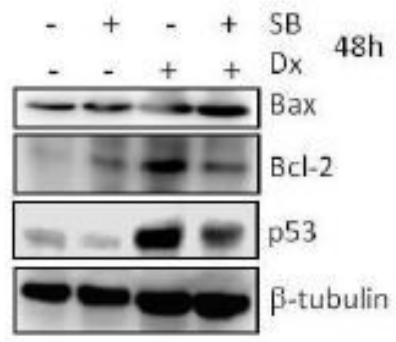

g
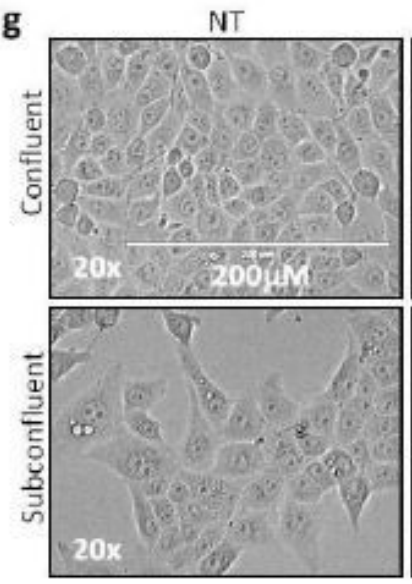

h

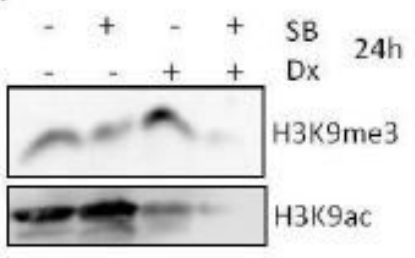

SB
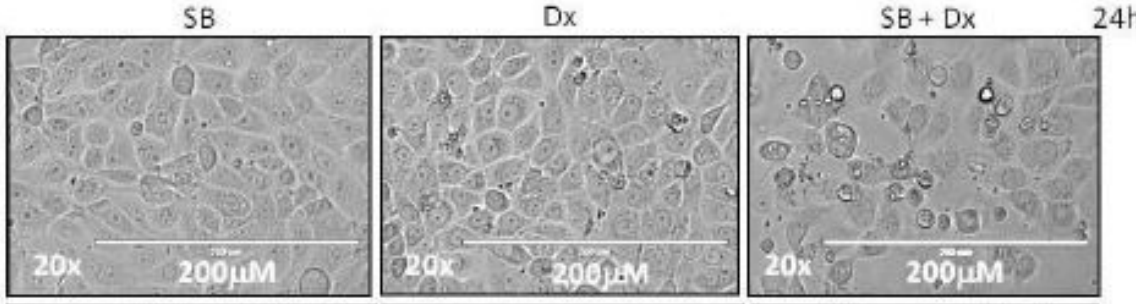

$20 x$
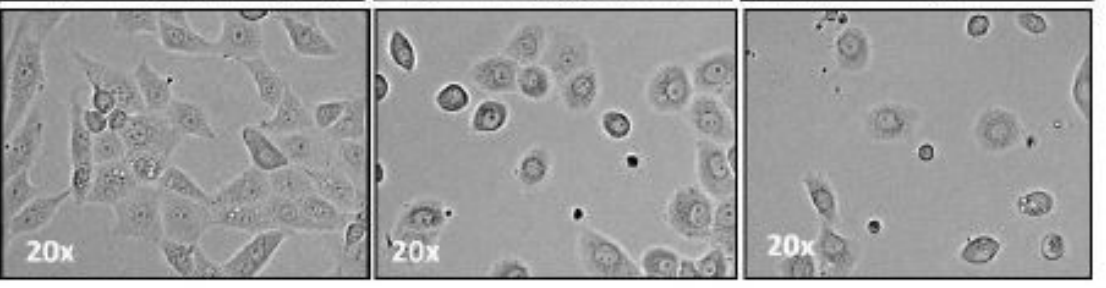

i

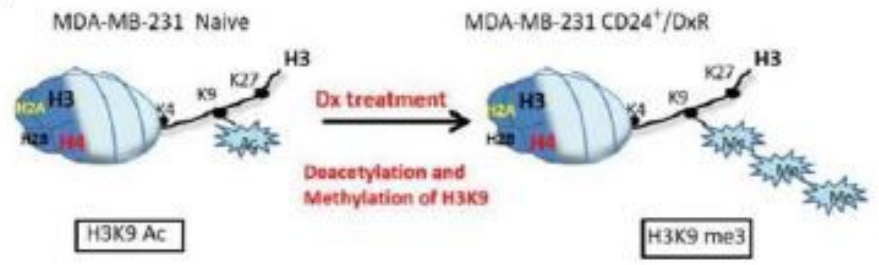

Figure 4

Inhibition of p38 activity impedes phenotype switching of MDA-MB-231 cells under doxorubicin treatment. (a) Differential activation of MAPKs in CD24+ and CD24- subpopulation. Parental and the magnetic sorted CD24+ and CD24- cells were starved for $2 \mathrm{~h}$. Then, cells were submitted to time kinetic using fetal bovine serum (FBS) as stimulus. Cell lysates were immunobloted with the depicted antibodies. The results are representative of two independent experiments. (b) Higher p38 phosphorylation (pp38) 
MAPK in CD24+ cells. Parental MDA-MB-231 cells were stained with anti-CD24/Pe-Cy7 (extracellular staining) and anti-pp38/FITC (intracellular staining). The pseudocolor plots are representative of triplicates. (c) Decreased phosphorylation of p38 (pp38) in SiCD24 cells treated with Dx. SiC and SiCD24 cells were treated with $D x(0.6 \square \mathrm{M})$ for 24 hours. Cell lysates were immunobloted with the depicted antibodies. All blots were performed at least twice. (d) Increased efficiency of Dx when associated with the p38 inhibitor SB203580. Cells were treated with SB203580 (SB) at 10ロM or/and Dx at $0.6 \square \mathrm{M}$ for $48 \mathrm{~h}$. Then, cells were counted and the growth percentage was calculated based on the initial number of cells before each treatment $(\%$ growth $=[\mathrm{fn} / \mathrm{in}-1] \times 100) \#$. Countings were performed in three independent experiments. (e) Reduction in the acquisition of Dx resistance in the presence of the p38 inhibitor SB203580. MDA-MB-231 cells were pre-treated with SB203580 (10ロM) and/or doxorubicin (0.6ロM) during $48 \mathrm{~h}$ before the addition of $\mathrm{Dx}$ at different concentrations (varying between $0.07 \square \mathrm{M}$ and $5 \square \mathrm{M}$ ) for $24 \mathrm{~h}$ and then cell viability was measured by MTT assay. Curves were fitted with non-linear regression as means of triplicates. (f) Increased expression of Bax but decreased expression of $\mathrm{Bcl} 2$ and $\mathrm{p} 53$ after cell treatment with the association of the p38 inhibitor SB203580 and Dx. MDA-MB-231 cells were treated with

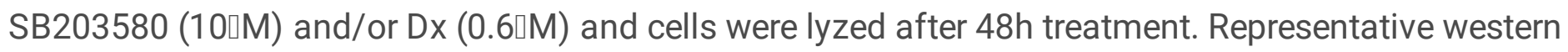
blotting is shown and the data have been reproduced twice. (g) Representative light microscopy images of cell population at confluence (106 cells) or subconfluence $(5 \times 105$ cells) density treated with SB203580 $(10 \varangle \mathrm{M})$ and/or Dx (0.6ロM) for 24h. Cell density and morphology were evaluated by microscopy (Evos Skedda). The microscopy images are representative of triplicates. (h) The p38 inhibitor SB203580 inhibits the tri-methylation state of H3K9 in Dx treated cells. After 24h of treatment with SB203580 (SB) at $10 \square \mathrm{M}$ and/or Dx at $0.6 \square \mathrm{M}, \mathrm{MDA}-\mathrm{MB}-231$ cells were lysed and the status of histone 3 was analyzed by western blotting using antibodies against tri-methylated (H3K9me3) or acetylated (H3K9ac) form of H3K9. (i) Schematic shows the histone modifications and its consequences on MDA-MB-231 cell phenotype after doxorubicin treatment. The reprogramming of doxorubicin-treated cells induced a cell cycle arrest and morphological modifications of MDA-MB-231 cells associated with the H3K9 histone state changes, acetylated vs metylated form under p38 control. 
a

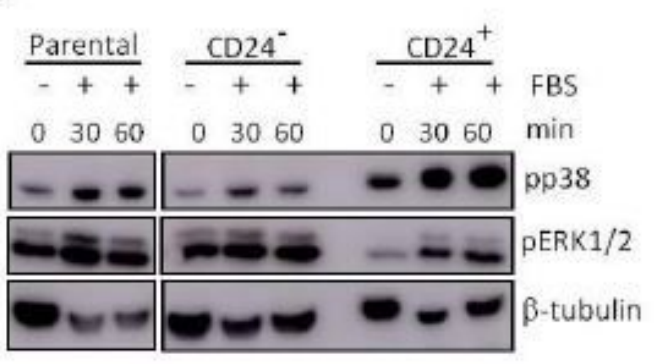

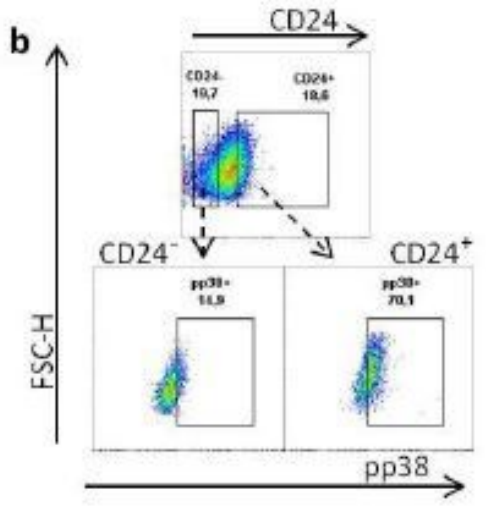

C

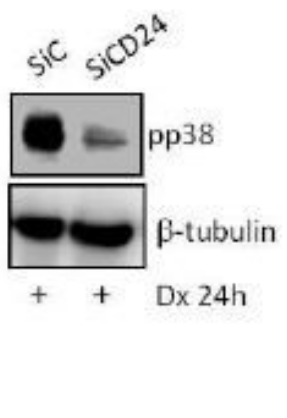

d

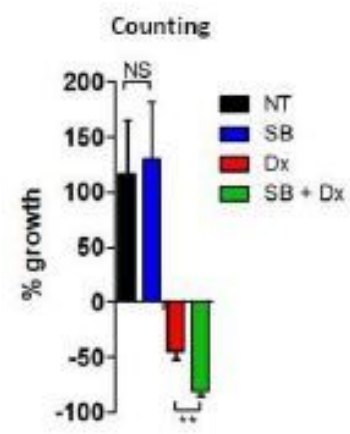

e

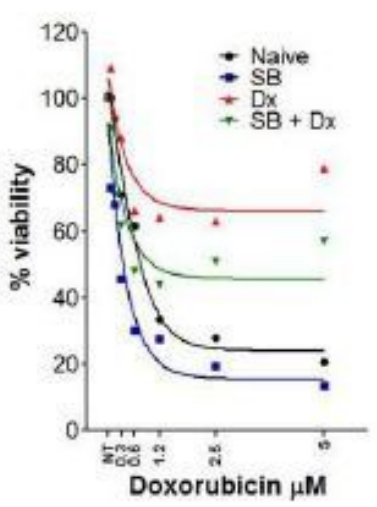

f

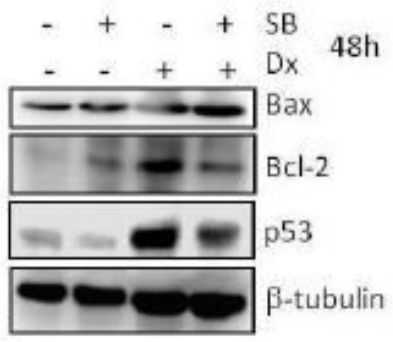

g
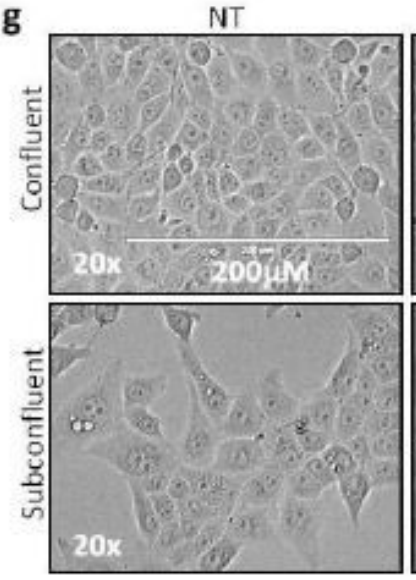

h

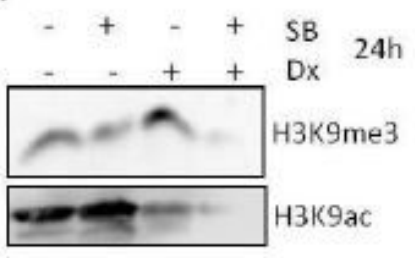

SB
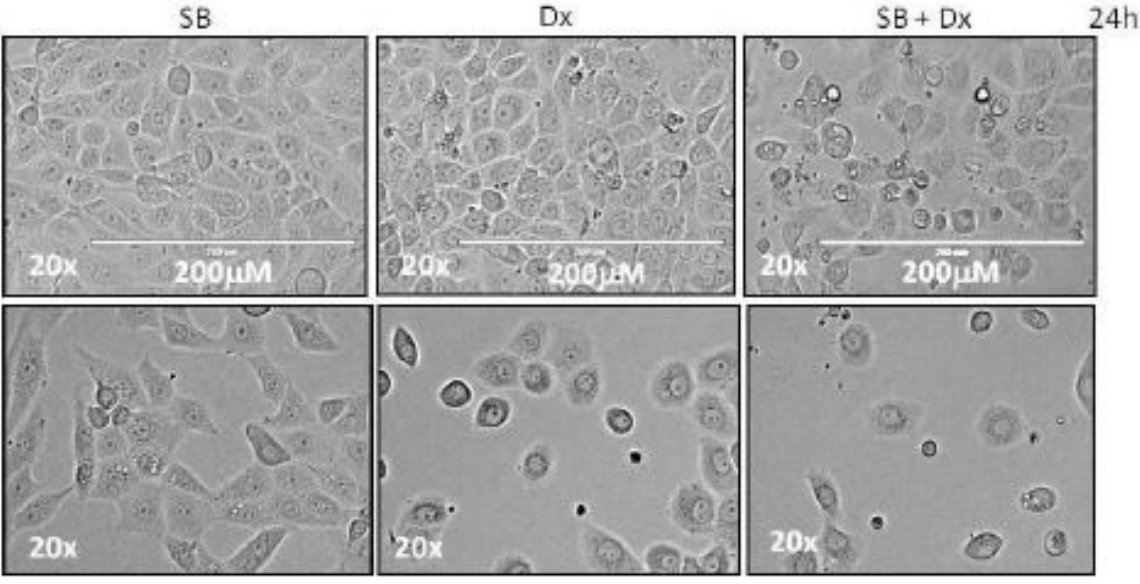

i

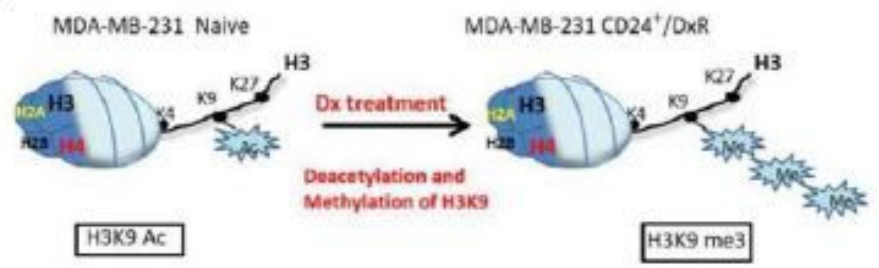

Figure 4

Inhibition of p38 activity impedes phenotype switching of MDA-MB-231 cells under doxorubicin treatment. (a) Differential activation of MAPKs in CD24+ and CD24- subpopulation. Parental and the magnetic sorted CD24+ and CD24- cells were starved for $2 \mathrm{~h}$. Then, cells were submitted to time kinetic using fetal bovine serum (FBS) as stimulus. Cell lysates were immunobloted with the depicted antibodies. The results are representative of two independent experiments. (b) Higher p38 phosphorylation (pp38) 
MAPK in CD24+ cells. Parental MDA-MB-231 cells were stained with anti-CD24/Pe-Cy7 (extracellular staining) and anti-pp38/FITC (intracellular staining). The pseudocolor plots are representative of triplicates. (c) Decreased phosphorylation of p38 (pp38) in SiCD24 cells treated with Dx. SiC and SiCD24 cells were treated with $D x(0.6 \square \mathrm{M})$ for 24 hours. Cell lysates were immunobloted with the depicted antibodies. All blots were performed at least twice. (d) Increased efficiency of Dx when associated with the p38 inhibitor SB203580. Cells were treated with SB203580 (SB) at 10ロM or/and Dx at $0.6 \square \mathrm{M}$ for $48 \mathrm{~h}$. Then, cells were counted and the growth percentage was calculated based on the initial number of cells before each treatment $(\%$ growth $=[\mathrm{fn} / \mathrm{in}-1] \times 100) \#$. Countings were performed in three independent experiments. (e) Reduction in the acquisition of Dx resistance in the presence of the p38 inhibitor SB203580. MDA-MB-231 cells were pre-treated with SB203580 (10ロM) and/or doxorubicin (0.6ロM) during $48 \mathrm{~h}$ before the addition of $\mathrm{Dx}$ at different concentrations (varying between $0.07 \square \mathrm{M}$ and $5 \square \mathrm{M}$ ) for $24 \mathrm{~h}$ and then cell viability was measured by MTT assay. Curves were fitted with non-linear regression as means of triplicates. (f) Increased expression of Bax but decreased expression of $\mathrm{Bcl} 2$ and $\mathrm{p} 53$ after cell treatment with the association of the p38 inhibitor SB203580 and Dx. MDA-MB-231 cells were treated with

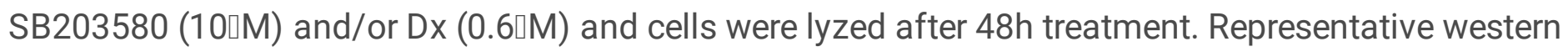
blotting is shown and the data have been reproduced twice. (g) Representative light microscopy images of cell population at confluence (106 cells) or subconfluence $(5 \times 105$ cells) density treated with SB203580 $(10 \varangle \mathrm{M})$ and/or Dx (0.6ロM) for 24h. Cell density and morphology were evaluated by microscopy (Evos Skedda). The microscopy images are representative of triplicates. (h) The p38 inhibitor SB203580 inhibits the tri-methylation state of H3K9 in Dx treated cells. After 24h of treatment with SB203580 (SB) at $10 \square \mathrm{M}$ and/or Dx at $0.6 \square \mathrm{M}, \mathrm{MDA}-\mathrm{MB}-231$ cells were lysed and the status of histone 3 was analyzed by western blotting using antibodies against tri-methylated (H3K9me3) or acetylated (H3K9ac) form of H3K9. (i) Schematic shows the histone modifications and its consequences on MDA-MB-231 cell phenotype after doxorubicin treatment. The reprogramming of doxorubicin-treated cells induced a cell cycle arrest and morphological modifications of MDA-MB-231 cells associated with the H3K9 histone state changes, acetylated vs metylated form under p38 control. 
a

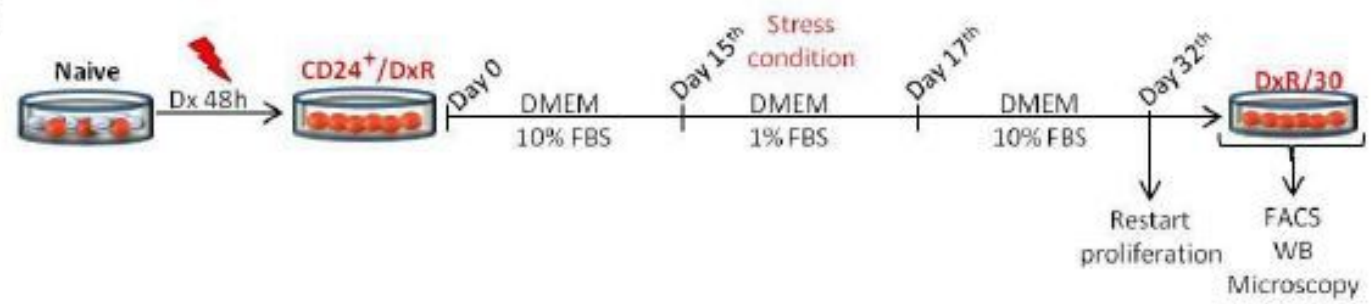

b

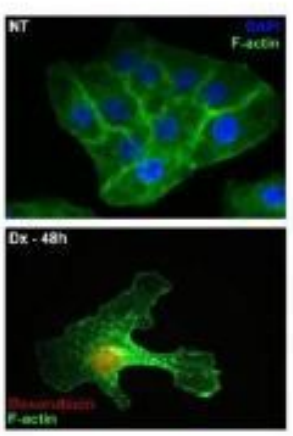

C

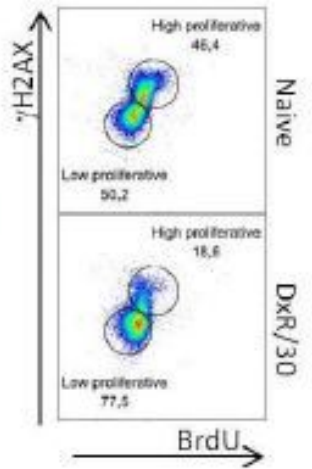

d

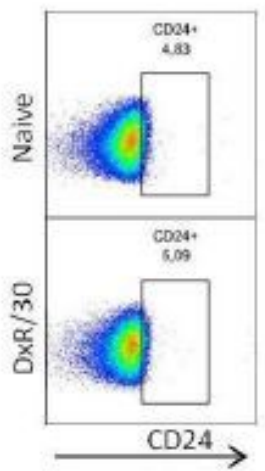

e

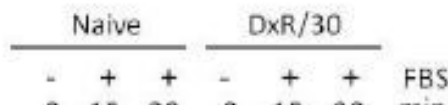

$\begin{array}{lllllll}0 & 15 & 30 & 0 & 15 & 30 & \mathrm{~min}\end{array}$

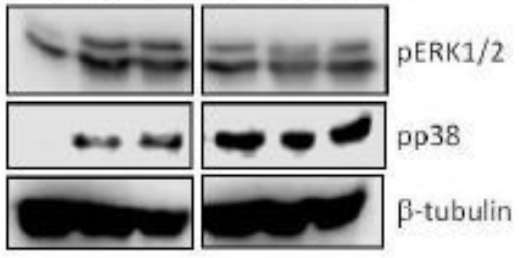

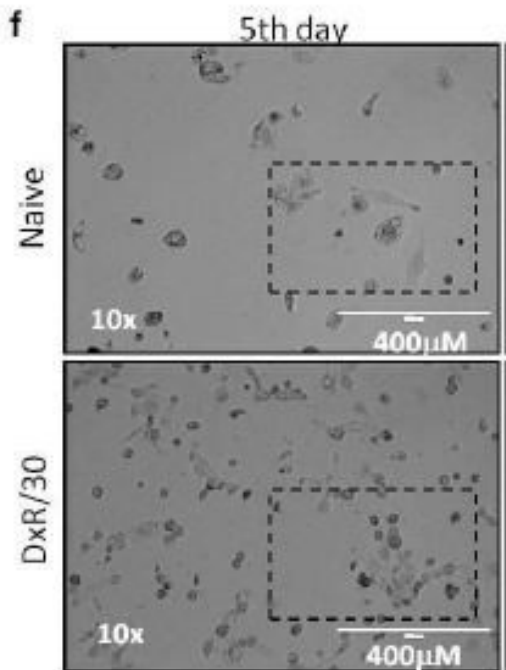

5th day

12th day

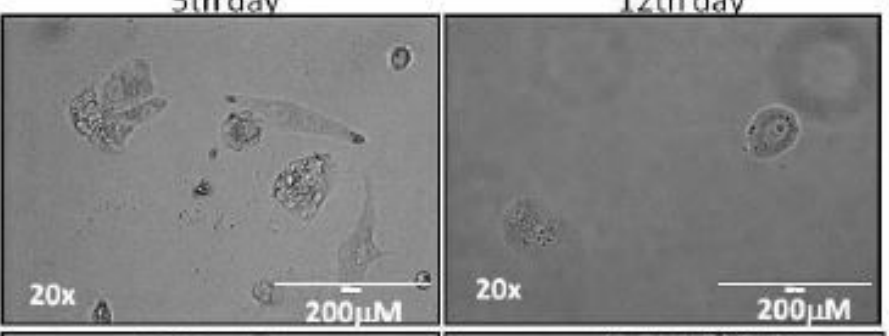

$20 x_{C}$

$200 \ddot{M M}$

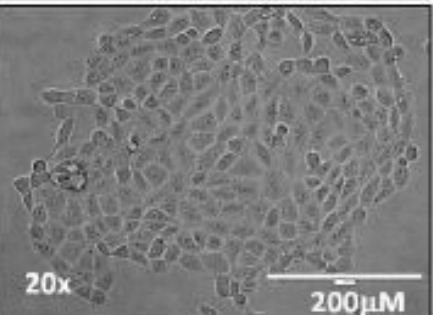

g

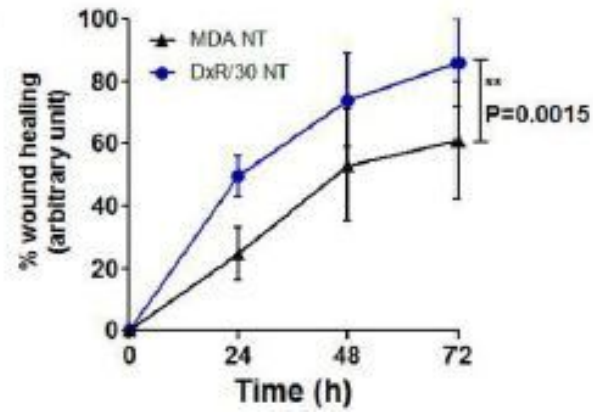

Figure 5

CD24+/DxR cells become proliferative and more invasive than naïve cells after a long-lasting period in drug-free environment. (a) Schematic shows the journey of CD24+/DxR cells from their switching to CD24+ phenotype to their entry in slow- cycling state and reversion into proliferative cells. CD24+/DxR cells were exposed to a stress condition (fetal bovine serum starvation $=1 \% \mathrm{FBS}$ ) during $48 \mathrm{~h}$. (b) Differences in morphology between naïve MDA-MB-231 and CD24+/DxR cells. Naïve MDA-MB-231 and 
CD24+/DxR cells were fixed, permeabilized and stained using anti-F-actin/Alexa488 and the nuclear dye DAPI. DAPI was not used in CD24+/DxR group due to co-localization with doxorubicin. (c) CD24+/DxR cells retrieve their capacity to proliferate (named as DxR/30 or revertant). Naive MDA-MB-231 and DxR/30 cells were incubated with $10 \square \mathrm{M}$ of BrdU (thymine analogue base) for $4 \mathrm{~h}$. Then, cells were stained with anti-BrdU/PerCP-Cy5.5 and anti-_H2AX/Alexa647 (intracellular staining). The low and high proliferative subpopulations were defined and analyzed. The pseudocolor plots are representative of triplicates. (d) DxR/30 cell population returns the basal ratio of CD24+ cells. Cells were stained with the fluorescent antibody anti-CD24/Pe-Cy7 (extracellular staining). Pseudocolor plots are representative of triplicates. (e) Constitutive activation of p38 MAPK in DxR/30 cells. After starvation for $2 \mathrm{~h}$, cells were stimulated with serum in different times. Cell lysates were immunobloted with the depicted antibodies. All blots were performed at least twice. (f) Higher resistance of DxR/30 cells to Dx treatment. MDA-MB-231 and DxR/30 cells were treated with $\mathrm{Dx}(0.6 \square \mathrm{M})$ for $24 \mathrm{~h}$. Then cells were counted, re-seeded in the same density and cultured in normal conditions (DMEM 10\% FBS). Cell density and morphology were analyzed by light microscopy (Evos Skedda) at 5 and 12 days post-doxorubicin treatment. (g) DxR/30 cells are more invasive than MDA-MB-231 cells. MDA-MB-231 and DxR/30 cells were seeded (8x105) in 6 wells plate and a scratch performed according to Mat and Med. Cell migrations were registered by light microscopy (Evos Skedda) at 24, 48 and 72 hours post scratch. Using ImageJ software the wound healing was measured and a closing-time percentage was calculated based on the initial scratch size of each cell type. Curves were fitted as means of duplicates +/- SD. ** $p<0,01$ (Two-way ANOVA with Bonferroni posttest). 
a

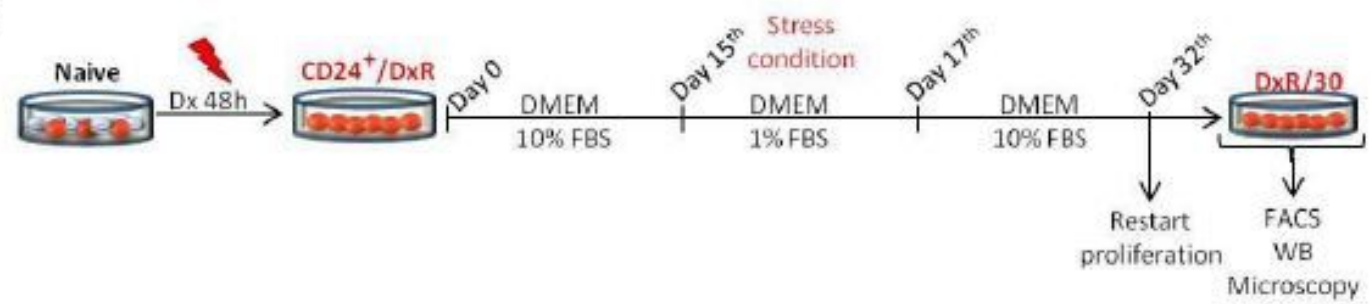

b

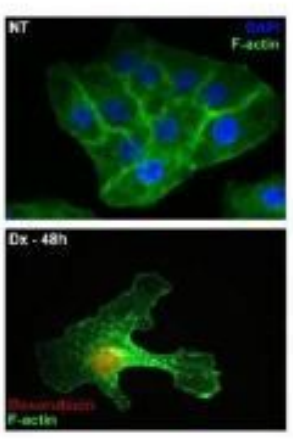

C

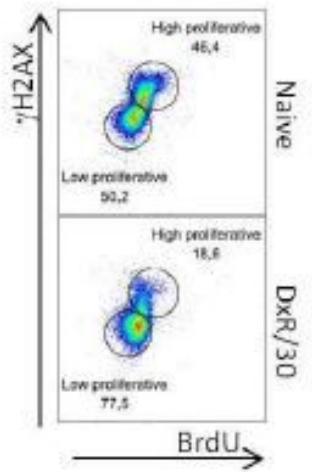

d

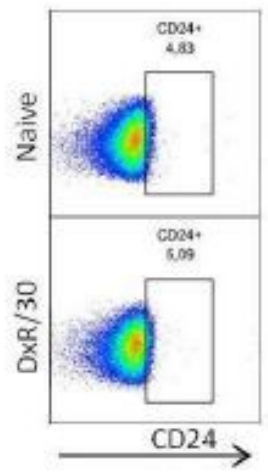

e

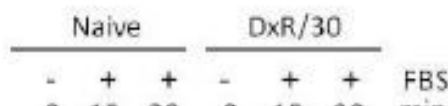

$\begin{array}{lllllll}0 & 15 & 30 & 0 & 15 & 30 & \mathrm{~min}\end{array}$

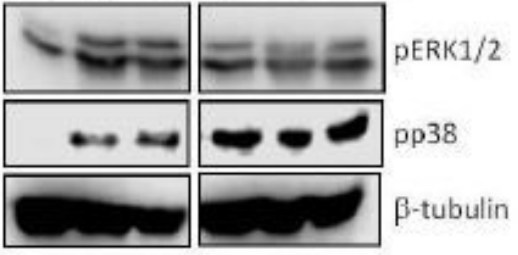

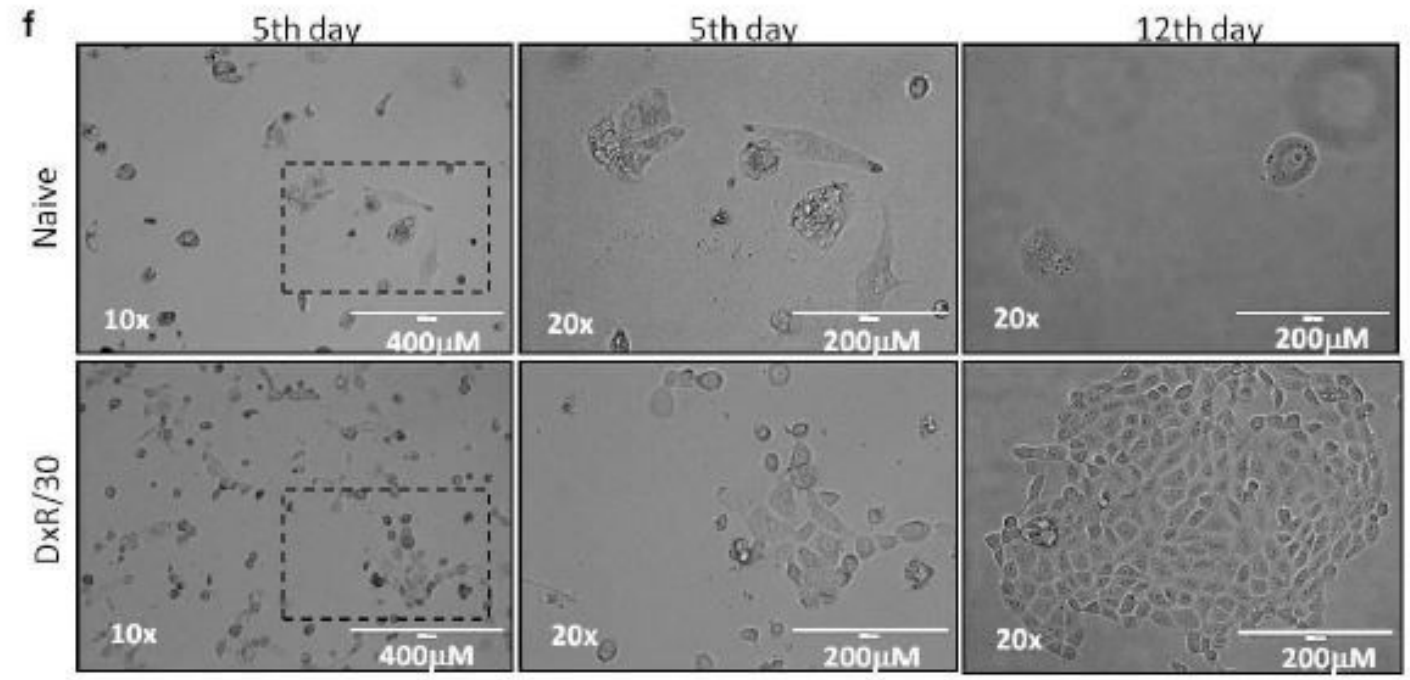

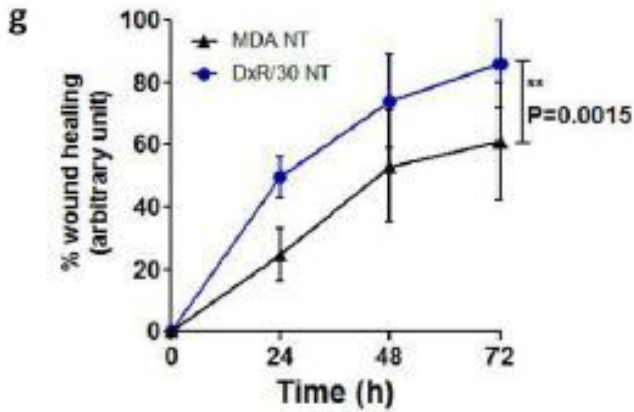

Figure 5

CD24+/DxR cells become proliferative and more invasive than naïve cells after a long-lasting period in drug-free environment. (a) Schematic shows the journey of CD24+/DxR cells from their switching to CD24+ phenotype to their entry in slow- cycling state and reversion into proliferative cells. CD24+/DxR cells were exposed to a stress condition (fetal bovine serum starvation $=1 \% \mathrm{FBS}$ ) during $48 \mathrm{~h}$. (b) Differences in morphology between naïve MDA-MB-231 and CD24+/DxR cells. Naïve MDA-MB-231 and 
CD24+/DxR cells were fixed, permeabilized and stained using anti-F-actin/Alexa488 and the nuclear dye DAPI. DAPI was not used in CD24+/DxR group due to co-localization with doxorubicin. (c) CD24+/DxR cells retrieve their capacity to proliferate (named as DxR/30 or revertant). Naive MDA-MB-231 and DxR/30 cells were incubated with $10 \square \mathrm{M}$ of BrdU (thymine analogue base) for $4 \mathrm{~h}$. Then, cells were stained with anti-BrdU/PerCP-Cy5.5 and anti-_H2AX/Alexa647 (intracellular staining). The low and high proliferative subpopulations were defined and analyzed. The pseudocolor plots are representative of triplicates. (d) DxR/30 cell population returns the basal ratio of CD24+ cells. Cells were stained with the fluorescent antibody anti-CD24/Pe-Cy7 (extracellular staining). Pseudocolor plots are representative of triplicates. (e) Constitutive activation of p38 MAPK in DxR/30 cells. After starvation for $2 \mathrm{~h}$, cells were stimulated with serum in different times. Cell lysates were immunobloted with the depicted antibodies. All blots were performed at least twice. (f) Higher resistance of DxR/30 cells to Dx treatment. MDA-MB-231 and DxR/30 cells were treated with $\mathrm{Dx}(0.6 \square \mathrm{M})$ for $24 \mathrm{~h}$. Then cells were counted, re-seeded in the same density and cultured in normal conditions (DMEM 10\% FBS). Cell density and morphology were analyzed by light microscopy (Evos Skedda) at 5 and 12 days post-doxorubicin treatment. (g) DxR/30 cells are more invasive than MDA-MB-231 cells. MDA-MB-231 and DxR/30 cells were seeded (8x105) in 6 wells plate and a scratch performed according to Mat and Med. Cell migrations were registered by light microscopy (Evos Skedda) at 24, 48 and 72 hours post scratch. Using ImageJ software the wound healing was measured and a closing-time percentage was calculated based on the initial scratch size of each cell type. Curves were fitted as means of duplicates +/- SD. ** $p<0,01$ (Two-way ANOVA with Bonferroni posttest). 
a

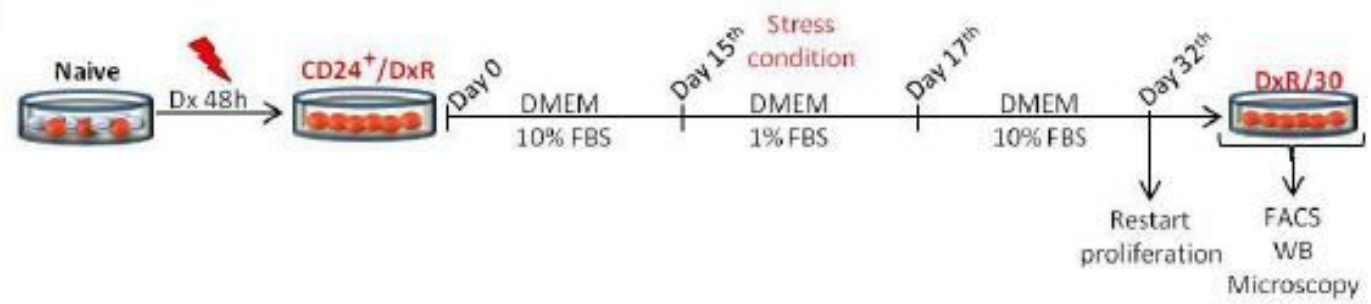

b

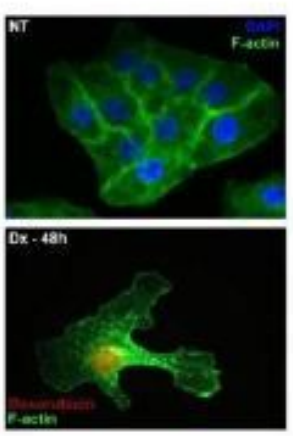

C

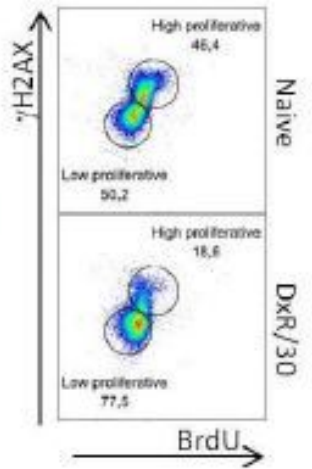

d

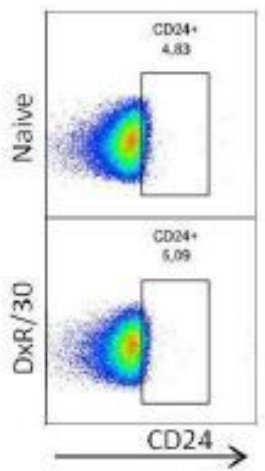

e

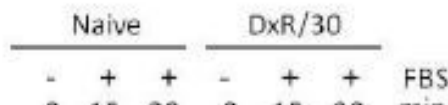

$\begin{array}{lllllll}0 & 15 & 30 & 0 & 15 & 30 & \mathrm{~min}\end{array}$

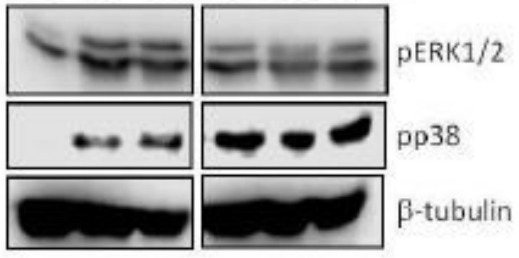

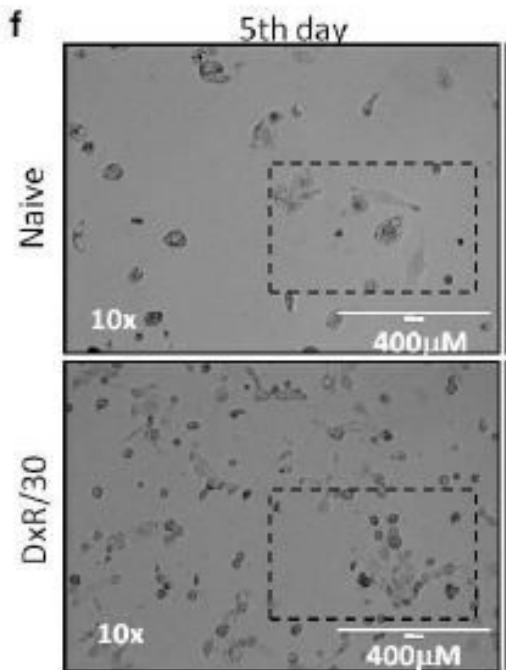

5th day

12th day

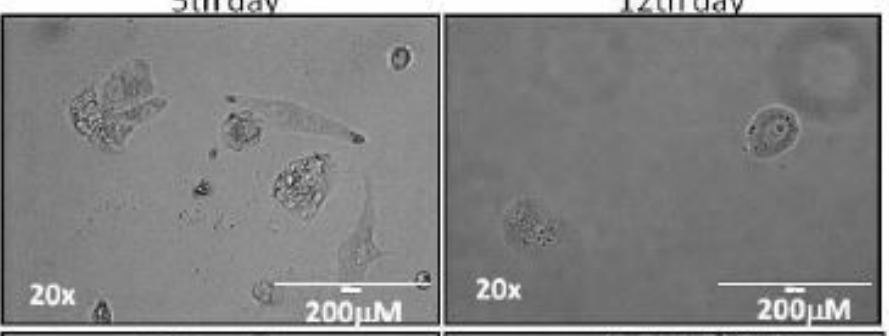

$20 x_{C}$

$200 \ddot{M M}$

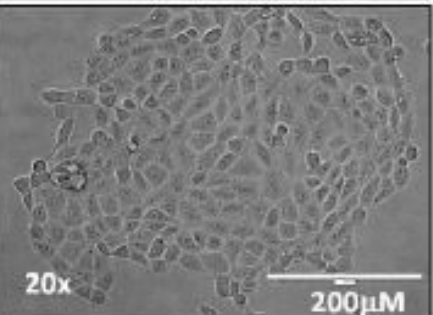

g

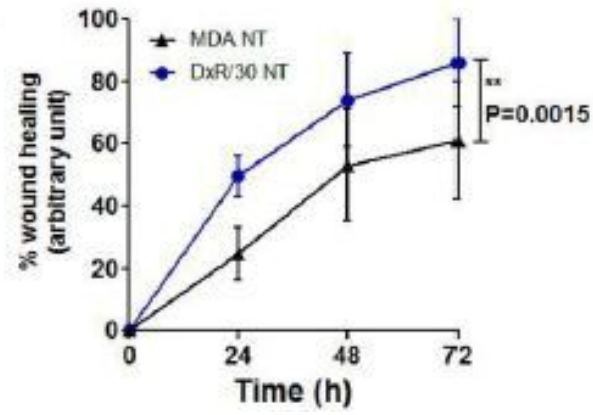

Figure 5

CD24+/DxR cells become proliferative and more invasive than naïve cells after a long-lasting period in drug-free environment. (a) Schematic shows the journey of CD24+/DxR cells from their switching to CD24+ phenotype to their entry in slow- cycling state and reversion into proliferative cells. CD24+/DxR cells were exposed to a stress condition (fetal bovine serum starvation $=1 \% \mathrm{FBS}$ ) during $48 \mathrm{~h}$. (b) Differences in morphology between naïve MDA-MB-231 and CD24+/DxR cells. Naïve MDA-MB-231 and 
CD24+/DxR cells were fixed, permeabilized and stained using anti-F-actin/Alexa488 and the nuclear dye DAPI. DAPI was not used in CD24+/DxR group due to co-localization with doxorubicin. (c) CD24+/DxR cells retrieve their capacity to proliferate (named as DxR/30 or revertant). Naive MDA-MB-231 and DxR/30 cells were incubated with $10 \square \mathrm{M}$ of BrdU (thymine analogue base) for $4 \mathrm{~h}$. Then, cells were stained with anti-BrdU/PerCP-Cy5.5 and anti-_H2AX/Alexa647 (intracellular staining). The low and high proliferative subpopulations were defined and analyzed. The pseudocolor plots are representative of triplicates. (d) DxR/30 cell population returns the basal ratio of CD24+ cells. Cells were stained with the fluorescent antibody anti-CD24/Pe-Cy7 (extracellular staining). Pseudocolor plots are representative of triplicates. (e) Constitutive activation of p38 MAPK in DxR/30 cells. After starvation for $2 \mathrm{~h}$, cells were stimulated with serum in different times. Cell lysates were immunobloted with the depicted antibodies. All blots were performed at least twice. (f) Higher resistance of DxR/30 cells to Dx treatment. MDA-MB-231 and DxR/30 cells were treated with $\mathrm{Dx}(0.6 \square \mathrm{M})$ for $24 \mathrm{~h}$. Then cells were counted, re-seeded in the same density and cultured in normal conditions (DMEM 10\% FBS). Cell density and morphology were analyzed by light microscopy (Evos Skedda) at 5 and 12 days post-doxorubicin treatment. (g) DxR/30 cells are more invasive than MDA-MB-231 cells. MDA-MB-231 and DxR/30 cells were seeded (8x105) in 6 wells plate and a scratch performed according to Mat and Med. Cell migrations were registered by light microscopy (Evos Skedda) at 24, 48 and 72 hours post scratch. Using ImageJ software the wound healing was measured and a closing-time percentage was calculated based on the initial scratch size of each cell type. Curves were fitted as means of duplicates +/- SD. ** $p<0,01$ (Two-way ANOVA with Bonferroni posttest). 
a

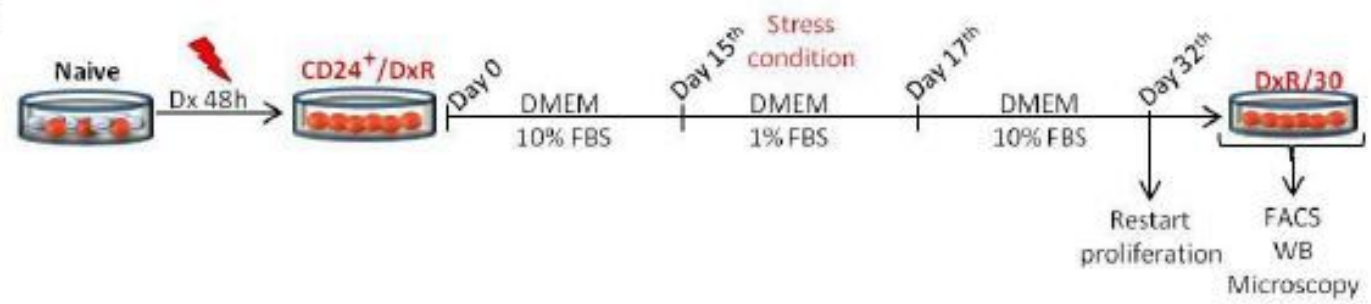

b

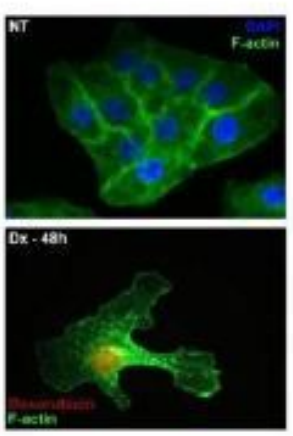

C

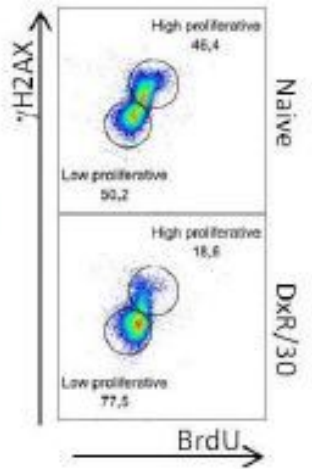

d

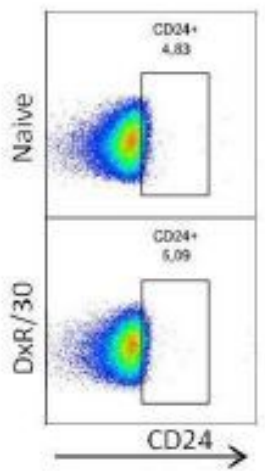

e

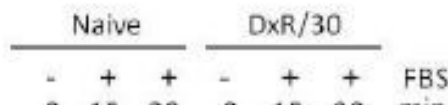

$\begin{array}{lllllll}0 & 15 & 30 & 0 & 15 & 30 & \mathrm{~min}\end{array}$

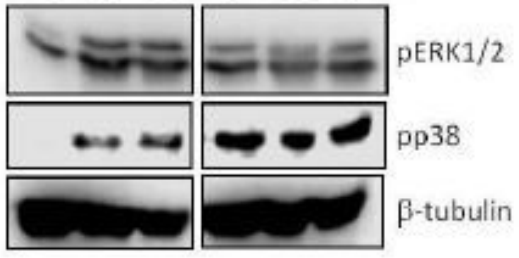

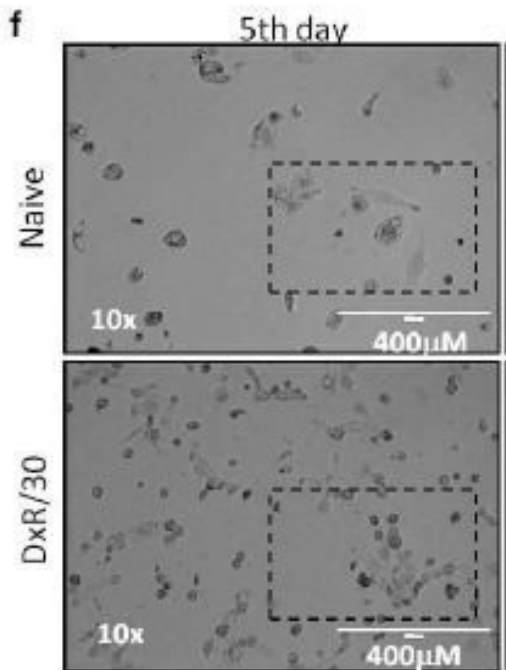

5th day

12th day

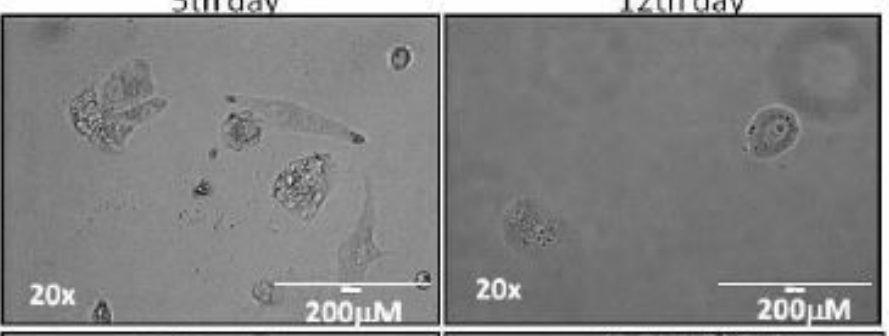

$20 x_{C}$

$200 \ddot{M M}$

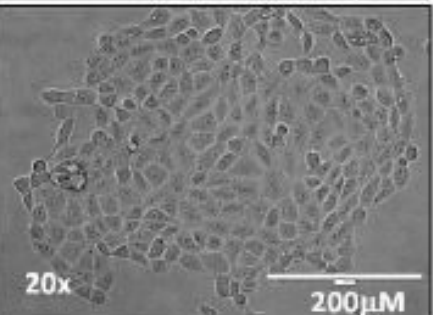

g

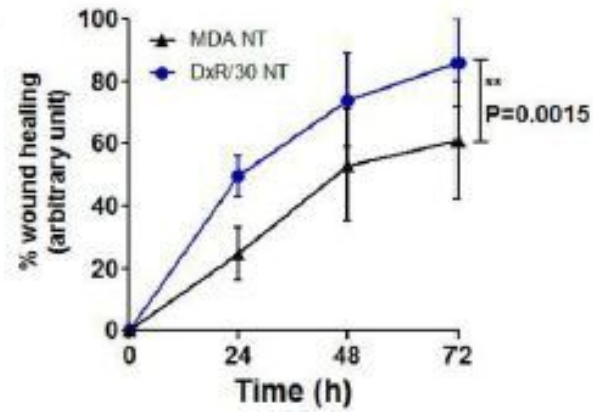

Figure 5

CD24+/DxR cells become proliferative and more invasive than naïve cells after a long-lasting period in drug-free environment. (a) Schematic shows the journey of CD24+/DxR cells from their switching to CD24+ phenotype to their entry in slow- cycling state and reversion into proliferative cells. CD24+/DxR cells were exposed to a stress condition (fetal bovine serum starvation $=1 \% \mathrm{FBS}$ ) during $48 \mathrm{~h}$. (b) Differences in morphology between naïve MDA-MB-231 and CD24+/DxR cells. Naïve MDA-MB-231 and 
CD24+/DxR cells were fixed, permeabilized and stained using anti-F-actin/Alexa488 and the nuclear dye DAPI. DAPI was not used in CD24+/DxR group due to co-localization with doxorubicin. (c) CD24+/DxR cells retrieve their capacity to proliferate (named as DxR/30 or revertant). Naive MDA-MB-231 and DxR/30 cells were incubated with $10 \square \mathrm{M}$ of BrdU (thymine analogue base) for $4 \mathrm{~h}$. Then, cells were stained with anti-BrdU/PerCP-Cy5.5 and anti--H2AX/Alexa647 (intracellular staining). The low and high proliferative subpopulations were defined and analyzed. The pseudocolor plots are representative of triplicates. (d) $\mathrm{DxR} / 30$ cell population returns the basal ratio of $\mathrm{CD} 24+$ cells. Cells were stained with the fluorescent antibody anti-CD24/Pe-Cy7 (extracellular staining). Pseudocolor plots are representative of triplicates. (e) Constitutive activation of p38 MAPK in DxR/30 cells. After starvation for $2 \mathrm{~h}$, cells were stimulated with serum in different times. Cell lysates were immunobloted with the depicted antibodies. All blots were performed at least twice. (f) Higher resistance of DxR/30 cells to Dx treatment. MDA-MB-231 and DxR/30 cells were treated with $\mathrm{Dx}(0.6 \mathrm{M})$ for $24 \mathrm{~h}$. Then cells were counted, re-seeded in the same density and cultured in normal conditions (DMEM 10\% FBS). Cell density and morphology were analyzed by light microscopy (Evos Skedda) at 5 and 12 days post-doxorubicin treatment. (g) DxR/30 cells are more invasive than MDA-MB-231 cells. MDA-MB-231 and DxR/30 cells were seeded (8x105) in 6 wells plate and a scratch performed according to Mat and Med. Cell migrations were registered by light microscopy (Evos Skedda) at 24, 48 and 72 hours post scratch. Using ImageJ software the wound healing was measured and a closing-time percentage was calculated based on the initial scratch size of each cell type. Curves were fitted as means of duplicates +/- SD. ** $p<0,01$ (Two-way ANOVA with Bonferroni posttest).

\section{Image not available with this version}

\section{Figure 6}

Schematic shows breast cancer cell population phenotype changes under drug stress toward a drug tolerant state arising through translocation of CD24 and sustained p38 activation. (a) In proliferative conditions, CD24 is mainly detected in the cytosol of all cells and the population is characterized by a low frequency of CD24+ cells (cells carrying CD24 in membrane). The transient phosphorylation of p38 leads to cyclin D1 expression and cell cycle progression. (b) Under drug treatment, CD24 translocation associated with an increased CD24 density on cell membrane occurs in every given cell. In accord with this, a sustained and strong p38 activation, an increased Bcl-2 expression and a tri-methylation of H3K9 are observed indicating a phenotype switching. (c) This transition state is sensitive to p38 inhibition since 
the use of a specific inhibitor, like SB203580, in association with doxorubicin reduces Bcl-2 expression and H3K9 tri-methylation leading to an increased cell death.

\section{Image not available with this version}

\section{Figure 6}

Schematic shows breast cancer cell population phenotype changes under drug stress toward a drug tolerant state arising through translocation of CD24 and sustained p38 activation. (a) In proliferative conditions, CD24 is mainly detected in the cytosol of all cells and the population is characterized by a low frequency of CD24+ cells (cells carrying CD24 in membrane). The transient phosphorylation of p38 leads to cyclin D1 expression and cell cycle progression. (b) Under drug treatment, CD24 translocation associated with an increased CD24 density on cell membrane occurs in every given cell. In accord with this, a sustained and strong p38 activation, an increased Bcl-2 expression and a tri-methylation of H3K9 are observed indicating a phenotype switching. (c) This transition state is sensitive to p38 inhibition since the use of a specific inhibitor, like SB203580, in association with doxorubicin reduces Bcl-2 expression and H3K9 tri-methylation leading to an increased cell death.

\section{Image not available with this version}

\section{Figure 6}

Schematic shows breast cancer cell population phenotype changes under drug stress toward a drug tolerant state arising through translocation of CD24 and sustained p38 activation. (a) In proliferative conditions, CD24 is mainly detected in the cytosol of all cells and the population is characterized by a low 
frequency of CD24+ cells (cells carrying CD24 in membrane). The transient phosphorylation of p38 leads to cyclin D1 expression and cell cycle progression. (b) Under drug treatment, CD24 translocation associated with an increased CD24 density on cell membrane occurs in every given cell. In accord with this, a sustained and strong $\mathrm{p} 38$ activation, an increased Bcl-2 expression and a tri-methylation of H3K9 are observed indicating a phenotype switching. (c) This transition state is sensitive to p38 inhibition since the use of a specific inhibitor, like SB203580, in association with doxorubicin reduces Bcl-2 expression and H3K9 tri-methylation leading to an increased cell death.

\section{Image not available with this version}

\section{Figure 6}

Schematic shows breast cancer cell population phenotype changes under drug stress toward a drug tolerant state arising through translocation of CD24 and sustained p38 activation. (a) In proliferative conditions, CD24 is mainly detected in the cytosol of all cells and the population is characterized by a low frequency of CD24+ cells (cells carrying CD24 in membrane). The transient phosphorylation of p38 leads to cyclin D1 expression and cell cycle progression. (b) Under drug treatment, CD24 translocation associated with an increased CD24 density on cell membrane occurs in every given cell. In accord with this, a sustained and strong $\mathrm{p} 38$ activation, an increased $\mathrm{Bcl}-2$ expression and a tri-methylation of $\mathrm{H} 3 \mathrm{~K} 9$ are observed indicating a phenotype switching. (c) This transition state is sensitive to p38 inhibition since the use of a specific inhibitor, like SB203580, in association with doxorubicin reduces Bcl-2 expression and H3K9 tri-methylation leading to an increased cell death.

\section{Supplementary Files}

This is a list of supplementary files associated with this preprint. Click to download.

- graphicalabstract.pdf

- graphicalabstract.pdf

- graphicalabstract.pdf

- graphicalabstract.pdf 